San Jose State University

SJSU ScholarWorks

Mineta Transportation Institute Publications

$10-2020$

\title{
Southern California Regional Workforce Development Needs Assessment for the Transportation and Supply Chain Industry Sectors
}

\author{
Tom O’Brien \\ California State University, Long Beach \\ Deanna Matsumoto \\ California State University, Long Beach \\ Diana Sanchez \\ California State University, Long Beach \\ Caitlin Mace \\ California State University, Long Beach \\ Elizabeth Warren \\ California State University, Long Beach
}

See next page for additional authors

Follow this and additional works at: https://scholarworks.sjsu.edu/mti_publications

Part of the Transportation Commons, and the Work, Economy and Organizations Commons

\begin{abstract}
Recommended Citation
Tom O'Brien, Deanna Matsumoto, Diana Sanchez, Caitlin Mace, Elizabeth Warren, Eleni Hala, and Tyler Reeb. "Southern California Regional Workforce Development Needs Assessment for the Transportation and Supply Chain Industry Sectors" Mineta Transportation Institute Publications (2020). https://doi.org/ 10.31979/mti.2020.1921
\end{abstract}

This Report is brought to you for free and open access by SJSU ScholarWorks. It has been accepted for inclusion in Mineta Transportation Institute Publications by an authorized administrator of SJSU ScholarWorks. For more information, please contact scholarworks@sjsu.edu. 


\section{Authors}

Tom O'Brien, Deanna Matsumoto, Diana Sanchez, Caitlin Mace, Elizabeth Warren, Eleni Hala, and Tyler Reeb 


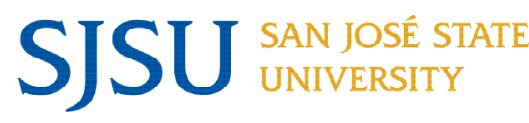

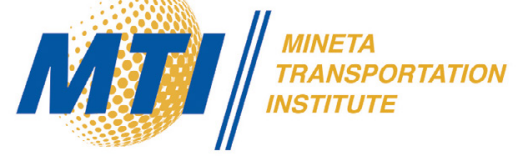

Southern California Regional Workforce Development

Needs Assessment for the Transportation and Supply

Chain Industry Sectors

Tom O’Brien, PhD, Deanna Matsumoto, Diana Sanchez,

Caitlin Mace Elizabeth Warren, Eleni Hala, and Tyler Reeb, PhD

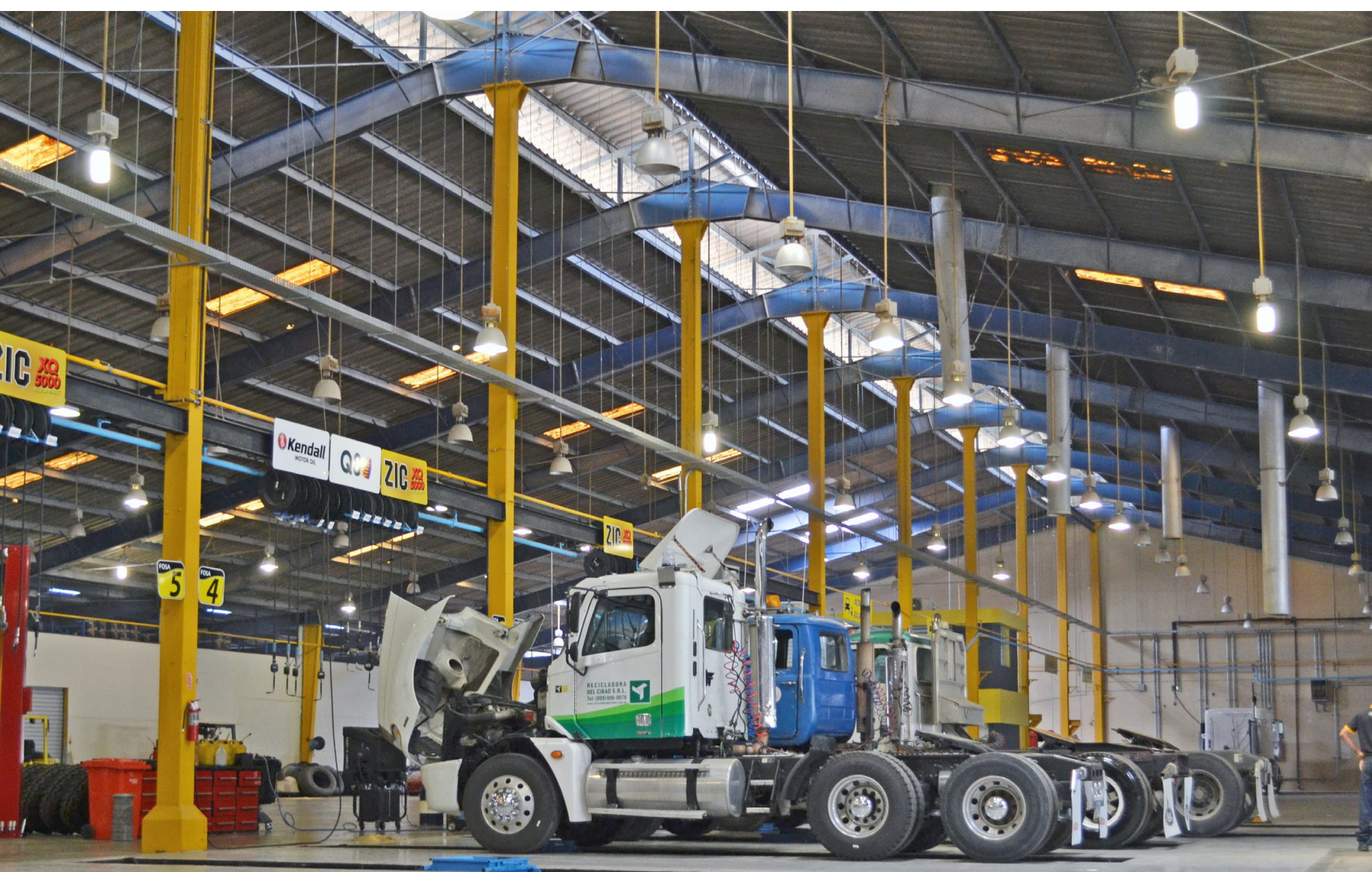

California State University
Transportation Consortium

CALIFORNIA STATE UNIVERSITY

LONG BEACH 


\section{Mineta Transportation Institute}

Founded in 1991, the Mineta Transportation Institute (MTI), an organized research and training unit in partnership with the Lucas College and Graduate School of Business at San José State University (SJSU), increases mobility for all by improving the safety, efficiency, accessibility, and convenience of our nation's transportation system. Through research, education, workforce development, and technology transfer, we help create a connected world. MTI leads the Mineta Consortium for Transportation Mobility (MCTM) funded by the U.S. Department of Transportation and the California State University Transportation Consortium (CSUTC) funded by the State of California through Senate Bill 1.

MTI focuses on three primary responsibilities:

\section{Research}

MTI conducts multi-disciplinary research focused on surface transportation that contributes to effective decision making. Research areas include: active transportation; planning and policy; security and counterterrorism; sustainable transportation and land use; transit and passenger rail; transportation engineering; transportation finance; transportation technology; and workforce and labor. MTI research publications undergo expert peer review to ensure the quality of the research.

\section{Education}

To ensure the efficient movement of people and products, we must prepare a new cohort of transportation professionals who are ready to lead a more diverse, inclusive, and equitable transportation industry. To help achieve this, MTI sponsors a suite of workforce development and education opportunities. The Institute supports educational programs offered by the Lucas Graduate School of Business: a Master of
Science in Transportation Management, plus graduate certificates that include High-Speed and Intercity Rail Management and Transportation Security Management. These flexible programs offer live online classes so that working transportation professionals can pursue an advanced degree regardless of their location.

\section{Information and Technology Transfer}

MTI utilizes a diverse array of dissemination methods and media to ensure research results reach those responsible for managing change. These methods include publication, seminars, workshops, websites, social media, webinars, and other technology transfer mechanisms. Additionally, MTI promotes the availability of completed research to professional organizations and works to integrate the research findings into the graduate education program. MTI's extensive collection of transportation-related publications is integrated into San José State University's world-class Martin Luther King, Jr. Library.

\section{Disclaimer}

The contents of this report reflect the views of the authors, who are responsible for the facts and accuracy of the information presented herein. This document is disseminated in the interest of information exchange. MTI's research is funded, partially or entirely, by grants from the U.S. Department of Transportation, the U.S. Department of Homeland Security, the State of California, and the California Department of Transportation, whom assume no liability for the contents or use thereof. This report does not constitute a standard specification, design standard, or regulation. 
Report 20-44

\title{
Southern California Regional Workforce Development Needs Assessment for the Transportation and Supply Chain Industry Sectors
}

\author{
Tom O'Brien, $\mathrm{PhD}$ \\ Deanna Matsumoto \\ Diana Sanchez \\ Caitlin Mace \\ Elizabeth Warren \\ Eleni Hala \\ Tyler Reeb, PhD
}

October 2020

A publication of the

Mineta Transportation Institute

Created by Congress in 1991

College of Business

San José State University

San José, CA 95192-0219 


\section{TECHNICAL REPORT DOCUMENTATION PAGE}

\begin{tabular}{|c|c|c|c|}
\hline $\begin{array}{l}\text { 1. Report No. } \\
20-44\end{array}$ & 2. Government Accession No. & \multicolumn{2}{|c|}{ 3. Recipient's Catalog No. } \\
\hline \multirow{2}{*}{\multicolumn{2}{|c|}{$\begin{array}{l}\text { 4. Title and Subtitle } \\
\text { Southern California Regional Workforce Development Needs Assessment For } \\
\text { The Transportation And Supply Chain Industry Sectors }\end{array}$}} & \multicolumn{2}{|l|}{$\begin{array}{l}\text { 5. Report Date } \\
\text { October } 2020\end{array}$} \\
\hline & & \multicolumn{2}{|c|}{ 6. Performing Organization Code } \\
\hline \multicolumn{2}{|c|}{$\begin{array}{l}\text { 7. Authors } \\
\text { Tom O’Brien, PhD, Deanna Matsumoto, Diana Sanchez, Caitlin Mace, Eliza- } \\
\text { beth Warren, Eleni Hala, Tyler Reeb, PhD }\end{array}$} & \multicolumn{2}{|c|}{$\begin{array}{l}\text { 8. Performing Organization Re- } \\
\text { port } \\
\quad \text { CA-MTI-1921 }\end{array}$} \\
\hline \multirow{2}{*}{\multicolumn{2}{|c|}{$\begin{array}{l}\text { 9. Performing Organization Name and Address } \\
\text { Mineta Transportation Institute } \\
\text { College of Business } \\
\text { San José State University } \\
\text { San José, CA } 95192-0219\end{array}$}} & \multicolumn{2}{|c|}{ 10. Work Unit No. } \\
\hline & & \multicolumn{2}{|c|}{$\begin{array}{l}\text { 11. Contract or Grant No. } \\
\text { ZSB12017-SJAUX }\end{array}$} \\
\hline \multirow{2}{*}{\multicolumn{2}{|c|}{$\begin{array}{l}\text { 12. Sponsoring Agency Name and Address } \\
\text { State of California SB1 2017/2018 } \\
\text { Trustees of the California State University } \\
\text { Sponsored Programs Administration } \\
\text { 401 Golden Shore, 5th Floor } \\
\text { Long Beach, CA } 90802\end{array}$}} & \multicolumn{2}{|c|}{$\begin{array}{l}\text { 13. Type of Report and Period } \\
\text { Covered } \\
\quad \text { Final Report }\end{array}$} \\
\hline & & \multicolumn{2}{|c|}{ 14. Sponsoring Agency Code } \\
\hline \multicolumn{4}{|l|}{$\begin{array}{l}\text { 15. Supplemental Notes } \\
\text { DOI: } 10.31979 / \mathrm{mti} .2020 .1921\end{array}$} \\
\hline \multicolumn{4}{|c|}{$\begin{array}{l}\text { 16. Abstract } \\
\text { COVID-19 brought the public's attention to the critical value of transportation and supply chain workers as lifelines } \\
\text { to access food and other supplies. This report examines essential job skills required of the middle-skill workforce } \\
\text { (workers with more than a high school degree, but less than a four-year college degree). Many of these middle- } \\
\text { skill transportation and supply chain jobs are what the Federal Reserve Bank defines as "opportunity occupations" } \\
\text {-- jobs that pay above median wages and can be accessible to those without a four-year college degree. This report } \\
\text { lays out the complex landscape of selected technological disruptions of the supply chain to understand the new } \\
\text { workforce needs of these middle-skill workers, followed by competencies identified by industry. With workplace } \\
\text { social distancing policies, logistics organizations now rely heavily on data management and analysis for their oper- } \\
\text { ations. All rungs of employees, including warehouse workers and truck drivers, require digital skills to use mobile } \\
\text { devices, sensors, and dashboards, among other applications. Workforce training requires a focus on data, problem } \\
\text { solving, connectivity, and collaboration. Industry partners identified key workforce competencies required in digital } \\
\text { literacy, data management, front/back office jobs, and in operations and maintenance. Education and training pro- } \\
\text { viders identified strategies to effectively develop workforce development programs. This report concludes with an } \\
\text { exploration of the role of Institutes of Higher Education in delivering effective workforce education and training } \\
\text { programs that reimagine how to frame programs to be customizable, easily accessible, and relevant. }\end{array}$} \\
\hline $\begin{array}{l}\text { 17. Key Words } \\
\text { Workforce development, } \\
\text { COVID-19, technological } \\
\text { innovations and integration, skills } \\
\text { gap, education and training }\end{array}$ & \multicolumn{3}{|c|}{$\begin{array}{l}\text { 18. Distribution Statement } \\
\text { No restrictions. This document is available to the pub- } \\
\text { lic through The National Technical Information Ser- } \\
\text { vice, Springfield, VA } 22161\end{array}$} \\
\hline $\begin{array}{l}\text { 19. Security Classif. (of this report) } \\
\text { Unclassified }\end{array}$ & $\begin{array}{l}\text { 20. Security Classif. (of this page) } \\
\text { Unclassified }\end{array}$ & $\begin{array}{l}\text { 21. No. of Pages } \\
97\end{array}$ & 22. Price \\
\hline
\end{tabular}

FORM DOT F 1700.7 (8-72) 
Copyright () 2020

by Mineta Transportation Institute

All rights reserved.

DOI: $10.31979 / \mathrm{mti} .2020 .1921$

Mineta Transportation Institute College of Business

San José State University San José, CA 95192-0219

Tel: (408) 924-7560

Fax: (408) 924-7565

Email: mineta-institute@sjsu.edu

transweb.sjsu.edu/research/1921 


\section{ACKNOWLEDGMENTS}

The authors would like to thank the industry partners and education and training providers who, during this unprecedented COVID-19 pandemic, gave their time and expertise to contribute to our research. We also appreciate the work of CITT Research Coordinator Ben Olson and Research Associates Alondra Garcia-Verdugo and Angelina Carballo for developing the Esri StoryMap that accompanies this report. Research Assistants Kyle Chin, Nicholas Roy, and Jesse Brouillette as well as CITT's Industry Outreach Specialist, C.J. Nord, provided support in the early phases of the research. Appreciation goes to Editing Press for editorial services, as well as MTI staff. 


\section{CONTENTS}

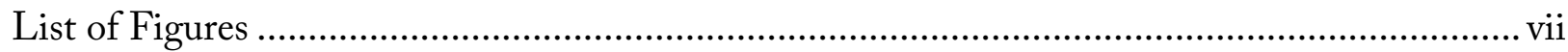

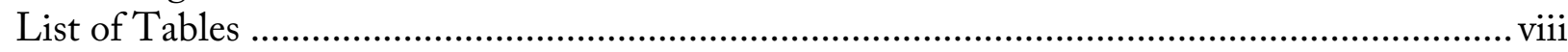

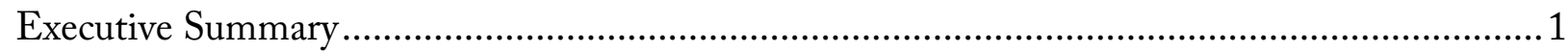

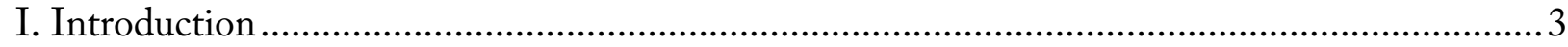

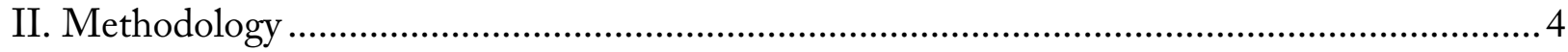

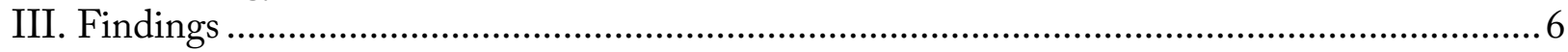

3.1 End-to-End Disruption and the Rapid Digitization of Processes ............................

3.2 Localization to Meet Consumer Demand .....................................................................

3.3 The Rise of Fourth-Party Logistics (4PLs) ..............................................................

3.4 Implications for Middle-Skill Workforce Development: Competencies Identified by Survey Respondents ...................................................................................

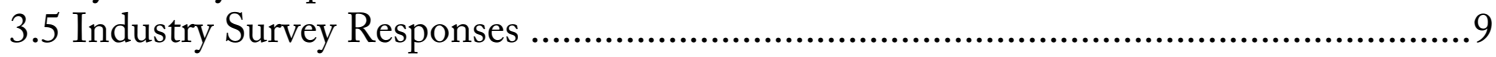

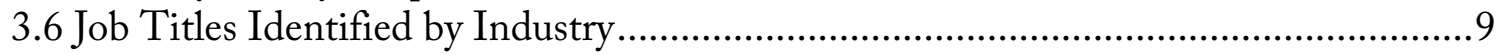

3.7 Industry-Identified Top Critical Employability Skills.............................................11

3.8 Industry-Identified Top Critical Digital Literacy Skills .............................................13

3.9 Industry-Identified Critical Front/Back Office Skills ................................................14

3.10 Industry-Identified Top Critical Data Management..............................................16

3.11 Industry-Identified Top Critical Operations \& Maintenance Skills .......................18

3.12 Industry-Identified Top Critical Agencies for Compliance Reporting and Doc-

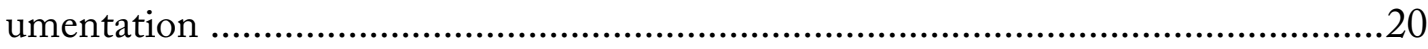

3.13 Industry-Identified Length of Training Program to Develop Critical Training

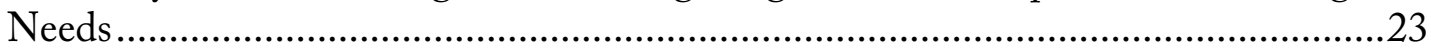

3.14 Industry-Identified Preferred Approaches to Work-Based Learning.......................23

3.15 Industry-Identified Employer-Valued Credentials/Certifications for Middle-

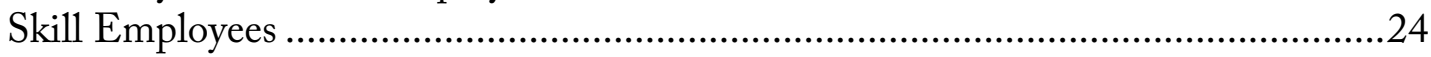

3.16 Education and Training Partner Responses ..........................................................25

3.17 Employability Skills Most Requested by Employers and Participants.....................25

3.18 Approaches to Work-Based Learning used for Program Development .................27

3.19 Education and Training Partner-Identified Barriers in Identifying and Delivering Effective Training Programs ........................................................................28

3.20 Industry and Education and Training Partner Survey and Interview Takeaways ...29

3.21 Industry-Vetted Content and Curriculum.............................................................29

3.22 Multidisciplinary Competencies Required .........................................................29

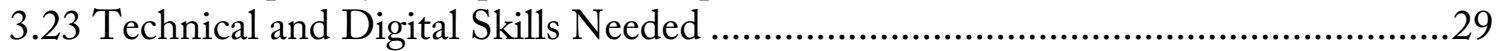

3.24 Employability Skills or Essential Skills Identified ....................................................30

3.25 Difficulty in Identifying Qualified Instructors.........................................................30

3.26 Other Barriers to Program Development ...............................................................30

3.27 Wraparound or Support Services for Participants ....................................................30

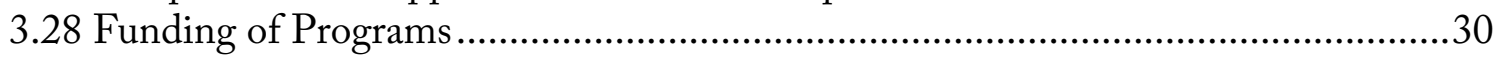

3.29 Delivery Models Preferred........................................................................................

3.30 Low Levels of AR/VR Training Platforms ............................................................31

3.31 Outreach and Marketing of Essential Transportation and Supply Chain Occu-

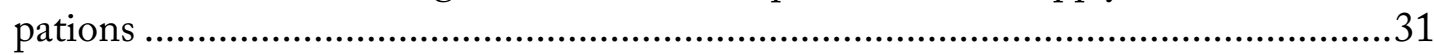

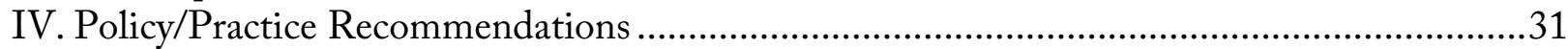

4.1 The Necessity for Upskilling ………….............................................................. 31 
4.2 Package New and Comprehensive Workforce Education Programming .................32

4.3 Cross-Train Workers and Explore Skill-Adjacent Jobs ........................................ 33

4.4 Develop the Capacity of First-Level Managers ......................................................34

4.5 Develop New Apprenticeship and Workforce Development Models .....................35

4.6 The Role of Institutes of Higher Education (IHEs) in the Future of Work............36

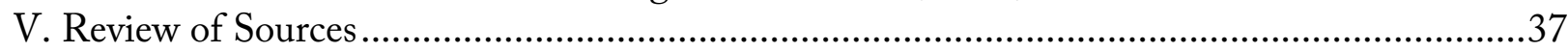

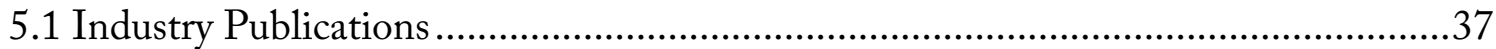

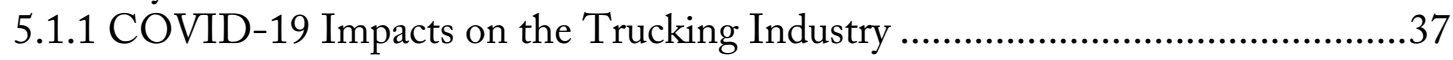

5.1.2 COVID-19: Managing Supply Chain Risk and Disruption............................38

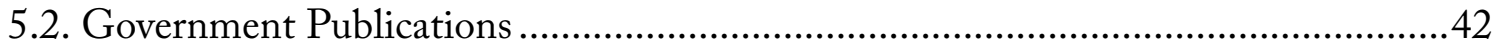

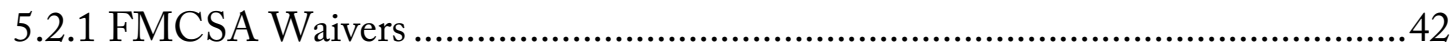

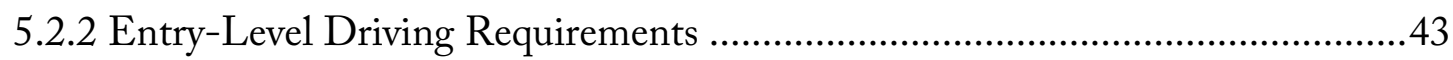

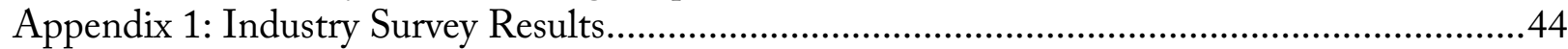

Appendix 2: Education and Training Partner Survey Monkey Results...................................53

Appendix 3: Industry Partner Survey Questions ............................................................63

Appendix 4: Education and Training Partner Survey Questions ..........................................64

Appendix 5: Industry Partner In-depth Interview Questions............................................68

Appendix 6: Education and Training Partner In-depth Interview Questions..........................69

Appendix 7: Burning Glass Technology's Labor Insights Data ..........................................70

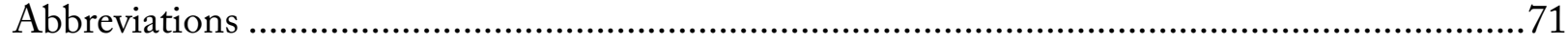

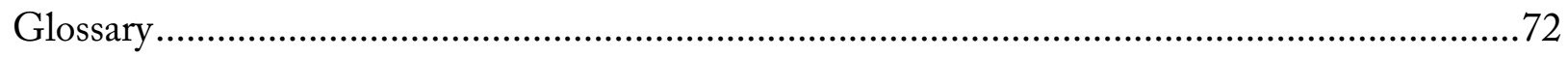

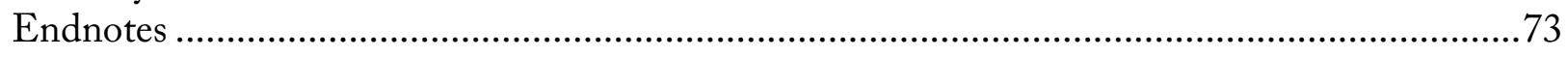

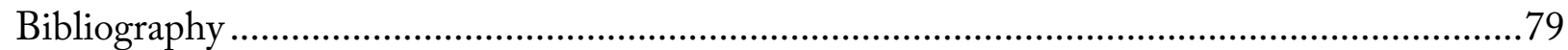

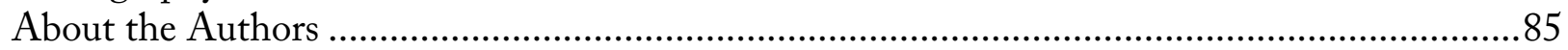




\section{LIST OF FIGURES}

Figure 1. Industry-identified Top Critical Employability Skills .................................................. 12

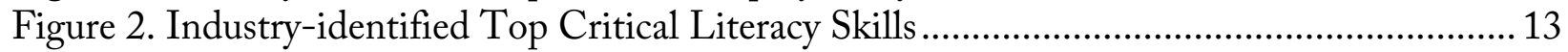

Figure 3. Industry-identified Top Critical Digital Literacy Skills.............................................. 15

Figure 4. Industry-identified Front/Back Office Skills ............................................................. 17

Figure 5. Industry-identified Top Critical Data Management .................................................. 19

Figure 6. Industry-identified Top Critical Agencies for Compliance Reporting and Docu-

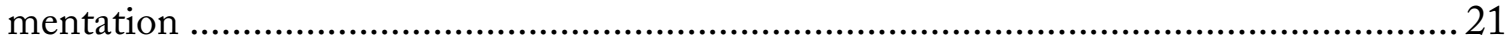

Figure 7. Industry-Identified Length of Training Program to Develop Critical Training

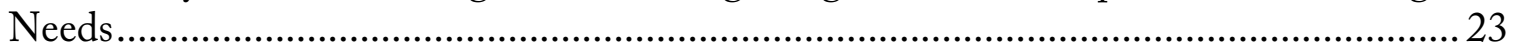

Figure 8. Industry-Identified Preferred Approaches to Work-Based Learning ........................... 24

Figure 9. Employability Skills Most Requested by Employers and Participants ..........................26

Figure 10. Approaches to Work-Based Learning used for Program Development...................... 27

Figure 11. Education and Training Partner-Identified Barriers in Identifying and Delivering Effective Training Programs .................................................................................... 28

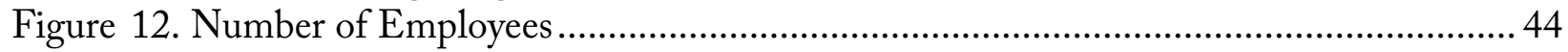

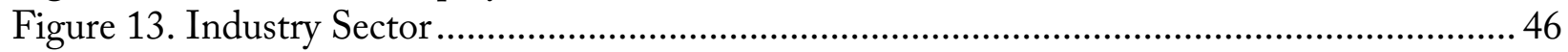

Figure 14. Primary Focus Workforce Development Efforts ....................................................... 47

Figure 15. Minimum Level of Education Required for Middle-Skill Employees.........................4 47

Figure 16. Bridging the Skills Gap Strategy ............................................................................... 48

Figure 17. Industry-Identified Workforce Development Education and Training Partners....... 48

Figure 18. Workforce Development Delivery ……….................................................................4 49

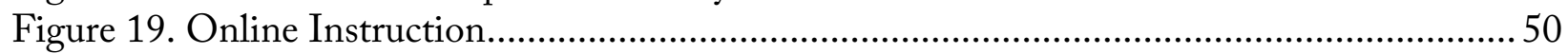

Figure 20. Use of Augmented or Virtual Reality in Instruction ...............................................5 50

Figure 21. Industry-Identified Barriers in Identifying and Delivering Effective Training Pro-

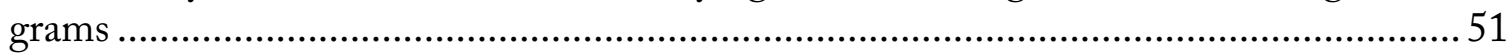

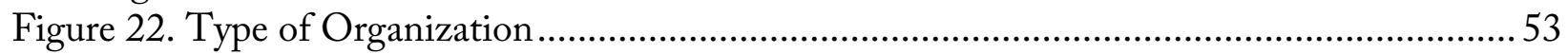

Figure 23. Industry Roles in Program Development................................................................. 54

Figure 24. Upskilling Incumbents Versus New Hires ...............................................................5 55

Figure 25. Industry Demand for Training Programs Within the Past Two Years....................... 56

Figure 26. Education and Training Partner-Identified Use of Augmented or Virtual Reality

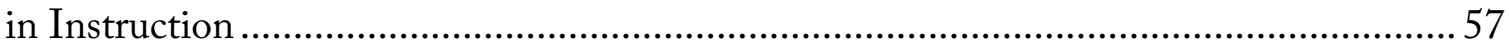

Figure 27. Education and Training Partner-Identified Supportive/Wraparound Services Provided 58 


\section{LIST OF TABLES}

Table 1. Industry-identified Front/Back Office Occupation Titles ........................................10

Table 2. Industry-identified Data Management Occupational Titles ......................................10

Table 3. Industry-identified Operations \& Maintenance Occupation Titles .............................11

Table 4. Industry-identified Compliance Reporting Occupation Titles ...................................11

Table 5. Industry-identified Employer-Valued Credentials/Certifications .............................25

Table 6. Industry-identified Anticipated Skills Gap for the Next Three Years .......................45

Table 7. Industry-identified Funding of Workforce Development Efforts .............................52

Table 8. How are Workforce Development Efforts Funded? ................................................55

Table 9. How do you Identify Workforce Development Competencies?................................56

Table 10. Education and Training Partner-Identified Supportive/Wraparound Services Requested, but not Provided (added by respondents as "other") ....................................59

Table 11. Workforce Skills Most Requested by Employers and Participants ..........................59

Table 12. What are the Transportation and Supply Chain Workforce Skills Most Requested by Employers and Participants (e.g., data analytics)? ................................................60

Table 13. What Are Your Most Pressing Obstacles to Delivering Effective Training Programs (added by respondents as "other")? ...............................................................60

Table 14. Education and Training Partner-Identified Best Practices (added by respondents as "other")

Table 15. Do you have any comments, suggestions, or recommendations about workforce development programs for the transportation and supply chain sectors? 


\section{Executive Summary}

Prior to the novel coronavirus (COVID-19) pandemic, high employer demand, dynamic technological advances, and a rapidly shrinking workforce presented immediate challenges to the transportation and supply chain sectors throughout California. COVID-19 brought the public's attention to the critical value of transportation and supply chain workers as lifelines to access to food and other supplies. At the same time, the pandemic underscored workforce gaps brought on by the need for robust data, heightened transparency, accuracy, speed, and efficiency-all elements of the Fourth Industrial Revolution (Fourth IR), a technical revolution characterized by a fusion of the digital, physical, and biological spheres, and characteristic of its unprecedented velocity. Within the context of transportation and supply chain workforce development, the Fourth IR more specifically refers to the use of robotics, artificial intelligence, automation, and digitalization in work processes.

With the pandemic, industry has been forced to quickly pivot. What would previously have been a multi-year process to gather business intelligence and digitize processes has been condensed into months, if not weeks, due to the imposition of shelter-in-place mandates. Legacy businesses, to stay competitive, will likely need to use $5 \mathrm{G}$ networks that can be twenty times faster, handle more data, and operate with more agility than $4 \mathrm{G}$ networks. Mobile devices, sensors, the Internet of Things, and a heavy reliance on dashboards for real-time metrics are rendering many manually processed tasks obsolete. These technological disruptions are changing the workplace demands placed on transportation and supply chain workers, particularly those considered middle-skill (those with more than a high school diploma, but less than a four-year college degree).

This report examines critical middle-skill workforce needs and program design factors from the perspectives of industry— "industry" in this report also includes public agencies with a goods movement division - and regional education and training providers. All rungs of transportation and supply chain employees, including front-line warehouse workers and truck drivers, now require digital skills such as mobile applications and the use of radio frequency identification (RFID) which allows for immediate data acquisition. ${ }^{1}$ This need is especially problematic given that $50 \%$ of workers involved in the transportation and storage sectors, including the supervisors of frontline workers, have low or no digital skills. ${ }^{2}$ COVID-19 has exacerbated this digital divide that has heightened economic inequalities during the past ten to fifteen years. ${ }^{3}$

Funding for workforce development has been steadily eroded since the 1990s. ${ }^{4}$ Private-sector funding for workforce development encompasses less than $5 \%$ of budgets in larger corporations, and the figure is less than $1 \%$ for small- and medium-sized businesses (SMEs), the focus of this project. ${ }^{5}$ Public- and private-sector spending on education and training efforts largely target those under the age of 25, with the U.S. ranked second-to-last among 29 developed nations for taxpayerfunded training. ${ }^{6}$ Funding workforce development, therefore, is a barrier that industry, education and training providers, and government agencies at the federal, state, and local levels must collaboratively address to close the gaps. In tandem, with shelter-in-place mandates from COVID-19, 
workforce program design and delivery strategies must now adapt to remote instructional platforms, which is challenging when providing the hands-on training required, particularly in transportation and supply chain workforce education. Moreover, this training often does not reach potential new hires nor those in positions threatened by automation: on-the-job training (OJT) is twice as likely to be provided for more highly skilled (rather than less-skilled) workers. ${ }^{7}$

This report lays out the complex landscape of selected technological disruptions of the supply chain to understand the workforce needs of middle-skill workers, followed by competencies required. This research presents promising practice recommendations for program content, design, and delivery, concluding with developments concerning the role of institutes of higher education (IHEs) in workforce education.

An eye toward equity is embedded throughout this research. People with lower levels of education, younger workers, women, people of color, and people with disabilities are disproportionately negatively affected by the economic downturn from COVID-19. The Bureau of Labor Statistics (BLS) reported that the May 2020 unemployment rates for Black/African-American (16\%) and Hispanic/Latinx (16.7\%) communities were much higher than for whites (11.8\%). ${ }^{8}$ The transportation and supply chain sectors have historically hired a racially and ethnically diverse workforce with Latinx and Black/African-Americans disproportionately represented in entry-level front-line work. ${ }^{9}$ Ensuring this workforce has the skillsets to move up the ranks is critical and requires the effective, long term collaboration between industry, workforce development agencies, and education and training programs.

Research that explores strategies that delve into these programmatic efforts are included in this report. A focus of this study is workforce development initiatives that use a skills-based approach to occupational mobility. These jobs are referred to by the Federal Reserve Bank as "opportunity occupations"-jobs that pay above median wages that can be accessible to those without a fouryear college degree. ${ }^{10}$ 


\section{Introduction}

Southern California is the nation's gateway for trade and logistics, and hence requires critical workforce development in these sectors. Prior to COVID-19, with the nation's busiest port complex, an international airport ranked second in the U.S. for passenger volume and fourth in the U.S. for air freight, an extensive rail and interstate highway system, and over 32 million square feet of warehousing, 21,430 new jobs were estimated to be created in the goods movement industries from 2017 to $2022 .{ }^{11}$ In 2018, trade by truck through the Otay Mesa (the Southern California U.S.Mexico border crossing for freight) had a total value of $\$ 46.7$ billion (including $\$ 17.2$ billion of exports and $\$ 29.5$ billion in imports). ${ }^{12}$ These industries needed 69,910 replacement workers over the same period to accommodate employment churn, or turnover, as $20 \%$ of this workforce is 55 or older. These high-demand trade and transportation jobs pay on average $14 \%$ higher wages than other industries in Southern California with an average annual wage of $\$ 63,130$. Twenty-two percent of all transportation and supply chain jobs in Los Angeles County are middle-skill and provide a living wage for a family of three, with a median average hourly wage of $\$ 26.08 .{ }^{13} \mathrm{With}$ the disruptions brought on by the pandemic, however, these figures most likely have changed, and current data are not available at the time of this writing.

After Governor Newsom established shelter-in-place policies on March 19, 2020, the State Public Health Officer designated transportation and logistics workers as "Essential Critical Infrastructure Workers." ${ }^{14}$ Disruptions caused by COVID-19 are expected to result in a surge of mergers, acquisitions, and consolidations of supply chain and transportation organizations, yet some small- and medium-sized enterprises (SMEs) will likely remain relevant in the overall logistics landscape albeit, according to our survey respondents, with furloughs and contraction. ${ }^{15}$ Diversifying offerings is directly correlated with SME relevance. ${ }^{16}$ However, many SMEs do not have access to the technological infrastructure of larger companies, nor the capacity and funding for workforce development. This is a critical time to learn how SMEs can compete for market share when technological infrastructure as well as the concomitant skilled workforce is in flux.

Operational resilience is key to surviving the pandemic. This increased reliance on technological connectivity throughout the logistics workforce requires new models of training that focus on data, connectivity, and collaboration. Organizations are struggling to find the talent needed to address operational efficiencies, system performance, safety, and security. ${ }^{17}$ As a result, employees who can conduct analysis, validate data sets, use digital tools, and forecast will be in high demand.

A company's highest cost when adopting technology is not the initial investment of software but rather the training of staff to effectively deploy the technology. ${ }^{18}$ Very few training and education programs are aligned with these newer "hybrid" jobs that require both sector-specific and digital skills. Moreover, digital skillsets constantly change, so talent must be malleable to embrace dynamic work environments. Competency-based, short-term programming using industry-driven curricula will likely be the model for workforce development going forward. 
COVID-19 has wholly disrupted education and training programs. Training using digital platforms such as augmented reality (AR) and virtual reality (VR) will be in demand to train workers remotely, as on-the-job (OJT) training is surpassing the traditional instructor-led classroom (both virtual and in-person). ${ }^{19}$ Reskilling or upskilling incumbents and new hires involves the process of developing technical skills as well as critical thinking collaborative and communication skills across channels. These skills play a critical role in determining an organization's value in the complicated, multifaceted supply chain landscape, especially during this pandemic.

\section{Methodology}

The Center for International Trade and Transportation (CITT), a center within the College of Professional and International Education at California State University, Long Beach, began to design the research for this project in April 2019, with beta testing survey groups launched in January and February 2020. The online surveys were launched at the end of February 2020 and closed in early June 2020. With the COVID-19 shelter-in-place mandates instituted in March 2020, CITT requested a two-month extension to capture some of the rapidly changing workforce competencies required of workers. The in-depth interview questions included questions directly related to the pandemic. The instruments are included in the appendix.

The CITT team designed, deployed, and implemented survey tools such as Mentimeter, a realtime polling application, together with online surveys (using SurveyMonkey). These instruments were supplemented with follow-up in-depth interviews with industry and education and training partner statewide leaders. All surveys were IRB-approved, and data are reported in the aggregate with all responses anonymized. The CITT research team used Burning Glass Technology's Labor Insight platform to verify and confirm survey findings. Labor Insight analyzes occupations and their required skills in real time and tracks more than 40,000 sources of job postings on job boards and corporate websites. CITT staff attended industry association conferences and webinars to gather data from statewide stakeholder leaders. Literature reviews include industry publications, peer reviewed articles, and government documents.

Unique to CITT's approach is the geographic reach of this analysis. It encompasses end-to-end (port to warehouse) workforce requirements, spanning the Ports of Long Beach and Los Angeles to the Inland Empire (San Bernardino and Riverside counties combined). Prior to the pandemic, the port complex had experienced record-breaking trade volume, while the Inland Empire has become a strategic link in the global supply chain. The Inland Empire leads Southern California in the construction of logistics and freight-related warehousing facilities.

With the complexity of the supply chain and its associated workforce development competencies, identifying stakeholders was key to obtaining accurate, relevant, and up-to-date data. CITT deployed its extensive network of regional partners in the transportation and supply chain sectors, developed through its 23-year history. Specifically, the research team mined CITT databases for 
relevant organizations within the five-county region: terminal operators, ports, labor, customs, freight forwarders, transloading facilities, intermodal facilities, rail, NVOCCs (Non-Vessel Operating Common Carriers), drayage, trucking (both long- and short-haul), distribution and warehousing facilities, manufacturers, and retail establishments. CITT also partnered with the University of California, Riverside Extension Program Development division, which houses extensive supply chain programs.

CITT then employed a total of 55 industry and education and training partner participants in this research. The research team acknowledge the difficulties partners faced when shelter-in-place mandates required many businesses to contract, furlough, or quickly realign processes. Similarly, education and training providers moved to remote work while trying to rapidly develop online coursework and delivery methods.

Thirty-five industry participants provided data and feedback. The research team received 19 industry survey responses and interviewed ten among these. Over $60 \%$ of industry respondents were from SMEs with fewer than 100 employees. Over 50\% had fewer than 49 employees. The top three industry sectors represented were trucking, distribution and warehousing, and third-party logistics providers (3PLs), i.e., companies that integrate warehousing and transportation services. (See Appendix 1.)

For education and training providers, CITT surveyed and/or interviewed leadership within workforce development boards, community-based non-profit organizations, community colleges, public transportation agencies, municipal governments, county Career and Technical Education (CTE) organizations, and the California Department of Corrections and Rehabilitation—all institutions which provide workforce development programs in the region. The Department of Corrections and Rehabilitation provides workforce development and adult education programs for students preparing for re-entry. Warehousing work is well-established within the state prison system. While the specifics of a pathway for re-entry workers is beyond the scope of this research, logistics could present a potential career choice for reintegrating into society after incarceration.

Including the beta testing cohort, 18 education and training providers participated with 12 survey responses and four interviews. Most respondents have partnered with supply chain and transportation industry sectors in workforce development. (See Appendix 2.)

The methodology involved (1) identifying logistics-related companies in Southern California from the ports to the Inland Empire (2) investigating various apprenticeship and workforce development models to inform best practices; (3) developing, implementing, and analyzing a combination of surveys, in-depth interviews, and beta focus groups with stakeholders; (4) developing models for workforce development using a workforce/apprenticeship intermediary infrastructure; and (5) developing an Esri StoryMap to present our findings.

The survey tools selected had to allow for ease of use and flexibility in responses to account for the complex nature of the supply chain. The research team provided two survey tools. Mentimeter, used for our beta testing groups (our launch webinars), was interactive and provided real-time 
feedback; a second online survey was widely disseminated to CITT as well as University of California, Riverside Extension supply chain partners. With Mentimeter, respondents could drive the discussion by leading with their own comments and questions. Though the research team was concerned about the constraints involved with this tool-including difficulties with participant buy-in because of time, scheduling, privacy, and usability - the team did not encounter pushback from the beta testing groups. The data received from these beta testing groups, per protocol, was not included in the research project's data bank; rather, the beta testing groups provided input into the structure, design, and type of survey questions that would be most effective in gathering information from other stakeholders.

After the SurveyMonkey online surveys were deployed, CITT staff, including a Senior Industry Outreach Specialist, conducted follow-up, in-depth interviews by phone and video conferencing to clarify and further articulate data received through the survey processes. Integral to the approach is the iterative nature of stakeholder feedback to allow for refinement and improvement of the workforce development competencies identified.

Once documented through the Esri StoryMap and this report, the methodologies and tools used in this analysis can be replicated for future California State University Transportation Consortium (CSUTC) workforce development assessment projects. It will be housed on the CSU- Multimedia Educational Resource for Learning and Online Teaching (MERLOT) SkillsCommons platform for statewide accessibility. CSU-MERLOT SkillsCommons is an online library of free and open educational resources (OER) for use by higher education faculty and students nationwide.

\section{Findings}

To remain agile, transportation and supply chain companies require investments in technology that manage data and optimize production and distribution capacity. The connected middle-skill employee works in an environment that includes robotics and automation, sensors, wearable/mobile technology, the Internet of Things, artificial intelligence, cloud computing and storage, and 3D printing. This research focus is on the lower levels of supply chain analytics maturity, where tasks are operational, descriptive, and diagnostic, as described by the Council for Supply Chain Management Professionals. ${ }^{20}$

Barriers to adopting the digital supply chain include workforce development gaps and cybersecurity concerns. ${ }^{21}$ In this section, a macroeconomic view of technical disruptions in the transportation and supply chain sectors are presented, followed by implications for workforce development. Industry and education and training partner responses are included. 


\subsection{End-to-End Disruption and the Rapid Digitization of Processes}

The surge of consumer demand for essential products has strained supply chains. In March 2020, a poll conducted by the Institute of Supply Chain Management found that nearly 75\% of 600 supply chain managers reported "supply chain disruptions in some capacity due to coronavirusrelated transportation restrictions." 22 Specifically, the transportation sector provides available timesensitive goods to medics, consumers, and companies; as a result, many companies and third-party logistics (3PLs) are competing among themselves for this business while they experience less demand. End-to-end transportation systems are disrupted as commodity demands change due to COVID-19.

Intermodal refrigerated rail lines have been discontinued as goods moved during the pandemic have shifted away from highly perishable items. ${ }^{23}$ Limitations on air traffic have restricted air cargo transport. Truckers have been heavily relied upon to transport groceries and medical supplies on land. Supply chain operators have maintained social distancing procedures and discontinued procedures that require drivers to have documents signed upon delivery; these protocols have prompted the accelerated implementation of digital tools. ${ }^{24}$

With the pandemic, steep fluctuations in supply and demand create inefficiencies in predicting and planning for loads, leading to extended wait times for truck drivers delivering at warehouses. ${ }^{25}$ Long waits further negatively impact carriers, brokers, and shippers. Web-based scheduling systems provide a solution by requiring truckers to schedule a dock appointment. Appointment scheduling also allows warehouse employees to efficiently prepare for loads and especially to prioritize emergency freight.

Digitization generally provides real-time, accurate data for a more efficient matching of supply and demand in facing capacity challenges. The Internet of Things provides valuable data analysis through data integration, visibility, and transparency along the supply chain. ${ }^{26}$ Real-time monitoring of goods transport also permits quick resolution of problems, such as bottlenecks, driver shortages, and dock congestion. With more data and strategic modelling, a digital platform provides predictive analyses for better preparation and planning. Digital bills of lading minimize costly errors and increase the speed of information transfer, reconciliation, processing, invoicing, and payment. Ultimately, these optimizations reduce operational costs.

These platforms for virtually connecting supply chain stakeholders have been on the rise during the pandemic and serve as a virtual global directory for accessing data. ${ }^{27}$ Industry respondents described collaborative efforts not seen prior to COVID-19 such as end-to-end communication between retail outlets and sourcing establishments, real-time truck parking notifications, and shared notifications of blank sailings, according to which vessels will not stop at ports because of low cargo loads. Another strategy to address the rapid fluctuations of inventory for the logistics companies is slow-steaming: the intentional selection of slower transportation methods to delay the arrival of 
non-perishables. Slow-steaming acts as a form of "floating storage" to wait for space in warehouses or to find alternative routes to market. ${ }^{28}$

Wearables are a potential safety measure for warehouse workers. Wearables include wristbands, goggles, employee badges, ear protection, and boots. These devices can be connected to the Internet of Things and include features for improving safety, such as alerting a worker when they are within six feet of another worker. Another potential safety benefit is tracing contact when an employee finds they have been exposed to (or tests positive for) COVID-19. Currently, there are privacy concerns about such wearables, particularly if they take biometric measurements. ${ }^{29}$

\subsection{Localization to Meet Consumer Demand}

Companies are moving manufacturing and distribution centers more locally to better serve customers' requests for speedy deliveries. ${ }^{30}$ Servicing consumers from larger, centralized facilities requires long shipping distances, and while technology has improved the flow of goods over long distances, such technology may also be used to move manufacturing and distribution closer to consumers. Technology can increase communication and collaboration between localized manufacturing and distribution centers. As an example of the benefits of localization, local pharmaceutical companies can deliver custom compound drugs for in-office or at-home administration speedily and safely. Research from the American Transportation Research Institute (ATRI) presents similar findings: the highest demand for truck drivers during the pandemic has been for those driving less than 100 miles. $^{31}$

\subsection{The Rise of Fourth-Party Logistics (4PLs)}

Fourth-party logistics (4PL) companies are the next wave of technological emergence in transportation and supply chain industries (as revealed in an industry partner interview). 4PL enterprises take third-party logistics (3PL) companies further by offering strategic and operational logistics solutions for larger businesses. While a 3PL can offer supply chain management for transportation, warehousing, and distribution, a 4PL extends this management to resources, technology, and infrastructure. By using a 4PL, companies can completely outsource the logistics portion of their business. Digital freight matching or load boards (online marketplaces where multiple truck owner-operators, shippers, and freight brokers can post and search for loads to move) combined with financial technology (fintech) used for mobile payment systems are examples of technological advances that provide businesses with a competitive edge.

\subsection{Implications for Middle-Skill Workforce Development: Competencies Identi- fied by Survey Respondents}

As the management of robust, accurate data is key to an efficient supply chain, as is ensuring its connectivity, middle-skill employees require a combination of problem-solving, collaboration, communication, and digital workplace skills. Industry and education and training provider respondents identified top workforce development competencies, presented below. 
CITT first researched types of middle-skill jobs in transportation and supply chain organizations and found the majority are in operations and maintenance, data management, compliance, front/back office staff, and human resources. The research team then examined the competencies by gathering data from industry association publications and online job postings. This data was compared to results from the Burning Glass Labor Insight analysis and were found to be comparable. (See Appendix 7.) The competencies noted were embedded into two surveys: one for industry partners and the other for education and training partners. The results of the surveys are presented in this section. Data presented in this section may be of particular value to workforce development organizations in their program development initiatives. Some of the data referenced in the text can be found as figures in Appendices 1 and 2.

\subsection{Industry Survey Responses}

Industry respondents were predominantly from SMEs, where the minimum amount of education required for middle-skill employees was a high school diploma or equivalent (55\% or respondents); some high school education (20\%); or a Bachelor's degree (15\%) or Associate of Arts degree (5\%). The current focus for identified workforce development efforts is placed on middle-skill employees, mid-level management, and entry-level employees. To meet their workforce skills gap, over $90 \%$ of respondents are training both incumbents and onboarding new hires. (See Appendix 1.)

\subsection{Job Titles Identified by Industry}

As part of the survey administered to industry, CITT asked for the current occupational titles of middle-skill workers within those identified job categories. These updated titles, when used in targeted, real-time analytical searches or online job searches, will provide for more accurate data on workplace competencies. The Bureau of Labor Statistics (BLS) is currently revising their Standard Occupational Classification (SOC) system to reflect current occupational titles. 
Table 1. Industry-Identified Front/Back Office Occupation Titles

- Account Manager

- Systems Support

- Business Analyst

- Implementation Manager

- Warehouse/Inventory Supervisors

- Customer Sales

- Product Acquisition

- Customer Service Specialist/supervisor/Rep

- Dispatcher

- Dispatcher

- Tracing Pricing

- Brokerage Agent

- Import Agent

- Warehouse Management Systems (WMS)

Manager/Coordinator

- Operations Supervisor/Manager

- Traffic Supervisor

- Warehouse Availability

- Container Availability

- Inventory Control
- Transportation Management Systems (TMS) Customer Care Associates

- Regulatory and Compliance

- Owner

- Logistics Coordinator

- Equipment Coordinator

- Project Coordinator

- Technician

- Administrative Analyst

- Port Captain

- Port Engineer

- Tank Barge Manager

- Health, Safety, Quality, \& Environment (HSQE) Specialist

- Human Resources (HR) Manager

- Logistics Coordinator

- Transaction Coordinator

- Dispatcher

- Safety/Maintenance Rep

\section{Table 2. Industry-Identified Data Management Occupational Titles}

- Account Manager

- Systems Support

- Business Analyst

- Implementation Manager

- Underwriters

- Chartered Financial Analyst (CFA)

- Delivery Management

- Financial Analyst

- Sales \& Marketing

- Construction Manager

- Planner

- Estimator

- Brokerage Agent

- Import Agent

- Dispatchers
- Traffic/Dispatch Supervisor

- Inventory Analyst

- Information Technology (IT) Analyst

- Availability Clerk

- Load Planners

- Owners

- Dispatch Workflow Planner

- Customer Service Rep/Scheduler

- Fleet Manager and Accounting Clerks

- Planner/Engineer I/II/III

- Commercial Manager

- Petroleum Scheduler

- Logistics Coordinator

- Operations Supervisor/Manager/Analyst 
Table 3. Industry-Identified Operations \& Maintenance Occupation Titles

\begin{tabular}{ll}
\hline - Security & - Fleet Manager and Staff-Dispatcher \\
- Estimator & - Equipment Coordinator \\
- Superintendent & - Planner/Engineer I/II/III \\
- General Foreman & - Senior Associate \\
- Foreman and Journeyman Wireman & - Principal \\
- Maintenance Specialist & - Fleet Engineering Team \\
- IT Analyst & - Inside Sales \\
- IT Administrator & - Safety/Maintenance Rep/Manager \\
- Project Coordinator & - Owner \\
\hline
\end{tabular}

Table 4. Industry-Identified Compliance Reporting Occupation Titles

\begin{tabular}{ll}
\hline - Account Manager & - Owner \\
- Systems Support & - Fleet Manager \\
- Business Analyst & - Human Resources \\
- Implementation Manager & - Dispatch Manager \\
- Mechanics & - Logistics Manager \\
- Delivery and Product Supervisors & - Safety Security and Environment (SSE) \\
- General Manager & \\
- Vice President, Safety and Enterprise & - Compliance \\
- Risk & - Complief Executive Officer (CEO) \\
- Brokerage Agent & - Chief Finance Officer (CFO) \\
- Import Agent & - Documentation Manager \\
- Quality and Compliance Manager/Officer & - Transportation Manager \\
\hline
\end{tabular}

\subsection{Industry-Identified Top Critical Employability Skills}

The top five industry-identified critical employability skills (sometimes referred to as soft or essential skills) include critical thinking and data-driven problem solving; customer service; communication and interpersonal; adaptability and resilience; and collaboration and teamwork. These skills align with responses received from education and training providers. 


\section{Figure 1. Industry-Identified Top Critical Employability Skills}

What are the employability skills (professional, engagement, or soft skills) most critical for middle-skill employees at your organization? (Please select all that apply)

Answered: 19 Skipped: 22

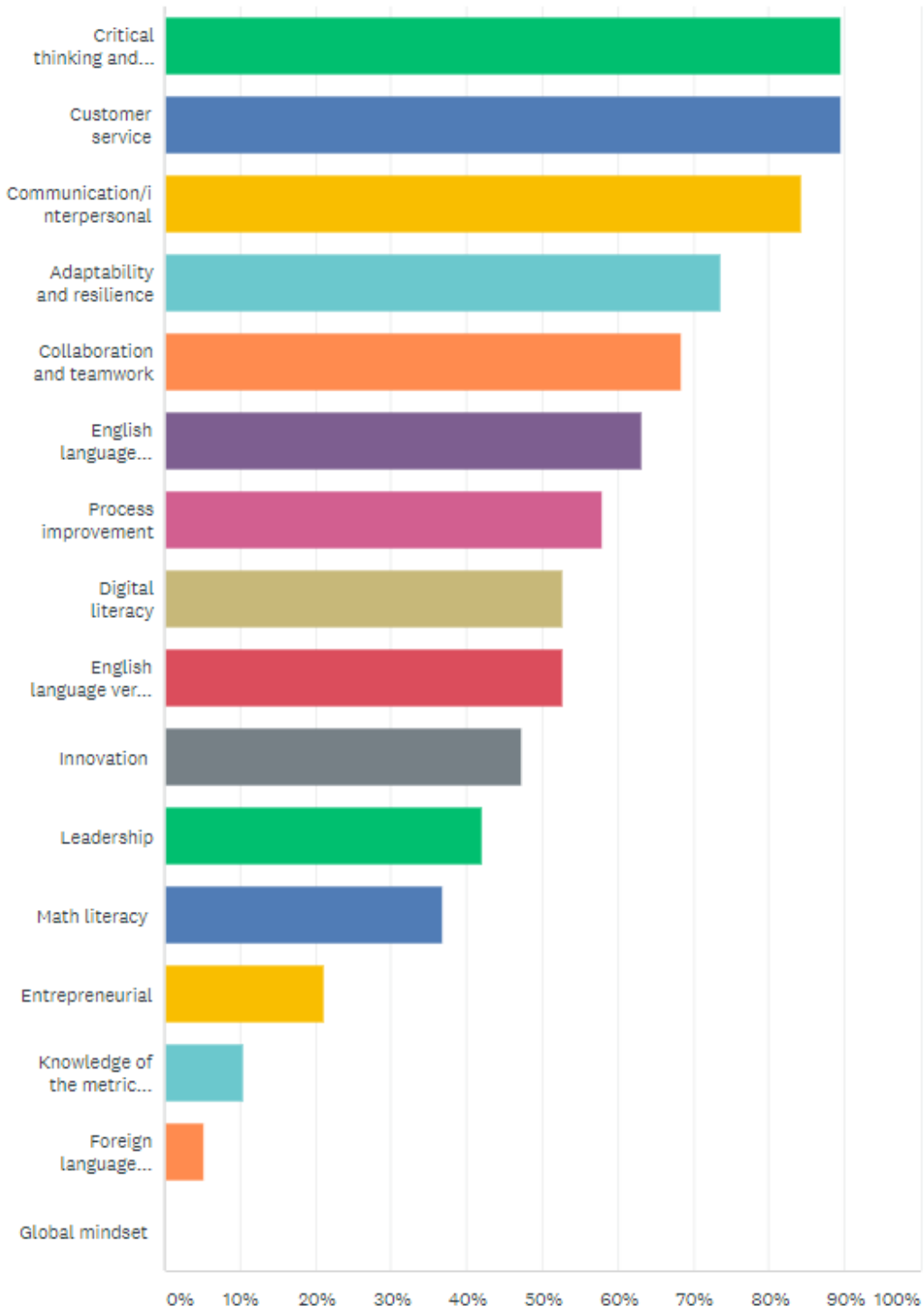

Critical thinking and data-driven problem-solving

English language literacy (reading and writing)

English language verbal communication

Knowledge of the metric system

Foreign language knowledge 


\subsection{Industry-Identified Top Critical Digital Literacy Skills}

Industry-identified digital literacy skills corroborates with literature we reviewed to show that skills in communicating via email and MS Outlook, Excel and Word are critical. Industry respondents also stated in interviews that using mobile and video conferencing apps, as well as cloud sharing platforms, proved essential with COVID-19 shelter-in-place policies.

Figure 2. Industry-Identified Top Critical Digital Literacy Skills

What are your most critical middle-skill workforce needs relating to digital literacy? Middle-skill workers are those with a high school diploma, but less than a four-year college degree. (Please select all that apply)

Answered: 19 Skipped: 22

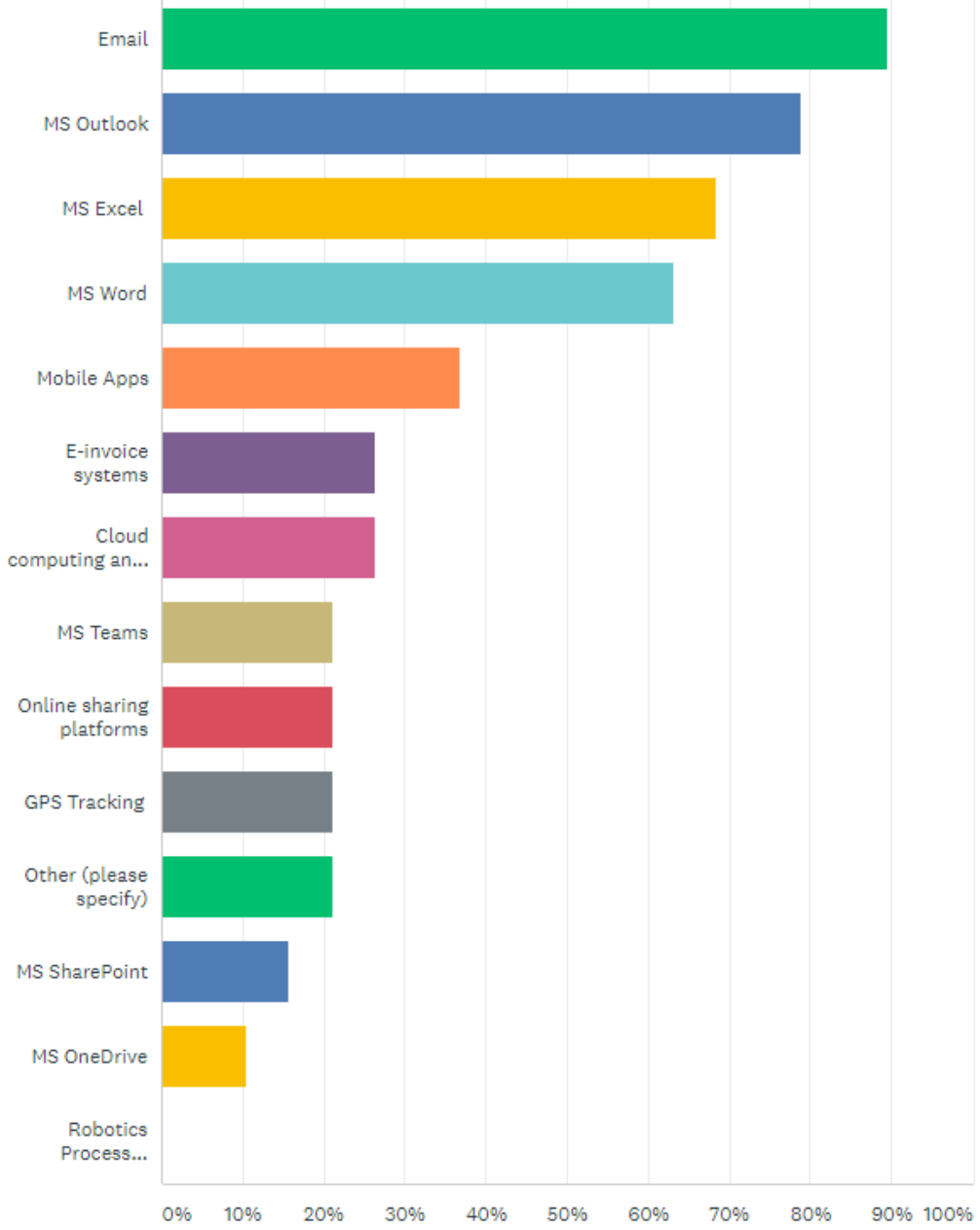

Cloud computing and storage

Robotics Process Automation 


\subsection{Industry-Identified Critical Front/Back Office Skills}

Front office workers include those who work directly with clients and customers. An example of a supply chain front office worker is a customer service representative, while a back office worker could be an accountant or human resources employee. The difference between front and back office occupations, particularly for SMEs, are blurring with both staff and tasks sometimes overlapping. The most critical skill sets for front/back office workers include MS Excel, Word, Customer Relationship Management (CRM) systems, Word, Transportation Management Systems (TMS), and navigating the regulatory compliance landscape. 
Figure 3. Industry-Identified Critical Front/Back Office Skills

What are your most critical middle-skill workforce needs related to front/back office management systems? (Please select all that apply)

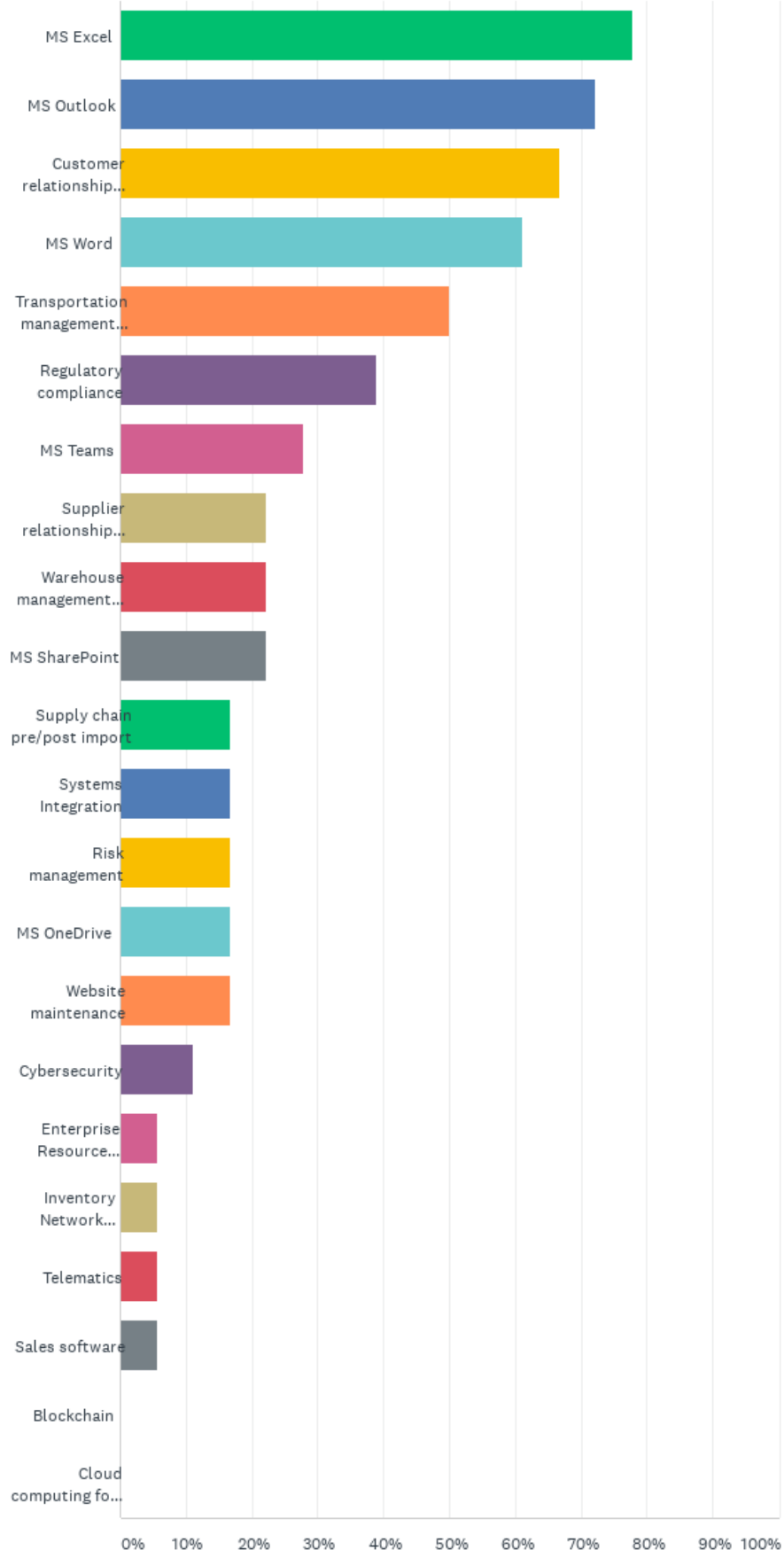

Customer relationship management systems (CRM)

Transportation management systems

Supplier relationship management systems

Warehouse management systems 


\subsection{Industry-Identified Top Critical Data Management}

The top critical data management competencies identified in the survey include skills in forecasting, demand planning/scheduling, automated data collection, asset management, data visualization, inventory and network optimization, and Electronic Data Interchange (EDI). All of these skills enhance data transparency. 
Figure 4. Industry-Identified Top Critical Data Management

What are your most critical middle-skill workforce needs relating to data management? (Please select all that apply)

Answered: 19 Skipped: 22

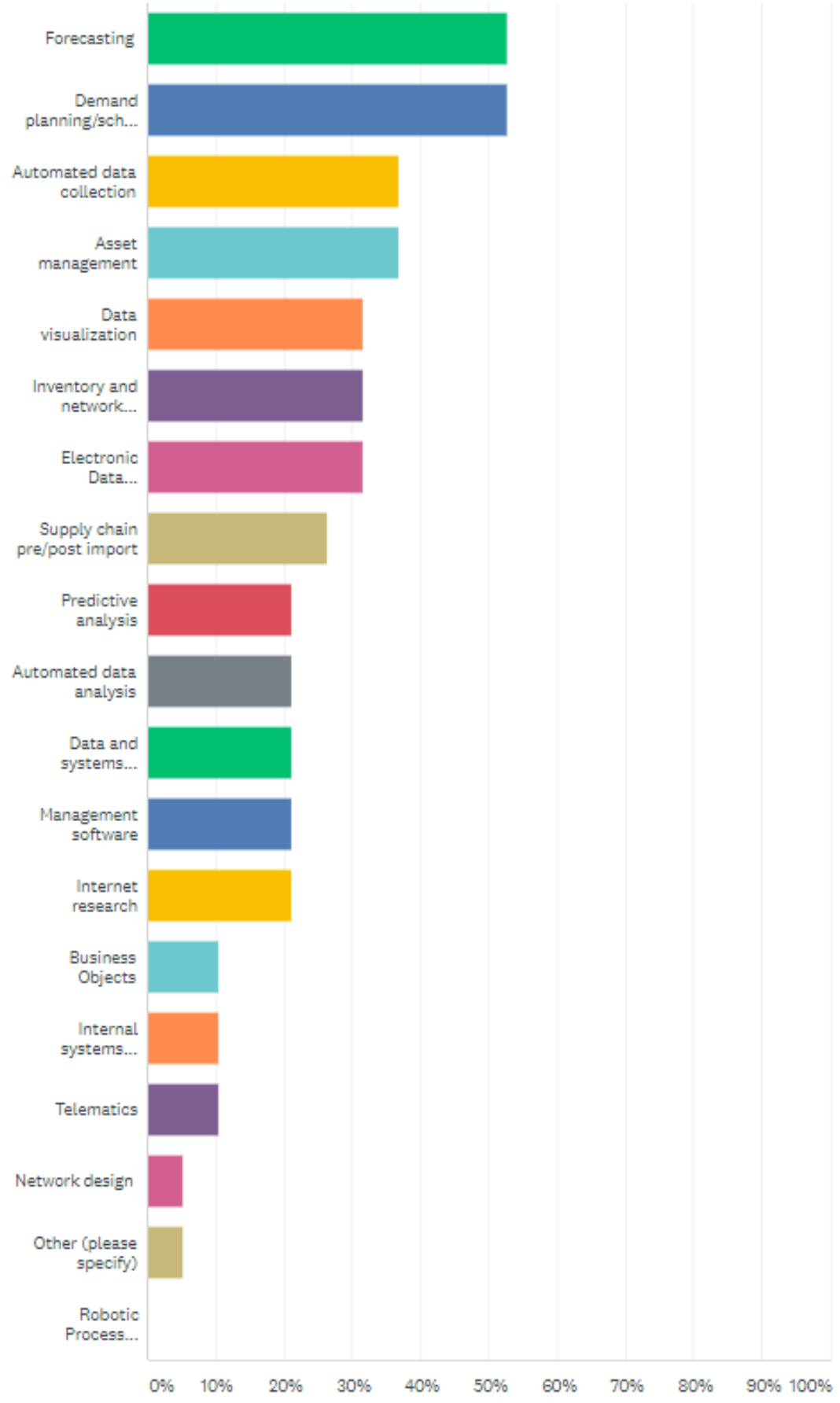

Demand planning/scheduling

Inventory and network optimization

Electronic Data Interchange (EDI)

Data and systems security

Internal systems adaptability 


\subsection{Industry-Identified Top Critical Operations \& Maintenance Skills}

The most critical middle-skill operations \& maintenance competencies include skills in compliance reporting, zero-emissions technology, fueling infrastructure, cybersecurity, use of sensors, and in fleet electrification. Other responses include hand-held radio frequency (RF) guns, Intelligent Transportation Systems (ITS), and Global Positioning System (GPS). These were added as "other" in the survey responses. 
Figure 5. Industry-Identified Top Critical Operations \& Maintenance Skills

What are your most critical middle-skill Operations \& Maintenance workforce needs? (Please select all that apply)

Answered: 15 Skipped: 26

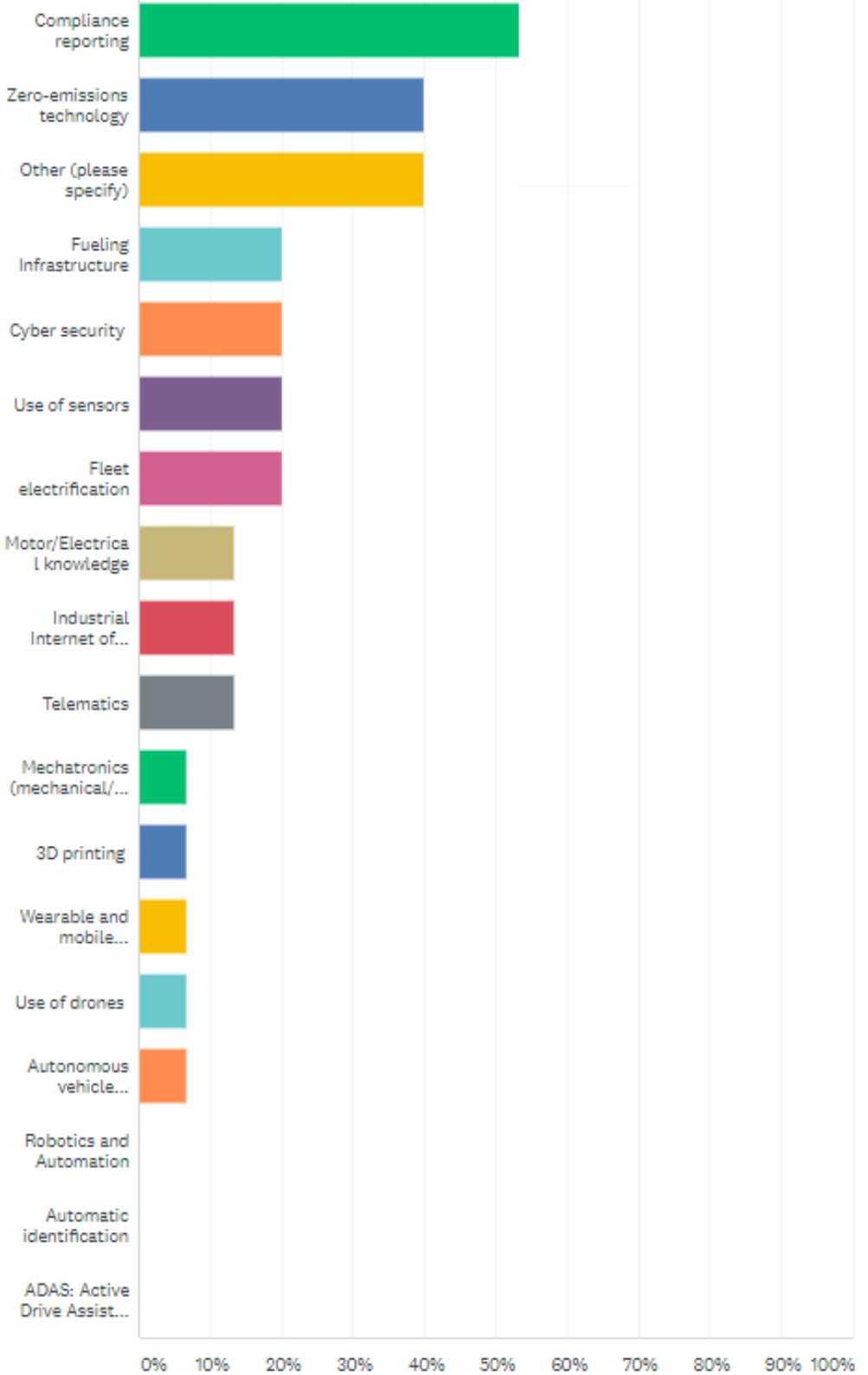

Industrial Internet of Things

Mechatronics (Mechanical/electrical/software aptitudes)

Wearable and mobile technology

Autonomous vehicle technology including cargo handling equipment

ADAS: Active Drive Assist Systems 


\subsection{Industry-Identified Top Critical Agencies for Compliance Reporting and Doc- umentation}

The top critical compliance reporting agencies will vary by industry sector. However, the Department of Transportation's Federal Motor Carrier Safety Administration (FMCSA) and the California Air Resources Board (CARB) were identified as the top two critical agencies for compliance reporting and documentation. 
Figure 6. Industry-Identified Top Critical Agencies for Compliance Reporting and Documentation

What compliance reporting and documentation is most critical to your organization? (Please select all that apply)

Answered: 19 Skipped: 22

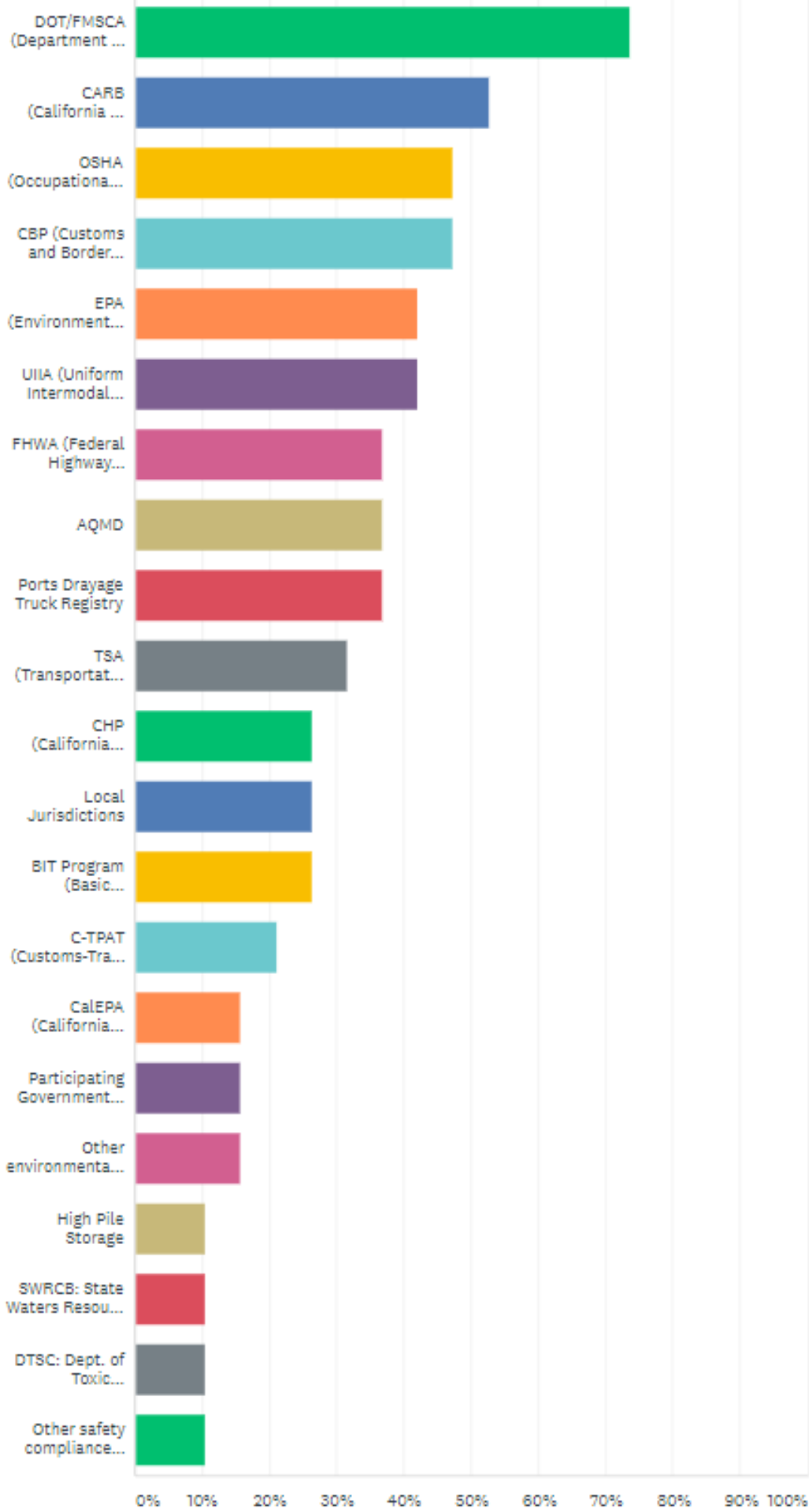


DOT/FMCSA (Department of Transportation/ Federal Motor Carrier Safety Administration)

CARB (California Air Resources Board)

OSHA (Occupational Safety and Health Administration)

CBP (Customs and Border Protection)

EPA (Environmental Protection Agency)

UIIA (Uniform Intermodal Interchange and Facilities Access Agreement)

FHWA (Federal Highway Administration)

TSA (Transportation Safety Administration)

CHP (California Highway Patrol)

BIT Program (Basic Inception of Terminals)

C-TPAT (Customs-Trade Partnership against Terrorism)

CalEPA (California Environmental Protection Agency)

Participating Government Agency (PGA)

Other environmental regulatory compliance reporting

SWRCB: State Waters Resource Control Board

DTSC: Dept. Of Toxic Substances Control

Other Safety Compliance Reporting 


\subsection{Industry-Identified Length of Training Program to Develop Critical Training Needs}

Nearly half of the industry respondents reported that the ideal length of training program to learn the most critical skills would be less than six months, with $24 \%$ responded less than one month. This is critical data when developing workforce development programming, as a Department of Labor Registered Apprenticeship requires a minimum of one year of training and education (referred to as related technical instruction, or RTI). One industry respondent noted one-day hackathons may be an effective strategy for training.

Figure 7. Industry-Identified Length of Training Program to Develop Critical Training Needs

What is the ideal length of program that will adequately prepare your employees to learn the necessary skills for your most critical training needs?

Answered: 17 Skipped: 24

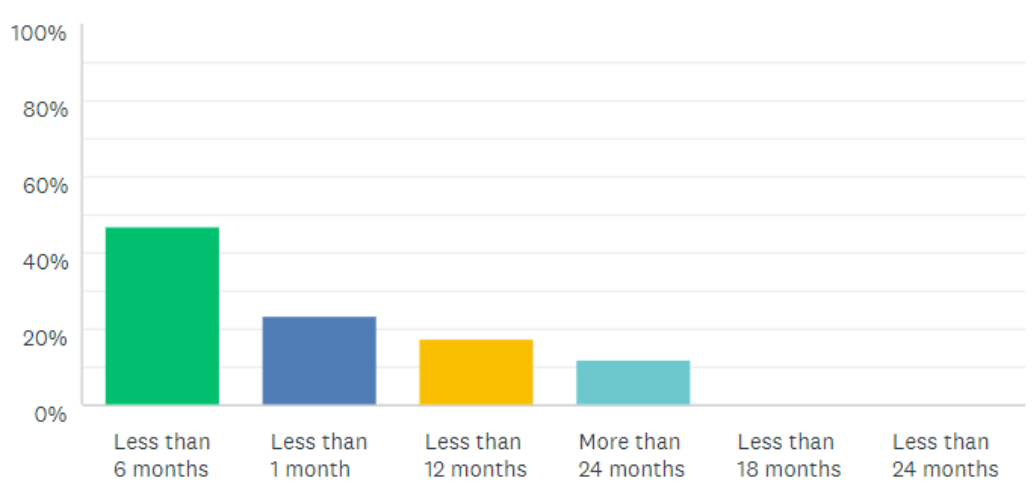

\subsection{Industry-identified Preferred Approaches to Work-Based Learning}

Companies responded that hands-on (on- or off-site) learning, online learning, mentorship, job shadowing, and continuing education designs work best for their organizations. Work-based learning should not be equated with unpaid internships. Less than $10 \%$ of respondents identified unpaid internships as designs that would work best for their organizations. 
Figure 8. Industry-Identified Preferred Approaches to Work-Based Learning

With a spectrum of approaches to work-based learning, what design would work best for your organization? (Please select all that apply)

Answered: 17 Skipped: 24

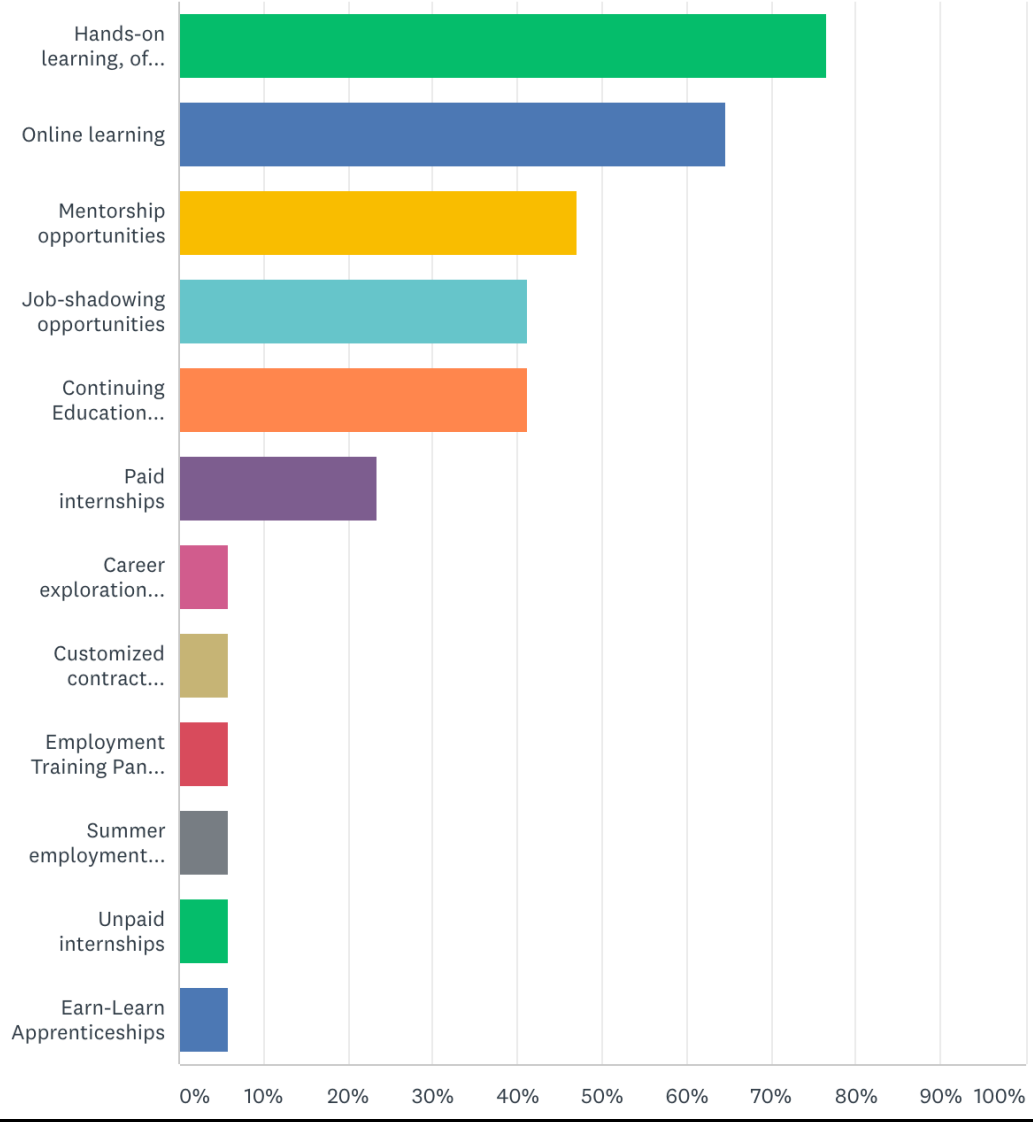

Hands-on learning, off- or on- site

Continuing education courses

Career exploration opportunities

Customized contract training

Employment Training Panel (ETP)

Summer employment opportunities

Earn-Learn Apprenticeships

\subsection{Industry-Identified Employer-Valued Credentials/Certifications for Middle- Skill Employees}

Employer-valued credentials and certifications provide information to new hires or incumbents wishing to upskill. Industry respondents provided credentials and certifications that are sought after in their sectors. 
- Certified Professional in Supply Management (CPSM)

- Certified Global Business Professional (CGBP)

- Chartered Life Underwriter (CLU)

- Certified Financial Planner (CFP)

- Retirement Income Certified Professional (RICP)

- Chartered Financial Consultant (ChFC)

- Global Logistics Specialist \& Global Logistics Professional Program

- General Journeyman

- Fire Life Safety

- Voice Data Video certifications

- Job Specific Certifications

- Licensed Customs Broker

- Certified in Production and Inventory Management (CPIM)

- Senior Professional in Human Resources (SPHR)

- Certified Global Business Professional (CGBP)

- Engineer in Training (EIT)

- Professional Engineer (PE)

- American Institute of Certified Planners (AICP)

- Professional Transportation Planner (PTP)

- Maritime licenses

- Universal Commercial Code

\subsection{Education and Training Partner Responses}

For education and training providers, CITT surveyed and/or interviewed leadership within workforce development boards, community-based non-profit organizations, community colleges, public transportation agencies, municipal governments, county Career and Technical Education (CTE) organizations, and the California Department of Corrections and Rehabilitation. The majority of respondents' workforce development efforts focused both on upskilling incumbents and training new hires. Education and training providers identified workforce development competencies through the DACUM (developing a curriculum) process, advisory boards, industry focus groups and surveys, certification testing, job classification reviews, and through Key Performance Indicator (KPI) studies. (See Appendix 2.)

\subsection{Employability Skills Most Requested by Employers and Participants}

The top five employability skills requested by employers and participants (as reported by education and training providers) were critical thinking and data-driven problem solving; communication 
and interpersonal skills; collaboration and teamwork; customer service, adaptability and resilience. These desired skill sets align with industry responses, presented previously.

Figure 9: Employability Skills Most Requested by Employers and Participants

What are the employability skills (professional, engagement, or soft skills) most requested by employers and participants? (Please select all that apply)

Answered: $11 \quad$ Skipped: 12

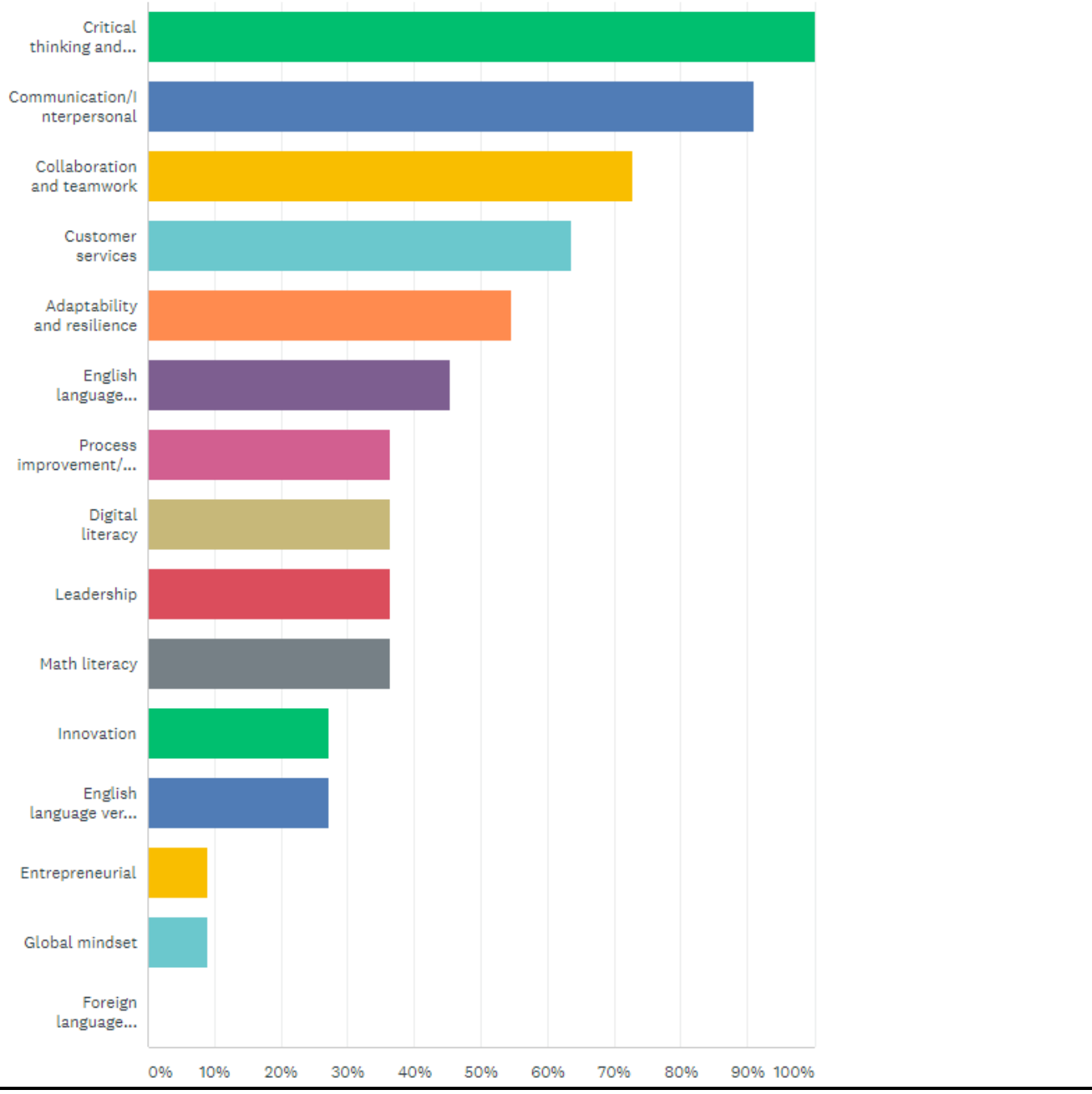

Critical thinking and data-driven problem solving

English language literacy (reading and writing)

Process improvement/ efficiency

English language verbal communications

Foreign language knowledge 


\subsection{Approaches to Work-Based Learning used for Program Development}

Approaches to work-based learning include hands-on training, paid internships, mentorship opportunities, summer employment opportunities, career exploration programs, and customized contract training.

Figure 10: Approaches to Work-Based Learning used for Program Development What approaches to work-based learning does your organization use? (Please select all that apply)

Answered: $12 \quad$ Skipped: 11

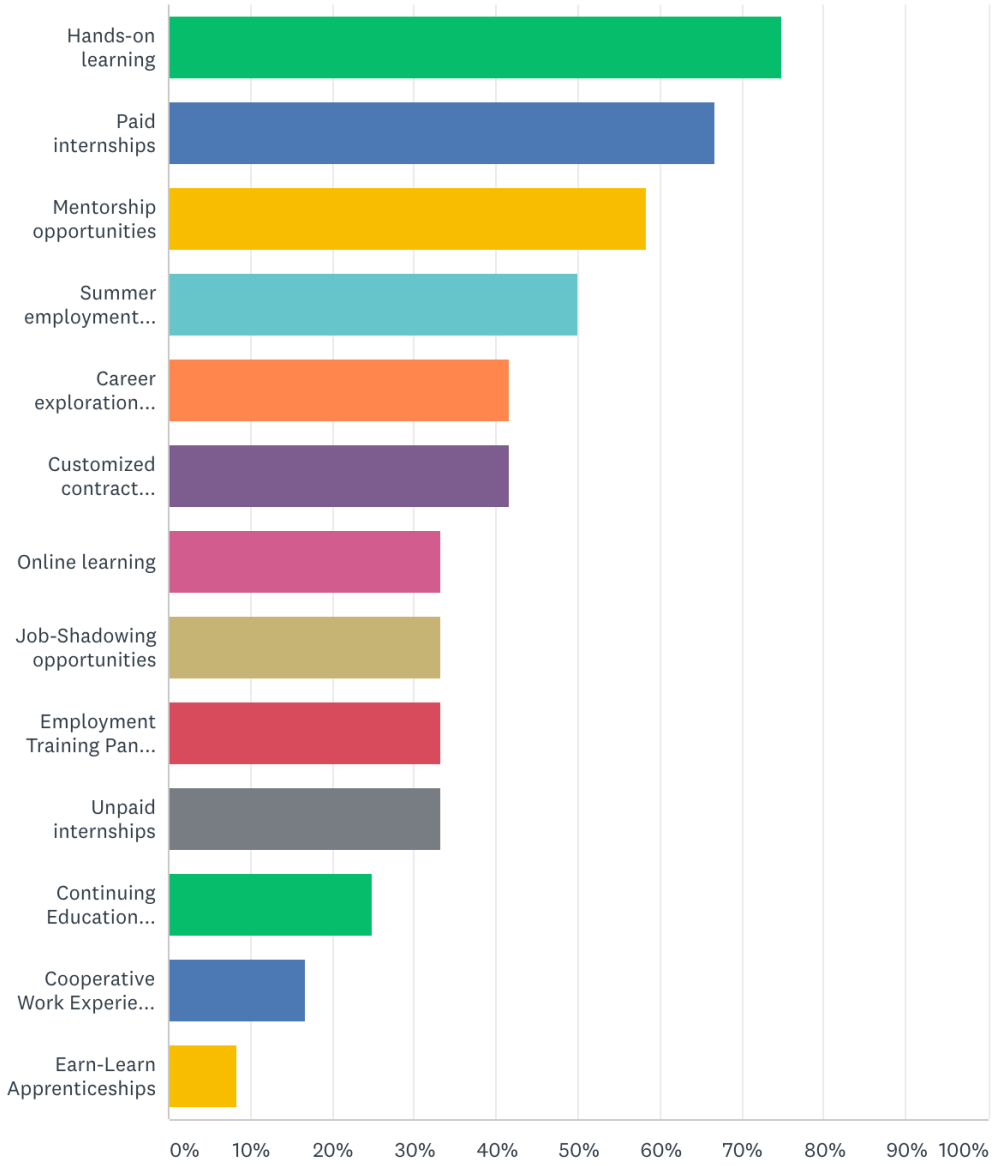

Summer employment opportunities

Career exploration programs

Customized contract training

Employment training panel programs (ETP) programs

Continuing education courses

Cooperative work experience education (CWE or CWEE) 


\subsection{Education and Training Partner-Identified Barriers in Identifying and Deliv- ering Effective Training Programs}

Barriers to delivering effective training programs include the lack of funding; shortage of training providers; difficulties in identifying training providers; employee preparedness and a lack of technical skills; organized labor opposition; and a lack of equipment or technology needed in instructional settings for certain occupations.

Figure 11: Education and Training Partner-Identified Barriers in Identifying and Delivering Effective Training Programs

What barriers/gaps have you encountered in identifying and delivering effective training programs? (Please select all that apply)

Answered: $11 \quad$ Skipped: 12

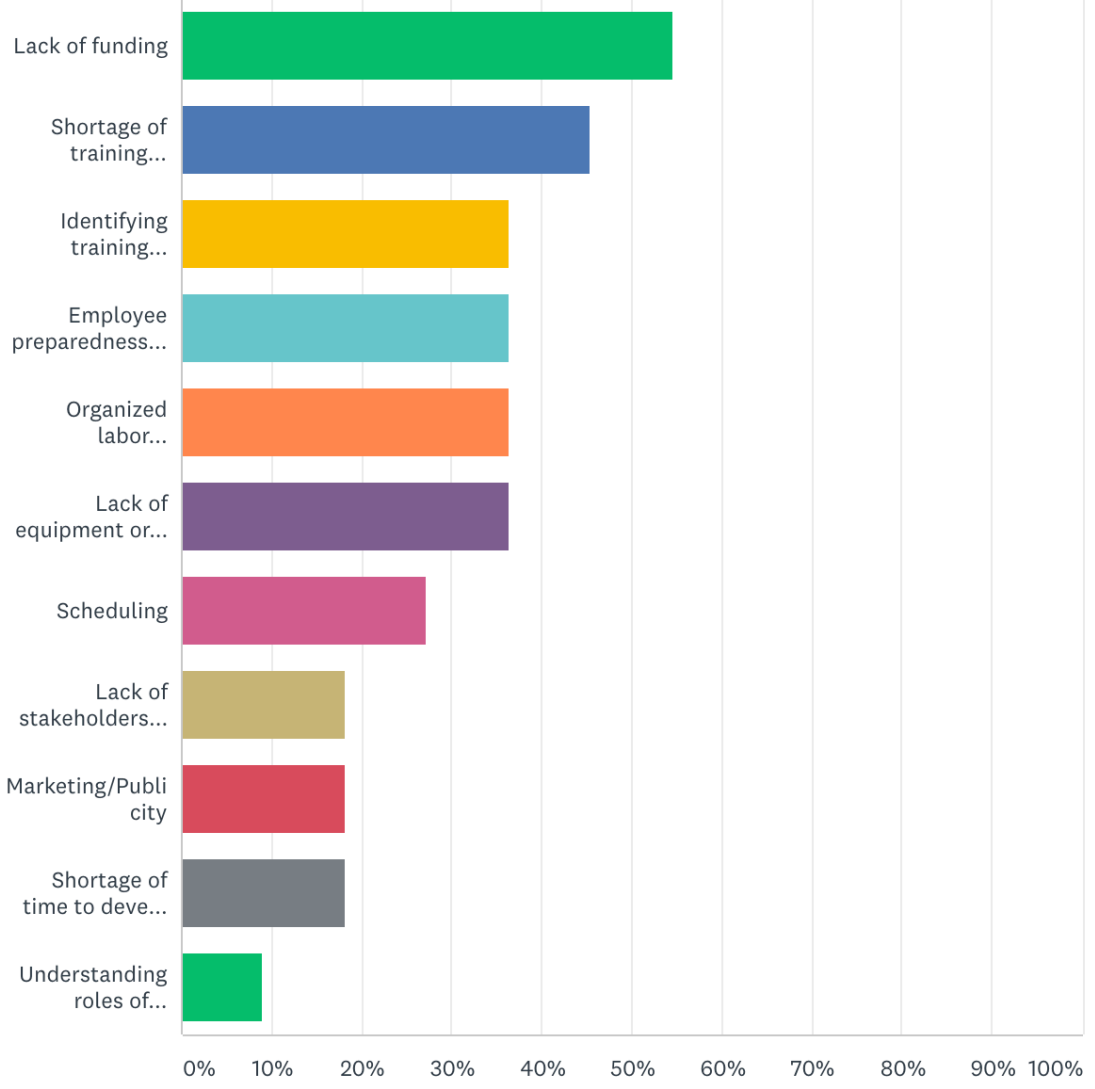

Shortage of training providers with needed skills

Identifying training providers

Employee preparedness/Lack of technical skills

Organized labor opposition

Lack of equipment or technology needed in instructional settings for specific occupations

Lack of stakeholder support

Shortage of time to develop sustainable programs

Understanding roles of industry and educational/training partners 


\subsection{Industry and Education and Training Partner Survey and Interview Takeaways}

Some survey and interview respondents reported that workforce development will likely not be prioritized during the pandemic while companies are contracting and trying to remain solvent, but they caution that there is still a strong need to actively collaborate to develop programs. Delays in OJT and assessment due to remote learning will result in setbacks in job placement and lower starting base salaries, which, in turn, will affect a worker's career trajectory for months, if not years. The following is a brief summary of the findings that can lead to new ways to strategize the development of training programs with SMEs in mind. These strategies will be discussed in Section IV.

\subsection{Industry-vetted Content and Curriculum}

The overwhelming majority of both education and training providers and industry respondents identified industry as integral to developing competencies, content, and curricula (including workbased learning) through advisory boards and industry associations. Recommendations include providing industry-supported forums and workshops; engaging practitioners in the delivery of content; providing training at industry locations; and using project-based learning. Viewing both industry and students as clients when designing programs and training to local or regional employment needs (the "pull" factor in employment) were cited by respondents as best practices in designing programs.

\subsection{Multidisciplinary Competencies Required}

Based on industry survey responses, middle-skill workers wear several hats within their organizations. This requires a multidisciplinary approach to training. For example, respondents identified staff responsible for operations and maintenance include dispatchers, inside sales representatives, planners, IT analysts, and security. Similarly, human resources personnel and mechanics, as well as owners and CEOs, often perform compliance responsibilities.

\subsection{Technical and Digital Skills Needed}

Industry survey and interview respondents identified basic digital skills such as email, MS Outlook, Word, Excel, and proficiency in sharing platforms such as Google Docs and Zoom as critical for middle-skill workers. Projections for the next three years include the identification of critical skillsets in machine learning, data science and analytics, project management and applications, systems management and integration, demand planning, forecasting, mechanical computer-based diagnostics, transportation and safety, maintenance and operations of material handling equipment, and compliance reporting. Other competencies identified relate to the operation and maintenance of electric and autonomous vehicles. 


\subsection{Employability Skills or Essential Skills Identified}

Survey and interview respondents reported critical thinking and data-driven problem solving, communication, collaborative/teamwork, customer service skills, and the ability to show adaptability and resilience as the most critical employability skills needed in the workplace. Industry and education and training partners identified similar sets of skills.

\subsection{Difficulty in Identifying Qualified Instructors}

Several respondents indicated that one of the top barriers to program development is identifying qualified instructors to teach the courses. Concerns include instructors with outdated skillsets; industry subject matter experts without instructional skills; and insurance requirements mandated for vendors and instructors working on some college campuses. The majority of industry respondents reported that in-house instruction and industry and trade associations provided the immediate training for employees.

\subsection{Other Barriers to Program Development}

Besides finding qualified instructors, respondents cited the lack of institutional support and prioritization, difficulties obtaining equipment, labor organization opposition, and the lack of effective collaborative partnerships between industry and education and training providers as barriers. Access to funding was also reported as a barrier.

\subsection{Wraparound or Support Services for Participants}

Support services (referred to as "wraparound services) are critical for participants to complete programs and gain the workforce competencies required. These services include access to career pathway counseling, transportation vouchers and subsidies, Temporary Assistance for Needy Families (TANF), childcare services, and adult literacy programs, among others. (See Appendix 2.)

\subsection{Funding of Programs}

The majority of industry respondents indicated that they self-fund their workforce training. Education and training providers use a variety of private- and public-sector funding methods including fee-based, contract, Workforce Innovation \& Opportunity Act (WIOA), Perkins, Employment Training Panel (ETP), Governor's, federal and Strong Workforce grants, apportionment, philanthropy, consultant monies, and sponsorships. Responses also included developing programs on a volunteer basis. Lack of funding to subsidize the training for entry-level workers and develop and revise mid-level training were cited as barriers to program development.

\subsection{Delivery Models Preferred}

Survey respondents reported hands-on, OJT programming, online learning, and mentorship as the most preferred forms of training within their organizations. Most respondents also favored short- 
term programming of less than six months of training, and some preferred less than one month. An industry partner also suggested one-day hackathons as an instructional design.

\subsection{Low Levels of AR/VR Training Platforms}

Both industry and education and training partners reported very low, if any instruction using AR and VR platforms. With the constraints of both remote learning and social distancing, AR and VR will be a necessary platform for the hands-on, OJT portion of instruction.

\subsection{Outreach and Marketing of Essential Transportation and Supply Chain Occu- pations}

With the COVID-19 pandemic, essential supply chain and transportation workers are no longer invisible to the public. Through this project's surveys and interviews, respondents discussed the potential for career advancement in these sectors and the need to publicize and market these career paths.

\section{Policy/Practice Recommendations}

This section presents strategies for designing instructional content and delivery for SMEs based on the findings above, together with current trends in workforce education. It begins with a discussion of the need for upskilling amid labor market changes brought on by COVID-19. Strategies to design workforce education programs will follow, with new paradigms of industry-requested skill sets. A first-level manager is highlighted as an example of an "opportunity occupation" that provides sustainable wages yet does not require a university degree. The Federal Reserve Bank has coined the term "opportunity occupation" to highlight these jobs that pay above the national annual median wage (adjusted by region) and have broader accessibility. ${ }^{32}$ The section ends with workforce development strategies for institutes of higher education (IHEs).

\subsection{The Necessity for Upskilling}

Understanding the outcome of the Great Recession provides recommendations for potential interventions to mitigate COVID-19 disruptions: decisions can be driven by analyzing data from previous economic downturns. ${ }^{33}$ Research on the effects of the 2007-2009 recession suggests that companies should retain employees to protect intangible capital including human capital, organizational knowledge, customer bases, and the supply chain, which all take years to establish. Moreover, laying off employees leads to a $10 \%$ reduction of income throughout the employee's lifetime beginning from career derailment, where employees have to work their way up the ladder to earn their previous income. ${ }^{34}$ With human capital representing the largest share of company assets, the "buy, not build" strategy of hiring new talent over training incumbents may not be sustainable: 
supply chain companies are in competition with a multitude of industries for the cloud computing and cybersecurity skills that are highly in demand. ${ }^{35}$

The U.S. has lagged far behind developed countries in investment in workforce training. MITbased labor economist David Autor advocates for a "Marshall Plan" to mobilize workforce development efforts in the U.S. ${ }^{36}$ According to the Organization for Economic Cooperation and Development $(\mathrm{OECD})$.

The United States spends less than other nations on government employment, training, and other labor services. As a percentage of economic activity, Canada spends three times as much, Germany about six times more, and Scandinavian countries up to more than twelve times as much. ${ }^{37}$

Historically, many federal and state apprenticeship workforce investment programs have focused on the construction trades. A concerted focus on digital skills building is required, as infrastructure is heavily reliant on the digital realm. Of the ten highest in-demand jobs needed in a "COVID19 economy," at least half can be classified as middle-skill transportation and supply chain occupations: IT Support/Help Desk; Sales Representative; Customer Service Specialist; Digital Marketing Specialist; and Project Manager. ${ }^{38}$

As presented earlier in this report, half of all transportation and storage sector workers, including those in supervisory, first-level management roles, have low levels of digital literacy. SME company employees have lower levels of digital literacy than employees in larger corporations. Criteria used for measuring baseline digital skills include prior computer use, ability to use computer-based assessments, and ability to perform basic tasks such as using a mouse or highlighting text. ${ }^{39}$ This lack of digital skills among front-line workers and their supervisors has long-term consequences for both the economic competitiveness of companies and workers' ability to grow professionally and remain relevant in the workplace.

\subsection{Package New and Comprehensive Workforce Education Programming}

The MIT Open Learning Workforce Education Program recommends a toolkit for effectively upskilling workers that includes new technology, education and training delivery methods, credentials, and tracking methods. Effective andragogy (that is, the provision of adult education) now involves online delivery models such as Khan Academy and Duolingo that provide short bursts of instruction followed by practice exercises, using a learning-by-doing strategy. ${ }^{40}$ An industry survey respondent suggested workforce training can be fast-moving, using one-day hackathons and gamification where highly coveted teamwork, collaboration, and communication skills are embedded in the learning. Another survey respondent recommended the practice of "chunking" coursework to be completed within a compressed amount of time so that students can start gainful employment sooner. In many cases, workforce development programs, including highly standardized apprenticeships, will be shortened by using competency-based and adaptive assessments for prior learning. Metrics will be based on hiring outcomes jointly developed between industry and government agencies rather than on numbers of participants. ${ }^{41}$ 
According to the MIT Workforce Education Program, these new assessment models—rather than a reliance on academic degrees-democratize the education and training process by delivering a "blockchain" in credentialing with transparency and strong cryptography. These assessment models are competency-based: assessment relies on skills rather than on educational level. ${ }^{42}$ By eliminating the need for a bachelor's degree in a job posting (in cases where a four-year college degree is not required), doors are open to qualified applicants who have the required the skill sets, but perhaps not a college degree.

These tracked credentials can be portable within and between sectors: foundational skills in project management, compliance documentation, human resource management, and data management, for example, can be used throughout the supply chain as well as in other industry sectors. The owner therefore potentially holds highly marketable skillsets. The credentials can also be cohesive and stackable. One set of skills can build atop others. Skills are standardized and recognized by different academic and training institutions as well as industry associations.

Instructional technologies include the immersive learning environments of augmented and virtual reality ( $\mathrm{AR}$ and $\mathrm{VR}$ ), platforms which are extensions of military flight simulation training used starting in 1934..$^{43}$ Technicians at Caterpillar and Mercedes Benz now use AR for mechanical diagnostics of trucks for object recognition and maintenance information. ${ }^{44} \mathrm{AR}$ no longer requires expensive equipment such as headsets; Android and $\mathrm{iOS}$ smartphones can be used to teach aspects of truck repair showing procedures and providing text or audio directions. Using smartphone AR to assist instructors in teaching diagnostics may provide avenues to recruit and retain highly needed alternative fuels vehicle technicians while simultaneously addressing the persistent shortage of qualified technicians. Instructors can concentrate on dialogue and problem-solving with students. Rote learning aspects can be accomplished with AR and VR. ${ }^{45}$

An example of an institute for higher education that is focusing on AR/VR in instruction is Clemson University Center for Workforce Development, a National Science Foundation (NSF) Advanced Technology Education (ATE) program that develops training in manufacturing and is certified through the Manufacturing Skills Standards Council (MSSC). These modules do not supplant instructors but allow for curricular integration into learning management systems such as BlackBoard and Canvas, making them widely accessible throughout post-secondary institutions.

\subsection{Cross-Train Workers and Explore Skill-Adjacent Jobs}

Some tactical innovations to building workforce capacity comes from Singapore, a nation that has been a leader in creating targeted supply chain education and training programs focusing on skillsets needed in the Fourth Industrial Revolution. To address the rapid internationalization and adoption of digitization in the wholesale trade industry, Singapore's National Trades Union Council (NTUC) launched a Skills Framework that provides information on industry, career pathways, and training programs that benefit workers, employers, and training providers. NTUC promotes the development of adjacent skillsets that can transition workers from jobs that will soon be redundant to those that are in high demand. This model is presented here because it demonstrates 
how job-related skillsets can be expanded to become high-demand, without the need to develop wholly new career pathways or workforce development programs.

An incumbent in procurement or sales, for example, may find more job opportunities if armed with competencies in inventory analysis, risk analysis, and compliance. Workforce training could be embedded into training by contextualizing job tasks based on these sector-specific technical skills combined with the essential skills of problem solving, transdisciplinary thinking, and the capacity to embrace lifelong learning.

Following this NTUC model, to create resilience within an organization, employees require crosstraining to develop a wide range of competencies to pivot or flex between tasks. An industry survey and interview respondent stated that workers need the capacity to articulate and self-identify what skillsets they need to develop within an organization, without an external or top-down process. Coveted workers would exercise autonomy - the ability to independently and intelligently make decisions to upskill and improve processes. The tasks of some front/back office workers are being rapidly automated, but the human-facing side of transactions can be further honed and refined through targeted workforce training. Industry partners in software development discussed the need for middle-skill employees such as customer success/service representatives (CSRs) and account managers to effectively articulate the user experience to engineers designing software. These front/back office employees, in addition to possessing customer/client-facing communication skills, would also need a functional level of understanding of how business systems and tools such as Excel, Flatfile databases, and Electronic Data Interchange (EDI) software integrate. Having these skills will allow the worker to seamlessly navigate between the client, project manager, and engineer. This is an example of both cross-training and expanding skillsets to create a new category of worker who is relevant during the Fourth Industrial Revolution.

\subsection{Develop the Capacity of First-Level Managers}

Satisfaction levels of supply chain management professionals are high, according to the latest CSCMP reports. In terms of compensation, for the middle-skill supply chain manager, national average annual salaries include $\$ 70,859$ for employees with a high school diploma; $\$ 87,518$ for employees with a two-year college degree; and $\$ 100,711$ for employees with some college education at a four-year university. ${ }^{46}$

First-level managers present a gateway to moving into higher-paying management positions without a college education. There is a workforce development gap in education and training for workers gaining entry to and succeeding at first-level management positions. ${ }^{47}$ This gap can be addressed through short-term programming as well as longer apprenticeship programs that focus on project management, data analysis, regulatory compliance, and digital skillsets.

First-level managers supervise front-line or first-line workers and are responsible for implementing strategies from top- and mid-level managers. From industry interviews, the research team learned that first-level managers need to be IT-fluent, strong in operations and communications, and proficient in management. Throughout the managerial levels in the supply chain, industry leaders 
have identified the need for emotional intelligence and the ability to embrace a culture of continuous improvement while new bodies of knowledge continually emerge. ${ }^{48}$

\subsection{Develop New Apprenticeship and Workforce Development Models}

COVID-19 has forced businesses to go lean, accelerating the trend toward shorter, competencybased programming. Institutes of higher education (IHEs) can serve as intermediaries in workforce education, researching and collaborating with industry to find the competencies required, while connecting public workforce agencies, labor, and training providers to students.

Two workforce education programs described below provide examples of initiatives that align with these trends, including a short-term certificate program and a Registered Apprenticeship, both in the transportation and supply chain industry sectors and both focused on building digital skills. In partnership with the California Energy Commission (CEC) and the Governor's Office of Business and Economic Development (GO-Biz), CITT developed a Sustainable Freight Foundations Certificate for high-demand mid-level freight managers covering regulatory and legal compliance, freight systems, infrastructure and energy ecosystems, data and metrics, and digital skills building. This freight program may be embedded as part of a larger Registered Apprenticeship in partnership with the American Association of Port Authorities (AAPA) through a Department of Labor Employment and Training Administration (DOLETA) Scaling Apprenticeships through Sectorbased Strategies grant.

For the CEC and GO-Biz Sustainable Freight Foundations Certificate, CITT closely aligned the curricula with industry-identified competencies; hired subject matter expert instructors with both industry and governmental experience; and delivered the program 100\% online starting in July 2020. This certificate program is short-term at a duration of four months (including 20 instructor contact hours), following industry and workforce development trends. The final assignment is a collaborative, hands-on capstone project that will use digital skills, note key performance indicators (KPIs) from industry, and mirror OJT. Participants receive continuing educational units and/or digital badges upon completion.

Applicants included private and public sector organizations working in goods movement such as freight practitioners (facilities, fleet, and operations managers, customer service representatives, planners) as well as planners working in the policy realm. Possibilities to replicate this program include the California Workforce Development Board's Employer Training Panel (ETP) programming, customized programming through continuing education programs at universities, and embedding the program in university degree programs and in professional development programs.

The DOLETA AAPA's Secure National Ports \& Supply Chain (SNaPS) will build and expand apprenticeship programs that will upgrade and expand the workforce for port members and related Transportation, Distribution, and Logistics (TDL) supply chain partners. SNaPs will create new pathways and build on existing apprenticeship programs in transportation, industrial and auto mechanics, shipbuilding and repair, and pathways involving advanced manufacturing, cybersecurity, and IT. Middle-skill occupations targeted include computer support specialist or technician; 
mechatronics engineer; and those involved with advanced manufacturing or a skilled trade. Most of the grant funding will help defray the cost for related technical instruction (RTI), OJT, and equipment. Apprentices will receive industry certification and credentialing. CITT will provide RTI (which may include the Sustainable Freight Foundations Certificate) with curricula aligned with CITT's Global Logistics Professional Designation Program.

\subsection{The Role of Institutes of Higher Education (IHEs) in the Future of Work}

The pandemic has swiftly upended workforce education, including the bodies of knowledge required for work; how we learn, teach, and assess remotely; and how we deliver instruction using new technology. Strategies to effectively teach require a reimagining of education to be customizable, personalized, and easily accessible. Viewing education with a terminus (for example, a bachelor's degree or a set of certifications) is tantamount to ensuring its obsolescence.

Prior to the pandemic, the Governor's bipartisan Little Hoover Commission outlined the roles state universities should prioritize in developing workforce education to address the rapid adoption of artificial intelligence (AI); upskill current and future workers in disciplines using AI; ensure skill assessment tools, education and training methods match future workforce needs; align the "scope, nature, and pace of employment changes" to industry needs; collaborate with workforce representatives, including labor; examine apprenticeships and other OJT training that will transition workers to "new and changed" workplaces; and research ethics in the development and the use of AI. ${ }^{49}$ Similarly, the MIT Workforce Education Project identifies universities' role in workforce education as one of scaling innovation and serving as an intermediary between stakeholders. Universities have the capacity to research emerging learning science (how we learn) and develop new teaching designs and methods with advanced tools such as AR/VR and Geographic Information Systems. Universities can work toward strengthening the digital infrastructure and delivery models to increase access while emphasizing lifelong workforce education, as recent research shows no generational differences in workplace learning capacity. ${ }^{50}$

Transportation and supply chain businesses now rely heavily on data and dashboards for connectivity and access to business intelligence. Universities can develop research and instruction on skillsets needed for data analysis and project management, including the critical capacity to manage with agility and responsiveness. These programs can be offered to incumbents and potential new entrants, as well to traditional students. As state universities prepare a majority of our teachers, a new form of instructor is now in demand, that of a Chief Learning Officer (CLO) - a sign of the importance of professional development and continual workforce education within organizations. ${ }^{51}$ Universities can take a leading role in developing this emerging profession.

In A World Without Work: Technology, Automation, and How We should Respond, labor economist David Susskind describes how human capital—the skills and talents people invest in themselves — can address economic inequality. ${ }^{52}$ Industry and education and training providers can now create content and delivery models never previously practiced in workforce education. The experimental nature of this task allows all stakeholders to be open to innovative and unconventional methods 
and strategies. More importantly, it presents a platform to examine and act on the larger issues of how stakeholders invest in the development of human capital, which may be one of the many first steps to address workforce education and its critical value in developing equity.

\section{Review of Sources}

With COVID-19, organizations had to rapidly change workplace processes. Relevant research sources included industry association and government publications that address the latest impacts. Data pertaining to the pandemic were difficult to access during this research process. However, industry associations such as the American Transportation Research Institute (ATRI) provided timely quantitative data on how fleets were adjusting to COVID-19 disruptions. Industry also published articles for supply chain and transportation companies to understand how digitization became even more crucial to data management and transparency with the pandemic. These articles are summarized below.

\subsection{Industry Publications}

\subsubsection{COVID-19 Impacts on the Trucking Industry}

The American Transportation Research Institute (ATRI) created a truck activity index from its truck GPS dataset. ${ }^{53}$ The data shows an initial spike in truck activity correlating with the high consumer demand for non-perishable food, paper products, and medical supplies. Importantly, these fluctuations were seen in with contracted freight which stays fairly stable throughout the year, excepting holidays. ${ }^{54}$ This surge was followed by an $8.3-10+\%$ decline in trucking operations in April, resulting from the impacts of stay-at-home orders in the states analyzed. Changes in freight levels were based on commodity hauled, truck industry sector, and fleet size.

Further findings from ATRI show a reduction in long-haul trips but a $100 \%$ increase in local trips under 100 miles. ${ }^{55}$ Smaller fleets were more likely to report much lower freight volumes than larger fleets. These findings highlight a need for strategic modelling, as some fleets are dealing with excess delivery capacity and others are facing a shortage. ${ }^{56}$

\section{How the Current Pandemic Is Accelerating Supply Chain Digitization}

Big data and logistics technology have become critical as supply chain systems experience immense pressure. The supply chain technology available today has enabled companies to continue operating despite the rapidly changing environment. Rich data, real-time updates, and paperless processing are especially critical for business to adopt in order to remain competitive. One tool to gather data is RFID tags, which "only need to be in the proximity of a sensor to relay data" in 
order to locate goods; they have the capability to replace barcodes which require physical scanning. ${ }^{57}$ Roughly $52 \%$ of firms already utilize RFIDs and $34 \%$ plan to implement them in their practice. Once data has been collected, metrics can be visually organized into a dashboard.

The unpredictability of supply chains as a result of the pandemic is causing many businesses to implement fast-tracking technology. Accurate inventory data is critical to fulfill volatile demand. Businesses also face the challenge of closed borders and transport restrictions, making it a competitive advantage to know exactly where shipments are to manage inventory storage. Having the right technology allows businesses to gather data on their inventory and create management strategies. Those with integrated supply chain technologies will be able to survive the pandemic because of their ability to make agile, data-driven decisions.

\subsubsection{COVID-19: Managing Supply Chain Risk and Disruption}

As COVID-19 creates supply chain disruptions, companies that operate with impacted countries should:

- Inform and educate employees of COVID-19 symptoms and prevention

- Incorporate IT systems to support work from home environments

- Emphasize collaboration with tier 1 suppliers

- Increase visibility and transparency with suppliers

- Diversify the supply chain by obtaining a secondary supplier of products

The following technologies are tools businesses can integrate to enhance their supply chains: ${ }^{58}$

- Internet of Things (IoT)

- Cloud Computing

- $5 \mathrm{G}$

- Artificial Intelligence

- 3D Printing

- Robotics

\section{Embracing the Digital Mindset}

A shortage of talent has constantly been a challenge in supply chain. As supply chains integrate technology, finding talent that understands the technology is becoming even more difficult. A survey conducted by Deloitte found that $20 \%$ of supply chain leaders believe the digital supply chain is currently predominant, while $80 \%$ expect it to become predominant in the coming five years. Digitizing supply chains will allow for data to be collected from the Internet of Things (IoT) and sensors. Data can help businesses make informed decisions regarding operations and develop 
insights utilizing advanced analytics; however, most companies lack the ability to organize, integrate, and capture data from multiple sources. Even still, the increasing use of technology in supply chains attracts millennials, who are natives to the IoT, to enter the workforce, which is a step toward bridging the digital gap. The following are projected desired skills for the next five years, ranked in descending order: ${ }^{59}$

- Project Management/Leadership

- Strategic/Problem-Solving Skills/Critical Thinking

- Supply Chain Management (e.g., degrees/certification programs)

- Analytics, Modeling, and Visualization

- Process Improvement/Lean/Six Sigma

- General Business Acumen and Cross-Functional Knowledge

- Change Management

- Systems Implementation

- Global Experience and Cultural Diversity

How Supply Chain Digitization Benefits Intermodal Marketing Companies (IMCs) and Trucking Drayage

IMCs and drayage logistics can benefit from digitization for the following reasons:

1. Companies can obtain accurate information regarding client demand, truck capacity, and truck driver status. The ability to measure demand will afford IMCs and truckers the ability to efficiently supply services.

2. Collecting data on current market behaviors leads to the ability to forecast future demand; forecasting informs companies of potential demand, allowing them to prepare and provide enhanced services. Artificial intelligence logistics modeling and machine learning can be used to identify trends and forecast demand.

3. GPS and Internet of Things (IoT) devices can efficiently identify the real-time location of assets and shipments. Knowing where shipments are located facilitates security, safety, and flow of goods during transit. Drayage logistics may note the benefits of real-time localization such as lower costs and effective asset utilization. 
4. Digitization can provide drayage providers better schedules for arrivals, pickups, and deliveries. This will help drivers maximize their time engaging in productive deliveries and limit idle time spent waiting for goods or loading.

5. Digitization and the incorporation of financial technology allow for faster processing, invoicing, and payment.

In conclusion, the implementation of technology maximizes productivity and efficiency, allowing companies to have a competitive advantage and set competitive prices. ${ }^{60}$

Microsoft Launches Initiatives to help 25 Million People Worldwide Acquire the Digital Skills Needed in a COVID-19 Economy

Middle skill transportation and supply chain jobs increasingly rely on digital skills. Examples of high-demand transportation and supply chain occupations include IT Support/Help Desk, Sales Representative, Customer Service Specialist, Digital Marketing Specialist, and Project Manager. Microsoft identified these occupations, among others, as targeted occupations for training to address the digital skills gap. There has been an increase in demand for digital skills with the COVID-19 economy. However, between 1996 and 2008, employer investment in training decreased, which may have contributed toward the digital divide experienced today. Microsoft is helping bridge the digital divide experienced among unemployed individuals, low income earners, women, and underrepresented minorities. To address the shortage of digital skills, Microsoft will:

- Use data to identify in-demand jobs and respective skills

- Provide free access to courses to develop digital skills

- Provide low cost certificates and free job-seeking tools to those who develop skills

While many countries face unemployment challenges during the pandemic, Microsoft forecasts the unemployment rate to increase an additional 15\% in the United States. Latinx populations have experienced higher rates of unemployment relative to African-Americans and Whites; addi-tionally, women have experienced higher rates of unemployment relative to men. ${ }^{61}$ This Microsoft initiative provides an example of online workforce development programming that can be accessible provided the participant has internet connectivity. It also serves as a valuable resource for work-force development organizations in developing competencies required in the COVID-19 econ-omy.

\section{Logistics Providers Weigh Workforce Reductions Amid Drop in Trade}

As logistics companies consider dismissing employees due to economic slowdown caused by the COVID-19 pandemic, the wellbeing of the company will depend on the diversity of their business portfolio. For example, a 3PL focusing on transporting automobiles will be more impacted than a 
3PL working in the health care industry. Lance Malesh, chief commercial officer of BDP International, says companies will need to consider "layoffs, furloughs, salary reductions and suspension of nonessential programs" in order to remain competitive. Unfortunately, small customs brokers and forwarders will be the most impacted, and one of four small business will close permanently according to a U.S. Chamber of Commerce and MetLife survey conducted March 25-28. Although relief was offered through the congressional CARES Act, it may not be sufficient to cover financial costs.

Information technology and human capital are two key components that can determine the success of a company, making it difficult for companies to decide who to lay off. Maintaining a balance between providing excellent customer service and laying people off is a difficult trade-off companies face as they strive to remain competitive in the market. ${ }^{62}$

\section{Transforming IT Training Programs into Successful Career On-Ramps}

The U.S. Bureau of Labor Statistics projected the IT market would be adding 546,200 new jobs between 2018 and 2028. This growth stems not only from IT companies entering the market, but also from the integration of IT among industries such as supply chain, health, finance, and so on. A study conducted by Burning Glass and Oracle Academy discovered that $90 \%$ of IT jobs were not within the IT industry. While there are some IT occupations that require a postsecondary degree, career pathways such as programming, IT support, and cybersecurity do not require a postsecondary degree.

As a result of the growing demand for IT workers, a wide range of training programs have emerged. Training programs come in the form of community college certificates, boot camp programs, and short-term training programs. Short-term training programs offered by communitybased organizations are the most popular because they are agile and offer many entry ramps that are tailored to an individual's skills and goals. Although there are many training programs offered, people of color, women, and members of other groups not represented in the IT industry face barriers to entry; it is critical that such barriers are addressed in order for industries to continue evolving and to ensure that opportunities for growth are available for all job-seekers. Barriers to entry often arise due to training program prerequisites such as a high school diploma or unpaid pre-work. IT training programs only prepare individuals for entry-level positions while failing to prepare their students for advancement. Career exploration is critical to establishing an awareness of opportunities that may lead to career advancement. Training programs can be enhanced by the following methods:

- Prepare students for advancement beyond entry level

- Improve coordination with employers and encourage workplace-based training

- Increase wraparound services for program participants

- Ensure training programs incorporate more "on ramps" for recruitment 
- Communicate with industry to identify IT career advancement needs

Employers hold the responsibility to communicate with training program coordinators to ensure that the courses will accurately train job-seekers to be successful upon entering the IT industry. Incorporating best practices and encouraging collaboration will lead to improved training programs and a more diverse labor market. This is critical to create and maintain racial and social equity. A 2017 IT study found that $40 \%$ of individuals left the industry due to mistreatment from employers, while women and people of color experienced being stereotyped. ${ }^{63}$

Industry publications provide timely, up-to-date, and relevant perspectives on workforce competencies that can be used by practitioners to create workforce programs that reflect the immediate needs of industry. Government reports and publications can also address the immediate needs of industries impacted by COVID-19, as presented below with documents from the Department of Transportation's Federal Motor Carrier Safety Administration (FMCSA).

\subsection{Government Publications}

\subsubsection{FMCSA Waivers}

On March 24, 2020, the Federal Motor Carrier Safety Administration (FMCSA) granted relief to drivers whose CDLs (or CLPs) and medical cards have expired or will expire by waiving renewal requirements until June 30, 2020.64, 65 This waiver requires that drivers had a valid CDL (or CLP) and medical card as of February 29, 2020. Another waiver, issued on March 28, 2020, lifts "the requirement that a CLP holder be accompanied by a CDL holder, with the proper CDL class and endorsements, seated in the front seat of the vehicle while the CLP holder operates a CMV on public roads or highways." ${ }^{66}$ Further, "a State may elect to administer a driving skills test to any non-domiciled CDL applicant, regardless of where the applicant received driver training." ${ }^{67}$

On April 9, 2020, the FMCSA issued a formal waiver of requirements set forth in 49 CFR 384.228 (b)-(c) to allow "third party CDL test examiners previously authorized by the State to administer the CDL skills test to also administer the CDL knowledge test without completing a CDL knowledge test training course." ${ }^{68}$ This waiver is in response to state driver licensing agency (SDLA) closure and diminished capacity, which affect their ability to administer CDL knowledge tests. ${ }^{69}$

FMCSA is further allowing CDL skills tests to be administered without an examiner physically present in the cab. A guide issued April 13, 2020, states that SDLAs may submit plans to admin-ister skills tests remotely in accordance with AAMVA's 2005 CDL Test System Model CDL Manual (AAMVA Model) to FMCSA for approval. Such plans may include observation from a second vehicle with either two employees or with an examiner and technology for recording that may be reviewed and deleted later.

FMCSA informed SDLAs on April 17, 2020 that they will not be penalized for failing to report driver violations, convictions, and disqualifications within the required ten-day period. This 
change is in effect until June 30. Because SDLAs are not required to report disqualification or conviction within 10 days, carriers could be using out-of-date information on the driver's motor vehicle record during the screening process. This leaves carriers relying on drivers' self-reports and otherwise at risk of using disqualified drivers.

\subsubsection{Entry-Level Driving Requirements}

Commercial Driver License (CDL) schools were required to enforce new entry-level driving requirements demanded by FMSCA on February 7, 2020. The following criteria were implemented: ${ }^{70}$

- Minimum standard for CDL schools will be set at a federal level, rather than state-bystate

- Schools are required to report hours spent behind the wheel to the Department of Transportation (DOT)

- While some states require instructors to be registered, instructors do not have to be registered with the DOT. Schools are able to self-certify drivers

- Instructor qualifications require a minimum of two years of experience, a clean MVR record, and a medical certification for classroom, on-road, and private range instruction

- The DOT requires 31 theory topics, as opposed to the previous four. In addition, 19 behind-the-wheel skills were mandated. 


\section{Appendix 1. Industry Survey Results}

CITT developed a survey to research industry trends in addressing workforce development needs based on the intersection of IT and operations. Competencies researched and surveyed include compliance reporting, data management, digital literacy, employability skills, front/back office skills, and operations maintenance. Workforce training program design questions were also included. In some cases, the results are presented in text in the body of the paper but without the figures. These figures are presented below.

Figure 12. Number of Employees

How many people are employed at your organization?

Answered: $31 \quad$ Skipped: 10

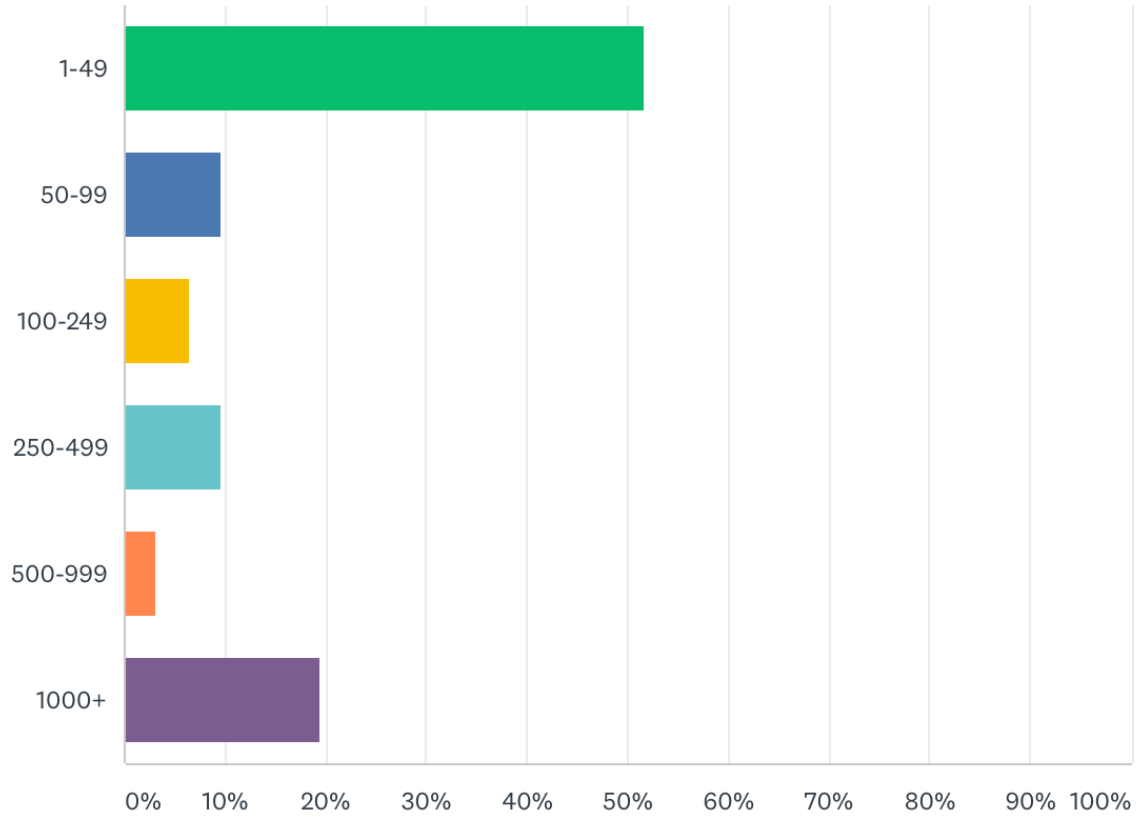


Table 6. Industry-Identified Anticipated Skills Gap for the Next Three Years

- Working in a paperless environment

- Adapting to new and emerging technology

- Systems Integration

- Automated Labor Reporting

- Warehouse Systems Management

- Transportation and Safety

- Electric Vehicles

- Autonomous Vehicles

- Machine Learning

- Data Science

- QuickBooks 


\section{Figure 13. Industry Sector}

What is your industry sector? (Please select all that apply)

Answered: 24 Skipped: 17

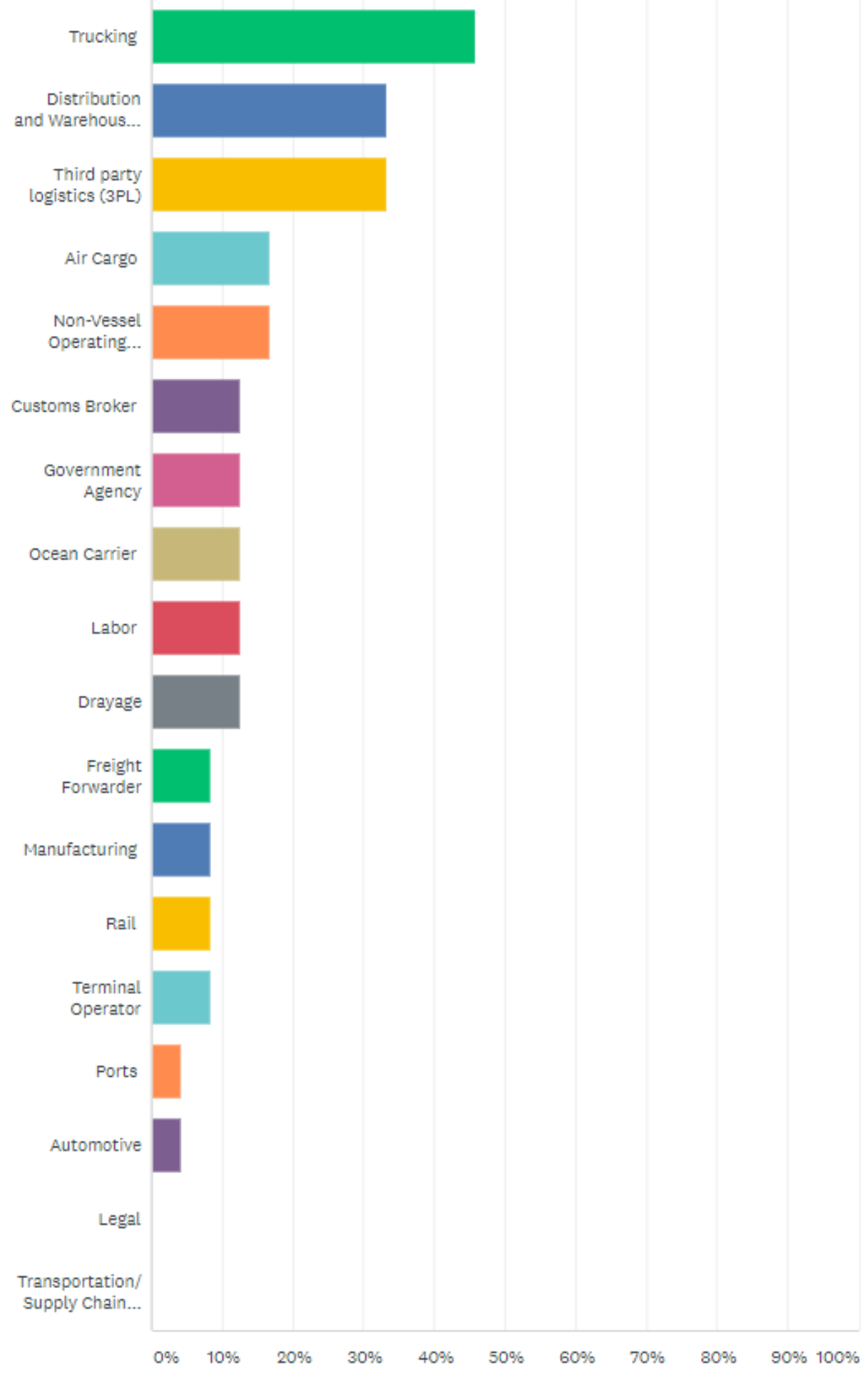

Distribution and Warehousing

Non-Vessel Operating Common Carrier (NVOCC)

Transportation/Supply Chain Talent Recruiter 
Figure 14. Primary Focus Workforce Development Efforts

Who is the primary focus of your current workforce development efforts?

Answered: 18 Skipped: 23

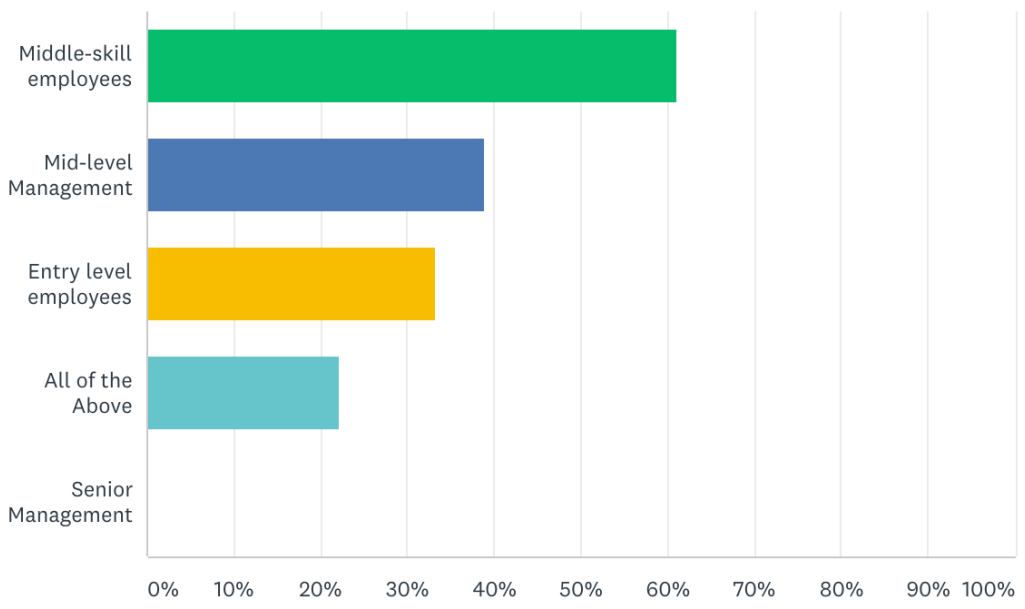

Figure 15. Minimum level of Education Required for Middle-Skill Employees

What is the minimum level of education required for middle-skill employees at your organization?

Answered: 18 Skipped: 23

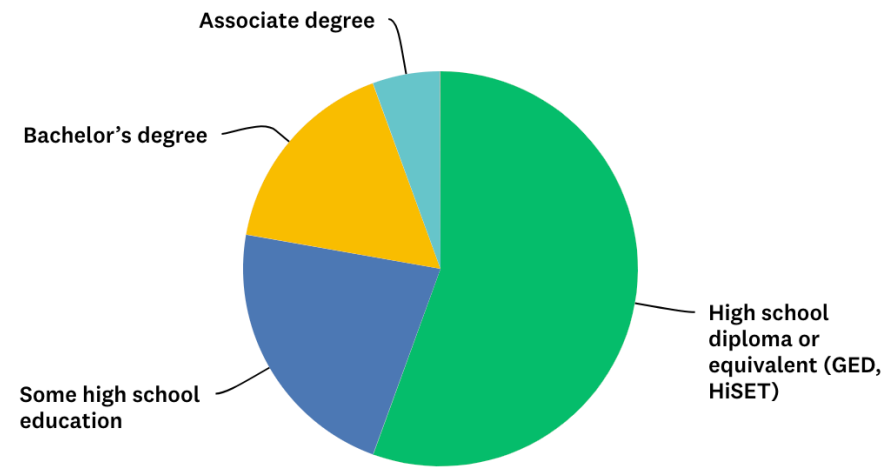


Figure 16. Bridging the Skills Gap Strategy

To meet this skills gap, will your organization hire new talent or upskill incumbents, or both?

Answered: 18 Skipped: 23

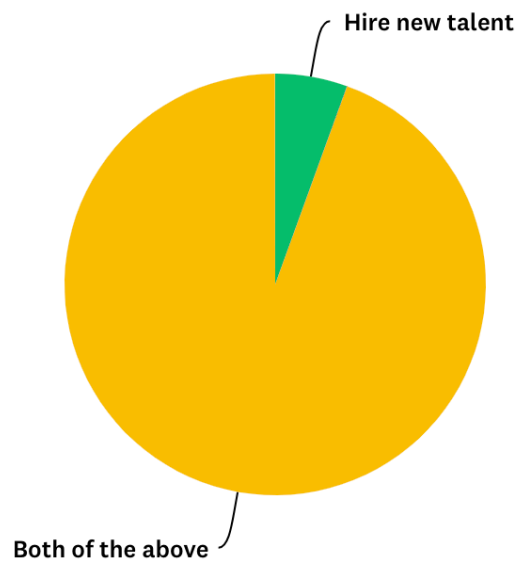

Figure 17. Industry-identified Workforce Development Education and Training Partners

If your organization has workforce development partners, what organizations do you partner with? (Please select all that apply)

Answered: 17 Skipped: 24

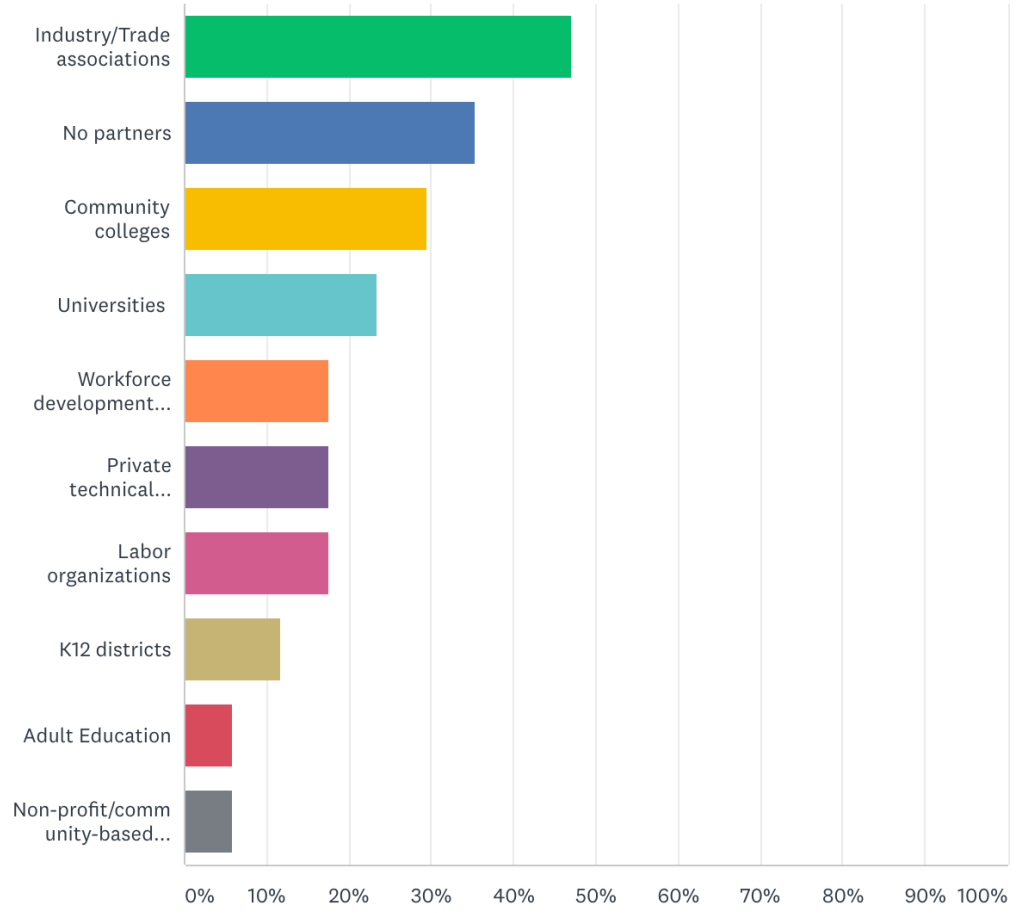


Workforce Development Boards/ Investment Board

Private Technical Colleges

Non-profit/community-based organizations

Figure 18. Workforce Development Delivery

How does your organization deliver workforce development programming? (Please select all that apply)

Answered: 17 Skipped: 24

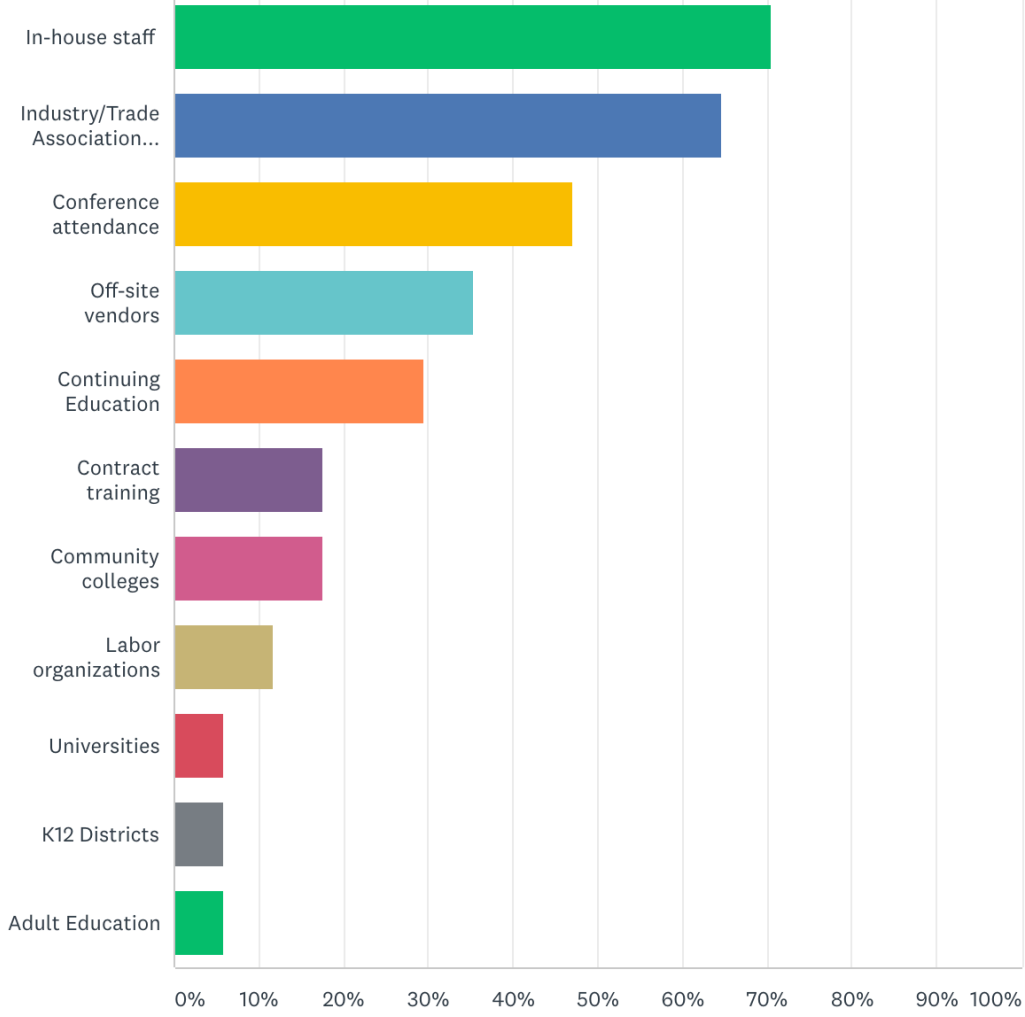

Industry/Trade Association training events 
Figure 19. Online Instruction

Do your company's training programs involve online courses?

Answered: 17 Skipped: 24

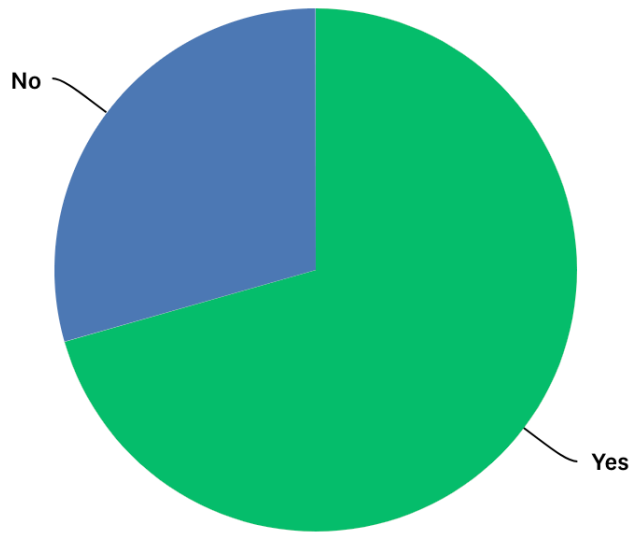

Figure 20. Use of Augmented or Virtual Reality in Instruction

Do your company's training programs involve the use of virtual reality (VR), augmented reality (AR), or both?

Answered: 17 Skipped: 24

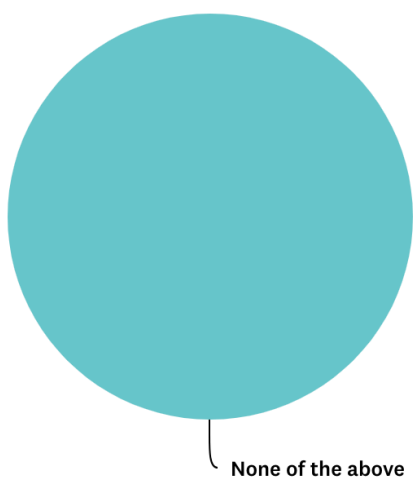


Figure 21: Industry-Identified Barriers in Identifying and Delivering Effective Training Programs

What barriers/gaps have you encountered in identifying and delivering effective training programs? (Please select all that apply)

Answered: $14 \quad$ Skipped: 27

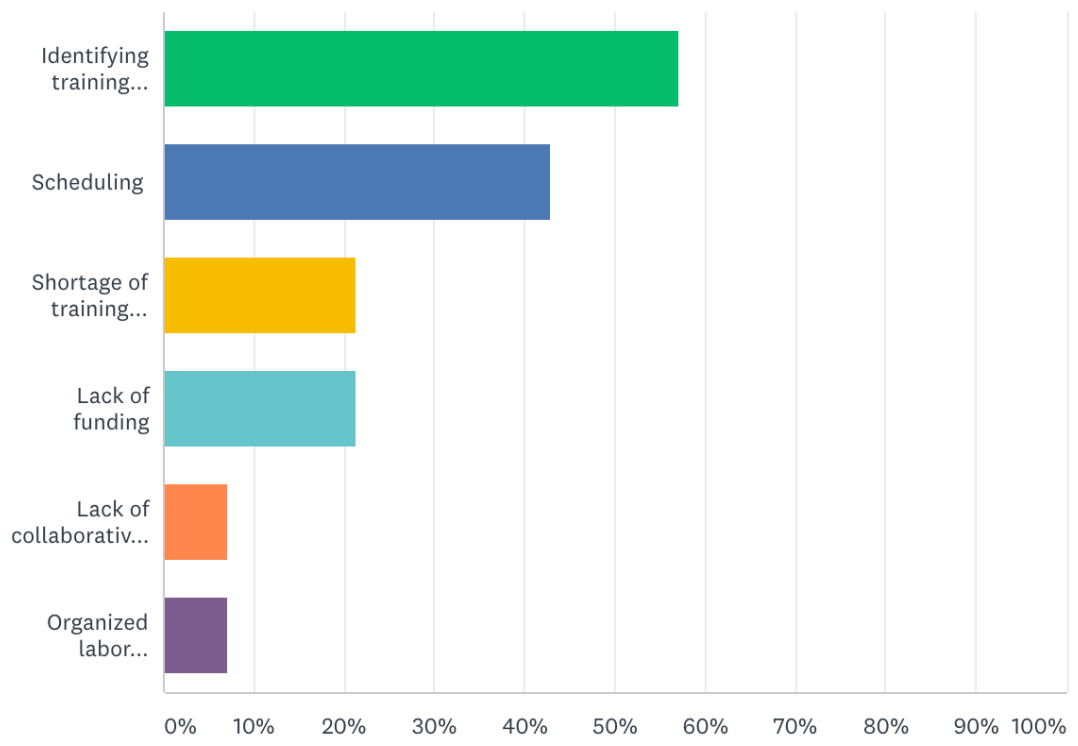

Identifying training providers

Shortage of training providers with needed skills

Lack of collaborative partnerships

Organized labor opposition

Employee continuing their training and education

Technical assessments/competency-based assessments

Career advancement of participants

Program completion figures 
Table 7. Industry-identified Funding of Workforce Development Efforts

- Internally funded

- Surplus

- Joint labor and management funding

- No process in place

- Internal training

- Self-funded

- Budgeting, Capital Expenditures (CapEx)

- $\mathrm{R} \& \mathrm{D}$ opportunities, training, conferences, mentor program

- Company pays

- HR budget

- Venture capital and revenue growth

- Company's general fund 


\section{Appendix 2: Education and Training Partner Survey Monkey Results}

CITT developed a survey for education and training providers to gather input on program design, content, assessment, and barriers to development and implementation. Some of the figures below were not included in the body of the paper because the data was presented in textual form.

Figure 22: Type of Organization

Which of the following best describes your organization? (Please select all that apply)

Answered: 7 Skipped: 16

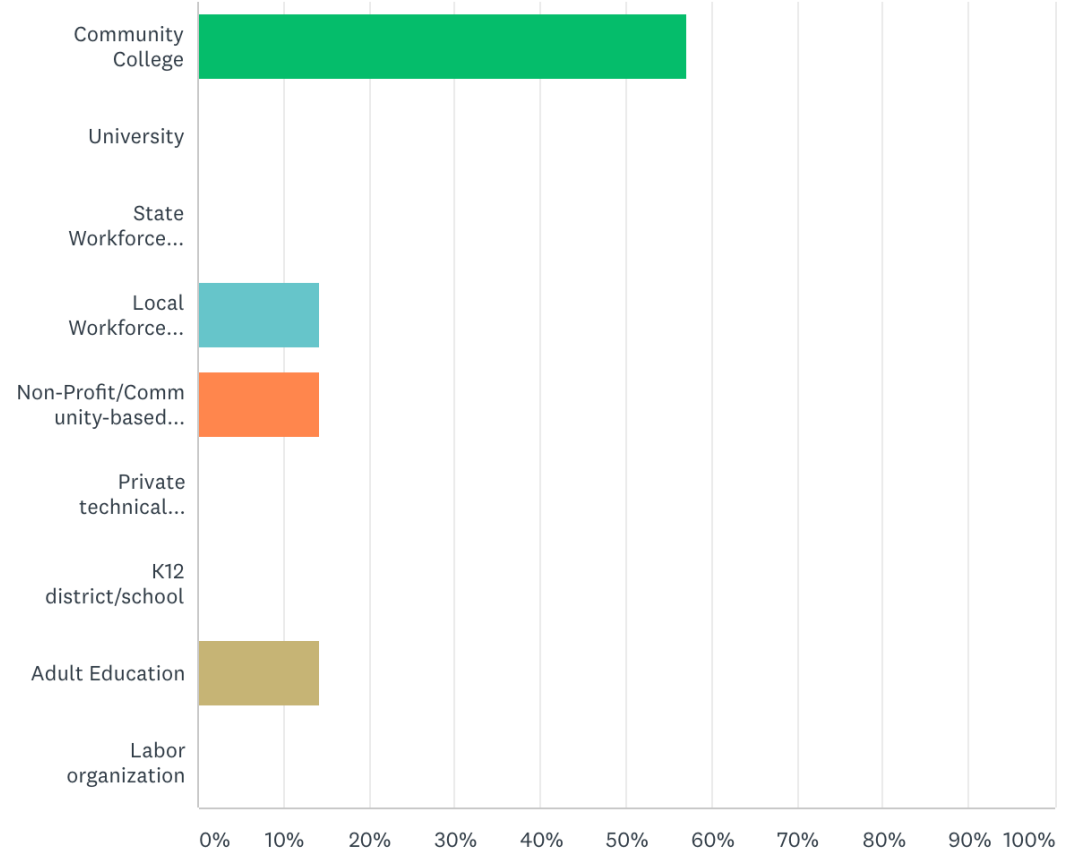

State workforce development board/investment board

Local workforce development/investment board

Non-Profit/Community-based organization

Private technical training institution 
Figure 23: Industry Roles in Program Development

If your organization has partnered with these sectors, what role do these industry partners play? (Please select all that apply)

Answered: $12 \quad$ Skipped: 1

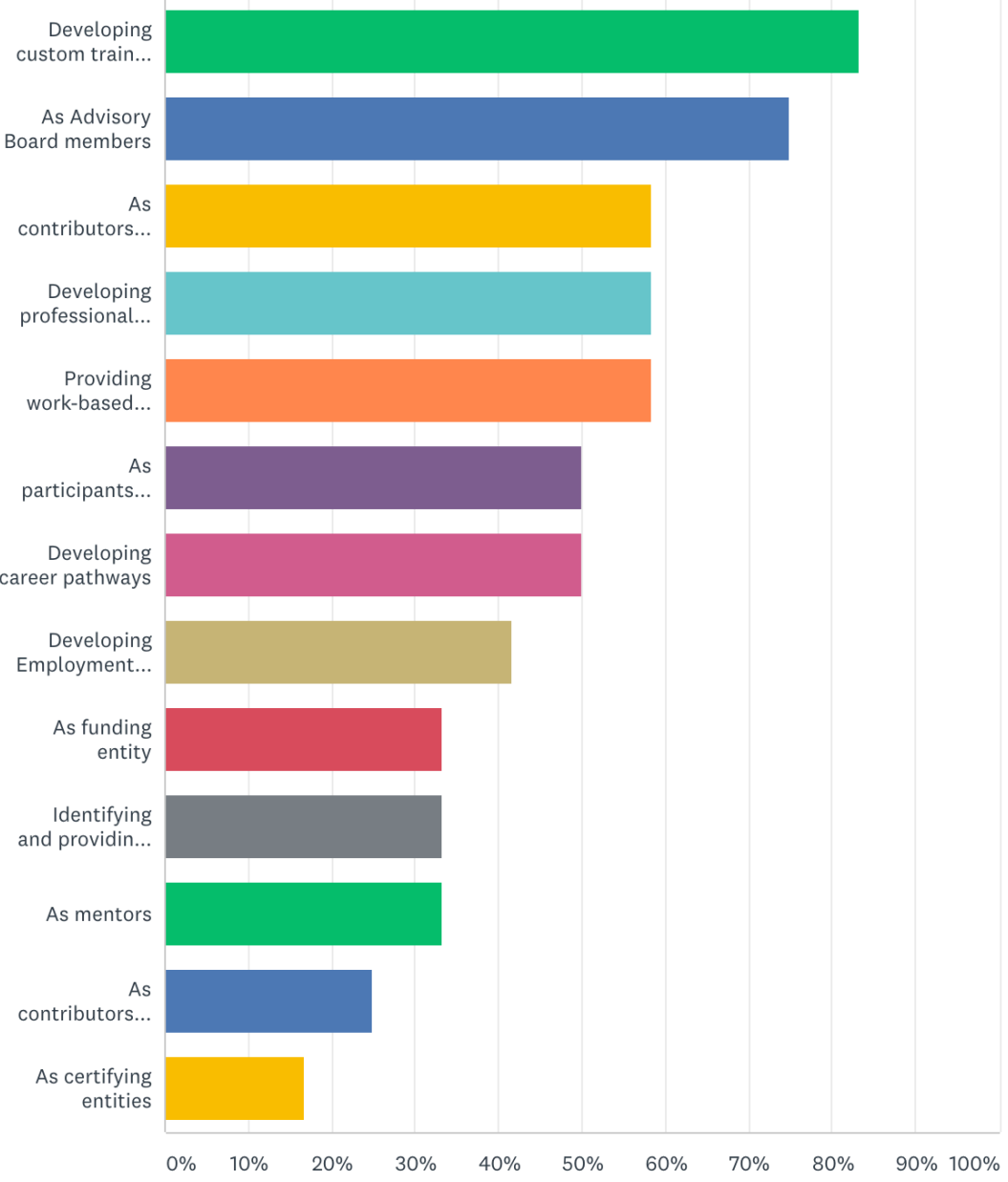

Developing custom training programs

As contributors to program content

Developing professional development for educators

Providing work-based learning opportunities for students

As participants of job fairs

Developing Employment Training Panel (ETP) programs

Identifying and providing instructors

As contributors of equipment/technology 
Figure 24: Upskilling Incumbents Versus New Hires

Do your workforce development efforts focus on upskilling incumbents, new hires, or both?

Answered: 12 Skipped: 11

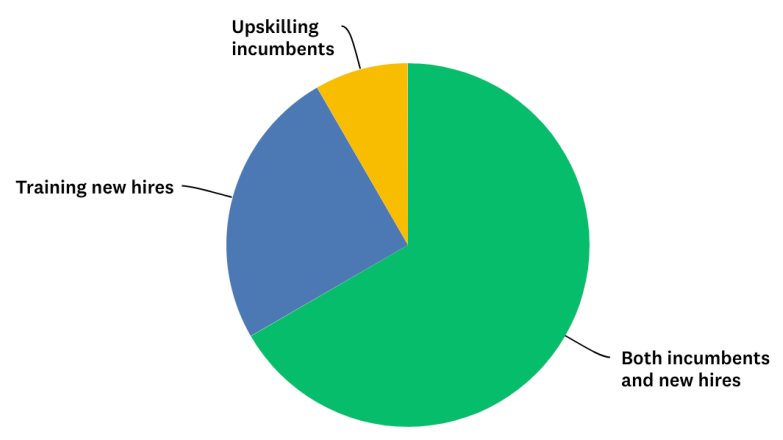

Table 8. How are Workforce Development Efforts Funded?

- Fee-based

- Contract

- Workforce Innovation \& Opportunity Act (WIOA)

- Perkins

- Employment Training Panel (ETP)

- Governor's grants

- Federal grants

- Volunteer

- Strong Workforce grants

- Apportionment

- Philanthropy

- Consultant Monies

- Tax-base

- Sponsorships 
Figure 25: Industry Demand for Training Programs Within the Past Two Years

Within the past 2 years, have industry requests to develop training programs in the transportation and supply chain sectors increased or decreased?

Answered: 12 Skipped: 11

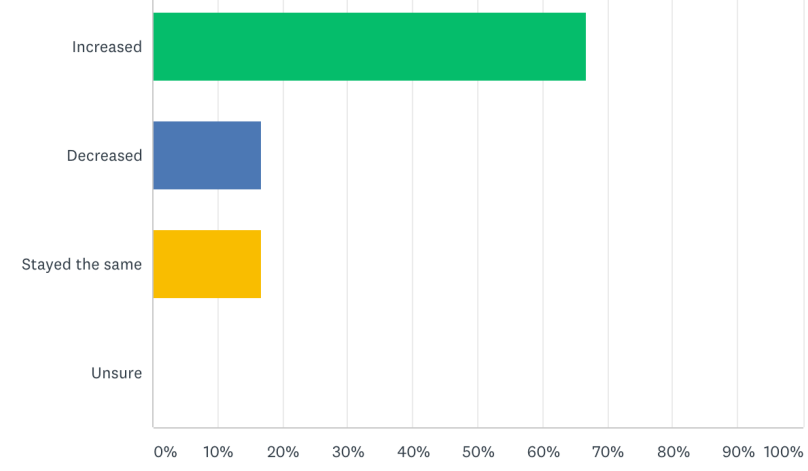

Table 9. How do you Identify Workforce Development Competencies?

- DACUM (developing a curriculum)

- Skill-based and written competency exams

- Advisory boards, industry demands, Labor Bureau statistics

- Assessment

- Trade advisory

- Through advisers

- Industry-led regional advisories, Key Performance Indicator studies, DACUM, primary research

- Subject evaluations, certification testing

- DACUM and job classification reviews.

- Industry focus groups and partnerships

- Align with industry demands

- Industry surveys 
Figure 26: Education and Training Partner-Identified Use of Augmented or Virtual Reality in Instruction

Does your organization's training programs involve the use of virtual reality $(V R)$, augmented reality (AR), or both?

Answered: 11 Skipped: 12

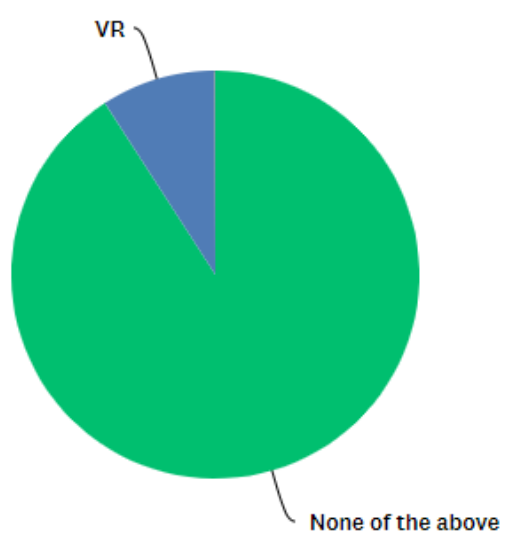


Figure 27: Education and Training Partner-Identified Supportive/Wraparound Services Provided

What supportive/wraparound services does your organization provide to participants?

Answered: $12 \quad$ Skipped: 11

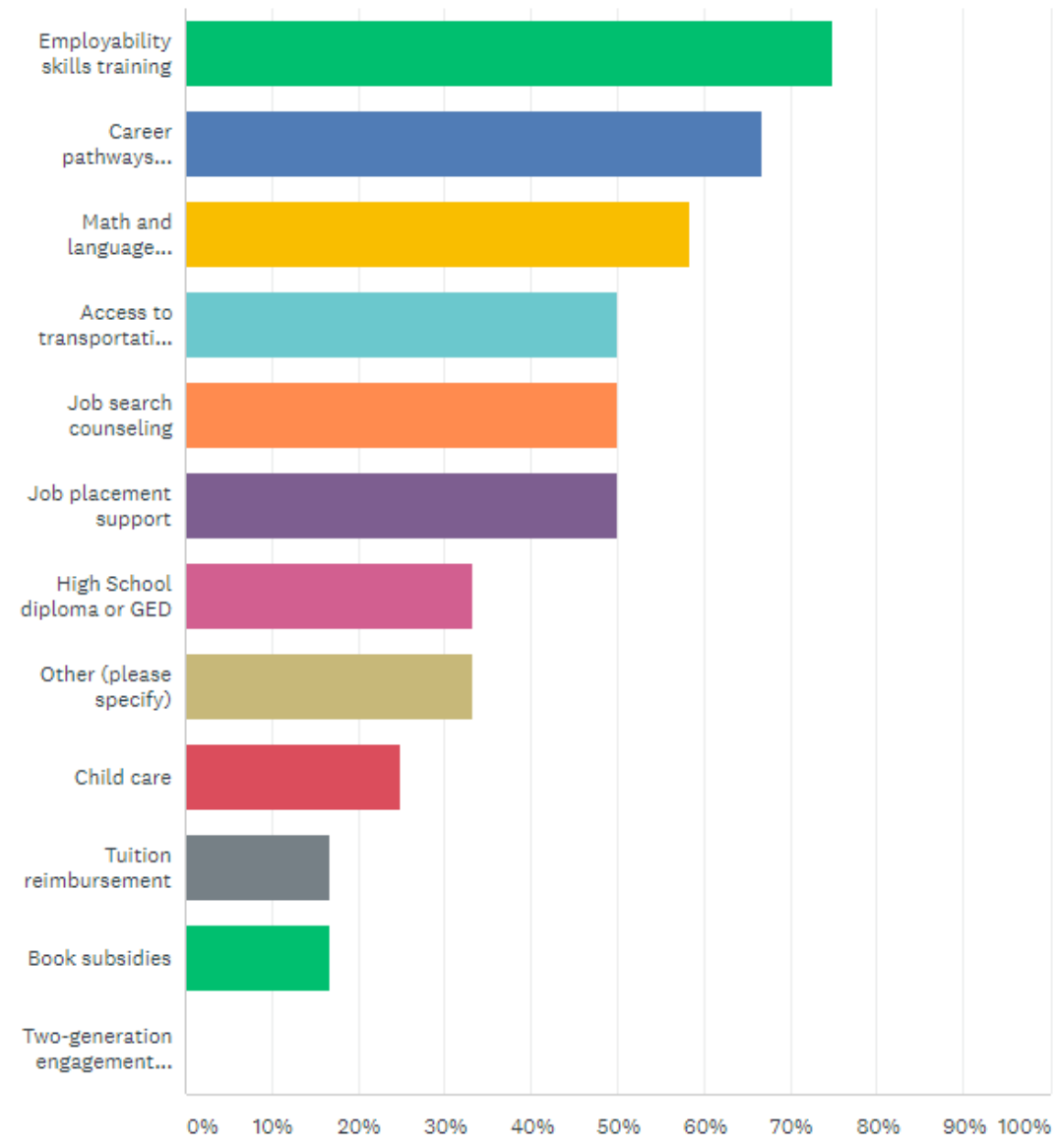

Career pathways counseling

Math and Language literacy courses

Access to transportation/transportation subsidies

Two-generation engagement strategies 
Table 10. Education and Training Partner-Identified Supportive/Wraparound Services

Requested, but not Provided (added by respondents as "other")

- Off-the-shelf computer training

- Computer-based training

- Mental health services (referrals)

- Job development

- Job placement

- Tuition reimbursement

- Transportation

Table 11. Workforce Skills Most Requested by Employers and Participants

Technical Skills

Employability Skills

Basic Skills
- Spreadsheets, analytics, project management, forecasting

- Mechanical computer-based diagnostics

- Skillsets in maintaining and operating material handling equipment

- Industry familiarity; basic concepts; industry vernacular; systems

- Basic competencies coupled with soft skills

- Soft skills/essential skills; continuous improvement; communication skills

- Documenting and talking intellectually to customers

- Being present; critical thinking and problem solving

- Math literacy 
Table 12. What are the Transportation and Supply Chain Workforce Skills Most Requested by Employers and Participants (e.g., data analytics)?

- Spreadsheet, analytics, project management, forecasting

- Mechanical skill-based computer-based diagnostics

- Basic competencies coupled with soft skills

- Willingness to learn and grow

- Soft Skills/Essential Skills

- Continuous Improvement

- Communication Skills

- Math literacy

- Knowing how to document and talk intellectually to customers

- Being present, critical thinking and problem solving

- Technical training

- Industry familiarity: basic concepts, industry vernacular, systems

- Excel

Table 13. What Are Your Most Pressing Obstacles to Delivering Effective Training Programs (added by respondents as "other")?

- Middle-management support (Operations Managers); enough time off "the floor" to complete training

- Equipment

- Willing faculty and institutional support/prioritization

- Overcoming low enrollment

- Funding to subsidize the training for entry-level workers, or funding to develop and revise midlevel training

- Finding vendors or instructors that have the knowledge and experience to teach specific training topics that are relatively local

- Finding vendors or instructors meeting insurance requirements

- The hows of developing effective training programs with industry 
Developing Competencies

Instructional Delivery
- View both industry and students as clients when designing programs

- Regular communication with industry partners and project stakeholders. Focus on industry-valued third-party credentials as evidence of common outcomes for completers across regional programs

- Train to local or regional employment needs

- Employer feedback (during and after training)

- Stay involved through social media

- Review government workforce data

- Involvement in advisory committee and professional associations

- Regular communication with industry partners and project stakeholders

- Networking

- Frequent, deliberate, strategic communications

- Honest conversations about needs and challenges

- Strategic, realistic planning

- Follow-up and follow-through

- Pre-Training Assessment

- Conducting surveys amongst technicians and supervisors to determine the greatest training need(s)

- Develop programs with industry

- Partnerships with vendors for technical material and technical material review

- Determine new strategies for the OJT instruction in terms of delivery, accessibility, and evaluation given the limitations placed on programs with COVID-19

- Provide industry-supported forums and workshops

- Training at [industry] location, using [industry] instructors, flexible hours

- Group workshops

- Engagement of practitioners in delivery of content

- Scheduling training classes early for maximized execution

- Use Project Based Learning and Adult Learning Principles where the workforce can complete case study exercises to make recommendations and then introduce the theory or practice. More hands-on for the technical areas of training

- Instructor and student guidance with a hand-in-hand approach 
Table 15. Do you have any comments, suggestions, or recommendations about workforce development programs for the transportation and supply chain sectors?

- We expect significant changes in the coming year due to Covid; Staying close to industry will be key to success

- Continue with workforce development meetings; offer opportunities to collaborate even if there is no initial structure

- Industry supported forums and workshops

- Development of "pull" versus "push"; Train to employment needs of local or regional needs

- Do the best you can to support all

- Need more knowledgeable instructors available for new alternative fuel technologies, particularly EVs, Hydrogen, and Hybrid vehicles

- Continue to engage employers 


\section{Appendix 3. Industry Partner Survey Questions}

1. How many people are employed at your organization?

2. What is your industry sector? (Please select all that apply)

3. What are your most critical middle-skill workforce needs relating to digital literacy? Middle-skill workers are those with a high school diploma, but less than a four-year college degree. (Please select all that apply)

4. What are your most critical middle-skill workforce needs related to front/back office management systems? (Please select all that apply)

5. What are job titles (e.g., Production Coordinator) at your organization that are associated with the competencies listed above?

6. What are your most critical middle-skill workforce needs relating to data management? (Please select all that apply)

7. What are job titles (e.g., Logistics Analyst) at your organization that are associated with the competencies listed above? (Please type in box below)

8. What are your most critical middle-skill Operations \& Maintenance workforce needs? (Please select all that apply)

9. What are job titles (e.g., Maintenance Technician) at your organization that are associated with the competencies listed above?

10. What compliance reporting and documentation is most critical to your organization? (Please select all that apply)

11. What are job titles at your organization that are associated with Compliance?

12. What are your organization's additional anticipated skills gaps (not included above) for the next three years?

13. What are the employability skills (professional, engagement, or soft skills) most critical for middle-skill employees at your organization?

14. How do you identify workforce development needs?

15. Who is the primary focus of your current workforce development efforts?

16. How do you fund workforce development efforts? 
17. Is your organization's budget for workforce development programming expanding, staying at the same level, or decreasing?

18. Do you fund outside training opportunities for your employees?

19. On average, for each employee, how much is spent on training per year?

20. Is there a cap per employee/per year on training costs?

21. What is the minimum level of education required for middle-skill employees at your organization?

22. To meet this skills gap, will your organization hire new talent or upskill incumbents, or both?

23. If your organization has workforce development partners, what organizations do you partner with?

24. How does your organization deliver workforce development programming?

25. What is the ideal program length that will adequately prepare your employees to learn the necessary skills for your most critical training needs?

26. What percentage of employees (new hires and incumbents, combined) would you consider training per year?

27. With a spectrum of approaches to work-based learning, what design would work best for your organization?

28. Do your company's training programs involve online courses?

29. Do your company's training programs involve the use of virtual reality (VR), augmented reality $(\mathrm{AR})$, or both?

30. Please list employer-valued credentials/certifications specific to your organization for middle-skill employees. (For example: Certified in Production and Inventory Management (CPIM), Certified Professional in Supply Management (CPSM), Certified Global Business Professional (CGBP), etc.)

31. What barriers/gaps have you encountered in identifying and delivering effective training programs? (Please select all that apply)

32. How do you assess the success or effectiveness of your training programs? (Please select all that apply) 
33. Do you have any comments, suggestions, or recommendations about workforce development needs in your industry and company? 


\section{Appendix 4. Education and Training Partner Survey Questions}

1. Which of the following best describes your organization?

2. Has your organization partnered with supply chain and transportation industry sectors to develop workforce development programs?

3. If your organization has partnered with these sectors, what role do these industry partners play? (Please select all that apply)

4. In the past two years, have industry requests to develop training partners in these sectors increased or decreased?

5. Do your workforce development efforts focus on upskilling incumbents, new hires, or both?

6. Who is the primary focus of your current workforce development efforts?

7. Are your education and training programs related to transportation and supply chain for credit, non-credit, or not-for-credit? (Please select all that apply)

8. Does your organization develop apprenticeships?

9. If your organization develops apprenticeships, are they...

10. What trends in workforce development programming do you see regarding length of training programs?

11. Within the past two years, has funding dedicated to workforce development programs at your organization increased, decreased, or stayed the same?

12. How do you fund workforce development efforts?

13. Within the past two years, have industry requests to develop training programs in the transportation and supply chain sectors increased or decreased?

14. How do you identify workforce development competencies?

15. What are the employability skills (professional, engagement, or soft skills) most requested by employers and participants? (Please select all that apply)

16. What are the transportation and supply chain workforce skills most requested by employers and participants (e.g., data analytics)? 
17. On average, during the last two years, what has been the length of time from initial training program concept to implementation?

18. What approaches to work-based learning does your organization use? (Please select all that apply)

19. Does your organization's training programs involve the use of virtual reality (VR), augmented reality (AR), or both?

20. What supportive/wraparound services does your organization provide to participants?

21. What supportive/wraparound services are not provided by your organization, but are requested by either participants or industry?

22. How do you assess the success or effectiveness of your training programs? (Please select all that apply)

23. What barriers/gaps have you encountered in identifying and delivering effective training programs? (Please select all that apply)

24. What are your most pressing obstacles to delivering effective training programs?

25. Please name a few of your best practices that have proven to be effective in your workforce development programs.

26. Do you have any comments, suggestions, or recommendations about workforce development programs for the transportation and supply chain sectors? 


\section{Appendix 5. Industry Partner In-depth Interview Questions}

1. How does your organization anticipate addressing workforce development needs for emerging technological advances in your industry?

2. What are COVID-19's impacts on technology at your organization?

3. What are the new skill sets needed for both incumbents and new hires to address impacts of COVID-19?

4. Do you see organizations contracting or expanding to address impacts of COVID-19?

5. What are the strategies and approaches most often used for workforce development in your organization?

6. What are barriers your organization faces regarding workforce development efforts?

7. Do industry associations support your organization's workforce development efforts? If they do support your training efforts, how?

8. How can partnering education and training organizations (community and technical colleges, universities, Workforce Development Boards, K12 school districts, communitybased organizations) support your organization's workforce development efforts, particularly in light of COVID-19's impacts? 


\section{Appendix 6: Education and Training Partner In-depth Interview Questions}

1. What trends in program development are you seeing in workforce development? In relation to impacts of COVID-19 and shelter-in place policies?

2. What are barriers to program development?

3. How do you address these barriers?

4. How will programs deliver the OJT portion of instruction with shelter-in-place policies?

5. Do you see new partnerships developing for future programs to respond to shelter-inplace policies?

6. What are best practices you can share for program development?

7. What are some career pathways with successful outcomes you can share for this study?

8. What are best practices for replicating, scaling, and sustaining programs?

9. Comments, questions. 


\section{Appendix 7: Burning Glass Technology's Labor Insights Data}

Our methodology includes a survey for industry leaders and education and training leaders. The survey provides additional information that is further researched utilizing Burning Glass Technology's Labor Insights, a platform that analyzes occupations and their in-demand skills in real time. The survey and the Labor Insight analysis are independent; however, the findings are consistent and validate one another. After combining all the skills among the different occupations, the top five skills are ranked as follows: (1) logistics, (2) customer service, (3) budgeting, (4) scheduling, and (5) Operations \& Management. 


\section{Abbreviations and Acronyms}

3PL

4PL

AAMVA

ADAS

AOBRD

ATA

ATRI

BIT

BLS

CAAP

CalEPA

CARB

CDL

CLP

COVID-19

DTSC

ELD

EPA

FHWA

FMCSA

FTL/TL

GAO

GPS

HOS

HTA

IRT

JIT

LIDAR

LTL

OEM

$\mathrm{O}-\mathrm{O}$

OOIDA

OSHA

OTR

SB1

SDLA

SME

SWRCB

TSA

UIIA
Third-Party Logistics

Fourth-Party Logistics

American Association of Motor Vehicle Administrators

Advanced Driver-Assistance Systems

Automatic On-Board Recording Device

American Trucking Associations

American Transportation Research Institute

Basic Inspection of Terminals

Bureau of Labor Statistics

California Air Action Plan

California Environmental Protection Agency

California Air Resources Board

Commercial Driver's License

Commercial Learner's Permit

COVID-19: (2019 Novel) Coronavirus Disease

Department of Toxic Substances Control

Electronic Logging Device

Environment Protection Agency

Federal Highway Administration

Federal Motor Carrier Safety Administration

Full Truckload/Truckload

Government Accountability Office

Global Positioning System

Hours of Service

Highway Traffic Act

Item Response Theory

Just in Time

Light Detection and Ranging

Less-than-Truckload

Original Equipment Manufacturer

Owner Operator

Owner-Operator Independent Drivers Association

Occupational Safety and Health Administration

Over the Road

Senate Bill 1

State Driver Licensing Agency

Small and Medium-sized Enterprises

State Waters Resource Control Board

Transportation Safety Administration

Uniform Intermodal Interchange and Facilities Access Agreement 


\section{Glossary}

Freight Forwarders

Intermodal

Internet of Things

Logistics

Supply Chain

Transloading

3PL

4PL

Dray or Drayage

Intermodal

Less-than-Truckload (LTL)

Over-the-Road (OTR) or

Long-Haul

Truckload

Warehouse Management System
Arrange the movement of goods.

Refers to two modes of transportation to move a good.

Refers to interconnected devices that share a network.

The management and coordination a complex operation.

The system of facilities, people, and resources that transport goods. Transferring a shipment from one mode of transportation to another. Third-party logistics company, which offers outsourced logistics services, including warehousing.

Assumes the same role as a 3PL, but serves as a point of contact for all parties involved beyond logistics.

Transportation of freight over short distances. Also known as cartage. Often refers to container movements from ship and rail yards.

Transportation of freight in which containers or trailers are transferred between different types of vehicles without unloading the freight. Typically used to refer to a combination of ship or rail and truck movement using containers.

Freight service moving shipments generally less than 10,000 pounds. These services often consolidate multiple shipments into a single truckload-size shipment for long-distance transport and then break consolidated shipments down again for final delivery.

Service that transports freight more than 150 miles from origin to destination.

For-hire freight service that moves shipments larger than 10,000 pounds, generally large enough to fill a truck to capacity, based either on legal allowable weight or trailer volume.

Allows a warehouse to control and administer operations. 


\section{Endnotes}

${ }^{1}$ Biju Kewalram, "Council Post: How The Current Pandemic Is Accelerating Supply Chain Digitalization," Forbes, accessed July 6, 2020, https://www.forbes.com/sites/forbestechcouncil/2020/06/24/how-the-current-pandemic-is-accelerating-supply-chain-digitalization/.

2 “Digital-Literacy-Data-Webinar-June-3-2020-Pdf-Slides.Pdf," accessed July 26, 2020, https://www.nationalskillscoalition.org/resources/webinars/text/Digital-literacy-data-webinarJune-3-2020-pdf-slides.pdf.

3 "MIT Open Learning Workforce Education Project | Open Learning," accessed June 8, 2020, https://openlearning.mit.edu/mit-open-learning-workforce-education-project.

4 "Microsoft Launches Initiative to Help 25 Million People Worldwide Acquire the Digital Skills Needed in a COVID-19 Economy," The Official Microsoft Blog, June 30, 2020, https://blogs.microsoft.com/blog/2020/06/30/microsoft-launches-initiative-to-help-25-millionpeople-worldwide-acquire-the-digital-skills-needed-in-a-covid-19-economy/

5 "Empowering a Resilient Transit Workforce," webinar, accessed July 24, 2020, https://www.enotrans.org/event/webinar-empowering-a-resilient-transit-workforce/

${ }^{6}$ Lauren Weber, "Why Companies Are Failing at Reskilling," Wall Street Journal, April 19, 2019, sec. Business,https://www.wsj.com/articles/the-answer-to-your-companys-hiringproblem-might-be-right-under-your-nose- 11555689542.

7 "Microsoft Launches Initiative to Help 25 Million People Worldwide Acquire the Digital Skills Needed in a COVID-19 Economy."

8 "Microsoft Launches Initiative to Help 25 Million People Worldwide Acquire the Digital Skills Needed in a COVID-19 Economy."

${ }^{9}$ Beth Gutelius and Nik Theodore, "The Future of Warehouse Work: Technological Change in the U.S. Logistics Industry," Center for Labor Research and Education (blog), October 22, 2019, http://laborcenter.berkeley.edu/future-of-warehouse-work/.

10 "Improving Noncollege Pathways to Skills and Successful Careers," Committee for Economic Development of The Conference Board, May 23, 2019, https://www.ced.org/reports/improvingnoncollege-pathways-to-skills-and-successful-careers.

${ }^{11}$ Los Angeles Economic Development Corporation, "Goods on the Move: Trade and Logistics in Southern California," accessed July 26, 2020, https://laedc.org/wp-content/uploads/2017/06/TL 20170515 Final.pdf.

12 "SANDAG :: PROJECTS :: San Diego's Regional Planning Agency," accessed July 28, 2020, https://www.sandag.org/index.asp?classid=19\&projectid=535\&fuseaction=projects.detail. 
${ }^{13}$ Los Angeles Economic Development Corporation, "Goods on the Move: Trade and Logistics in Southern California," accessed July 26, 2020, https://laedc.org/wp-content/up-

loads/2017/06/TL 20170515 Final.pdf.

14 "Essential Critical Infrastructure Workers," accessed April 8, 2020, https://covid19.ca.gov/img/EssentialCriticalInfrastructureWorkers.pdf.

15 "How 3PLs Are Evolving to Stay Competitive," Transport Topics, March 30, 2020, https://www.ttnews.com/articles/how-3pls-are-evolving-remain-relevant.

16 "How 3PLs Are Evolving to Stay Competitive," Transport Topics, March 30, 2020, https://www.ttnews.com/articles/how-3pls-are-evolving-remain-relevant.

${ }^{17}$ Deloitte, "MHI Annual Industry Report, Embracing the Digital Mindset, Connecting Data, Talent and Technology in Digital Supply Chains," 2020.

18 “MIT Open Learning Workforce Education Project | Open Learning," accessed June 8, 2020, https://openlearning.mit.edu/mit-open-learning-workforce-education-project.

19 “Harnessing Informal Learning," Training Industry (blog), accessed July 7, 2020, https://trainingindustry.com/magazine/may-jun-2020/harnessing-informal-learning/

20 “CSCMP May 2020 3PL Study Webinar PPT - FINAL.Pdf," accessed May 24, 2020, https://cscmp.informz.net/cscmp/data/images/CSCMP May 2020 3PL Study Webinar PPT FINAL.pdf.

21 “The Three Biggest Barriers Impeding Adoption of the Digital Supply Chain," accessed July 4, 2020, https://www.supplychainquarterly.com/articles/1613-the-three-biggest-barriers-impeding-adoption-of-the-digital-supply-chain.

${ }^{22}$ Mark Brohan, "Coronavirus Effect: B2B Sellers Scramble for Inventory," Digital Commerce 360, March 16, 2020, https://www.digitalcommerce360.com/2020/03/16/coronavirus-effectb2b-sellers-scramble-for-inventory/

23 "Union Pacific Shutters Operation of Multimodal Service Cold Connect," FreightWaves, May 10, 2020, https://www.freightwaves.com/news/union-pacific-shutters-operation-of-multimodalservice-cold-connect.

24 "What COVID-19 Means For Logistics, Now And In The Future," PYMNTS.Com (blog), April 15, 2020,https://www.pymnts.com/news/b2b-payments/2020/covid-19-logistics-supplychain/.

25 "Dock Appointment Scheduling Software Cuts Driver Wait Times, Optimizes Warehouse Workforce," FreightWaves, accessed April 30, 2020, https://www.freightwaves.com/news/dockappointment-scheduling-software-cuts-driver-wait-times-optimizes-warehouse-workforce. 
26 "MHI Next-Gen Supply Chain Update: Tapping into the Value of Supply Chain Data," MHI view, accessed May 7, 2020, https://videos.mhi.org/mhi-next-gen-supply-chain-update-tappinginto-the-value-of-supply-chain-data.

27 “A New Digital Network for Freight Forwarders Booms during COVID-19," FreightWaves, May 1, 2020, https://www.freightwaves.com/news/a-new-digital-network-for-freight-forwarders-booms-during-covid-19.

${ }^{28}$ Biju Kewalram, "Council Post: How The Current Pandemic Is Accelerating Supply Chain Digitalization," Forbes, accessed July 6, 2020, https://www.forbes.com/sites/forbestechcouncil/2020/06/24/how-the-current-pandemic-is-accelerating-supply-chain-digitalization/.

29 "Wearables Could Be Key for Worker Safety as Warehouses, Manufacturers Eager to Reopen | Supply Chain Dive," accessed May 12, 2020, https://www.supplychaindive.com/news/coronavirus-warehouse-manufacturer-reopen-safety-wearables-internet-of-things-iot/577401/

${ }^{30}$ Mike Ogle, "Closing the Gap," accessed May 14, 2020, https://www.mhisolutions-digital.com $/ \mathrm{mhiq} / 0220$ volume 8 issue 2/MobilePagedArticle.action?articleId=1562097.

31 "ATRI-OOIDA-COVID-19-Impacts-on-the-Trucking-Impacts-05-2020.Pdf," accessed May 5, 2020, https://truckingresearch.org/wp-content/uploads/2020/05/ATRI-OOIDACOVID-19-Impacts-on-the-Trucking-Impacts-05-2020.pdf.

${ }^{32}$ Federal Reserve Bank of Cleveland, "Opportunity Occupations: A Way Ahead for People without a College Degree," A Look Behind The Numbers, June 16, 2020, https://www.clevelandfed.org/newsroom-and-events/publications/a-look-behind-the-numbers/albtn-opportunityoccupations.

${ }_{33}$ Mike Cummings, "Managing Roiling Labor Markets amid COVID-19," YaleNews, April 2, 2020, https://news.yale.edu/2020/04/02/managing-roiling-labor-markets-amid-covid-19.

${ }^{34}$ Mike Cummings, "Managing Roiling Labor Markets amid COVID-19," YaleNews, April 2, 2020, https://news.yale.edu/2020/04/02/managing-roiling-labor-markets-amid-covid-19.

${ }^{35}$ Lauren Weber, "Why Companies Are Failing at Reskilling," Wall Street Journal, April 19, 2019, sec. Business, https://www.wsj.com/articles/the-answer-to-your-companys-hiring-problem-might-be-right-under-your-nose-11555689542.

${ }^{36}$ Lohr, Steve. 2020. "The Pandemic Has Accelerated Demands for a More Skilled Work Force.” The New York Times, July 13, 2020, sec. Business. https://www.nytimes.com/2020/07/13/business/coronavirus-retraining-workers.html.

${ }^{37}$ Lohr, Steve. 2020. "The Pandemic Has Accelerated Demands for a More Skilled Work Force.” The New York Times, July 13, 2020, sec. Business. https://www.nytimes.com/2020/07/13/business/coronavirus-retraining-workers.html. 
38 "Microsoft Launches Initiative to Help 25 Million People Worldwide Acquire the Digital Skills Needed in a COVID-19 Economy," The Official Microsoft Blog, June 30, 2020, https://blogs.microsoft.com/blog/2020/06/30/microsoft-launches-initiative-to-help-25-millionpeople-worldwide-acquire-the-digital-skills-needed-in-a-covid-19-economy/

${ }^{39}$ National Skills Coalition. 2020. “American Workers' Digital Skills: What the Data Tells Us.” https://www.nationalskillscoalition.org/resources/webinars/text/Digital-literacy-data-webinarLune-3-2020-pdf-slides.pdf.

${ }^{40}$ William B Bonvillian et al., "Preliminary Report- The Workforce Education Project," n.d., 94.

${ }^{41}$ Lohr, Steve. 2020. “The Pandemic Has Accelerated Demands for a More Skilled Work Force.” The New York Times, July 13, 2020, sec. Business. https://www.nytimes.com/2020/07/13/business/coronavirus-retraining-workers.html.

${ }^{42}$ William B Bonvillian et al., "Preliminary Report- The Workforce Education Project,” n.d., 94.

43 Ibid.

${ }^{44}$ ARPost, "How AR Is Changing The Trucking Industry," ARPost (blog), accessed July 14, 2020, https://arpost.co/2018/11/16/how-ar-is-changing-the-trucking-industry/.

45 “Virtual Reality Reinvents Truck Driver Training," MHI Blog (blog), September 12, 2017, http://s354933259.onlinehome.us/mhi-blog/virtual-reality-reinvents-truck-driver-training/

46 "Working Hard for the Money," accessed July 1, 2020, https://www.supplychainquarterly.com/articles/3450-working-hard-for-the-money.

47 "Improving Noncollege Pathways to Skills and Successful Careers." 2019. Committee for Economic Development of The Conference Board. May 23, 2019. https://www.ced.org/reports/improving-noncollege-pathways-to-skills-and-successfulcareers.

48 "CSCMPodcast: Supply Chain Conversation: Future of Leadership Series: What Is the Future of Leadership?," accessed July 13, 2020, https://cscmpodcast.libsyn.com/future-of-leadershipseries-what-is-the-future-of-leadership.

49 "Artificial Intelligence: A Roadmap for California," Little Hoover Commission, accessed July 26, 2020, https://lhc.ca.gov/report/artificial-intelligence-roadmap-california.

50 "Categorizing Workers' Needs by Generation Such as Baby Boomers or Millennials Is Not Supported by Research or Useful for Workforce Management," National Academies, accessed July 27, 2020, https://www.nationalacademies.org/news/2020/07/categorizing-workers-needsby-generation-such-as-baby-boomers-or-millennials-is-not-supported-by-research-or-usefulfor-workforce-management. 
51 "Chief Learning Officers as Organizational Transformers," MIT J-WEL, January 9, 2020, https://jwel.mit.edu/assets/video/chief-learning-officers-organizational-transformers.

${ }^{52}$ Daniel Susskind, A World Without Work: Technology, Automation, and How We Should Respond (New York: Metropolitan Books, 2020).

53 "New Data Show COVID-19 Impacts on the Trucking Industry - American Transportation Research Institute," accessed April 30, 2020,https://truckingresearch.org/2020/04/22/new-datashow-covid-19-impacts-on-the-trucking-industry/.

54 "Freight Economy Rebound May Be Underway," SONAR, April 24, 2020, http://sonar.freightwaves.com/freight-market-pulse/freight-economy-rebound-maybe-underway-carrierbankruptcies-and-unseated-trucks-will-drive-next-spot-rate-surge.

55 "COVID-19 Impacts on the Trucking-Impacts-05-2020.Pdf." n.d. Accessed May 5, 2020. https://truckingresearch.org/wp-content/uploads/2020/05/ATRI-OOIDA-COVID-19Impacts-on-the-Trucking-Impacts-05-2020.pdf.

56 “COVID-19 Action Guide Industry Dive," accessed May 18, 2020, https://lp.descartes.com/eblast-tm-covid19-actionguide/.

${ }^{57}$ Biju Kewalram, "Council Post: How The Current Pandemic Is Accelerating Supply Chain Digitalization," Forbes, accessed July 6, 2020, https://www.forbes.com/sites/forbestechcouncil/2020/06/24/how-the-current-pandemic-is-accelerating-supply-chain-digitalization/.

${ }^{58}$ Biju Kewalram, "Council Post: How The Current Pandemic Is Accelerating Supply Chain Digitalization," Forbes, accessed July 6, 2020, https://www.forbes.com/sites/forbestechcouncil/2020/06/24/how-the-current-pandemic-is-accelerating-supply-chain-digitalization/.

${ }^{59}$ Deloitte, "MHI Annual Industry Report, Embracing the Digital Mindset, Connecting Data, Talent and Technology in Digital Supply Chains."

60 "How Supply Chain Digitization Benefits IMCs and Trucking Drayage | Blume Global Optimizing Drayage Through Digitizing Your Logistics," Blume Global, accessed April 30, 2020, https://www.blumeglobal.com/learning/how-supply-chain-digitization-benefits-imcs-andtrucking-drayage/

61 "Microsoft Launches Initiative to Help 25 Million People Worldwide Acquire the Digital Skills Needed in a COVID-19 Economy."

62 "Logistics Providers Weigh Workforce Reductions amid Drop in Trade," FreightWaves, April 8, 2020, https://www.freightwaves.com/news/logistics-providers-weigh-workforce-reductionsamid-drop-in-trade.

63 "Transforming IT Training Programs into Successful Career On-Ramps," JFF, accessed July 24, 2020,https://www.jff.org/resources/transforming-it-programs-successful-career-ramps/. 
64 "FMCSA Issues Waiver for Expiring Licenses and Medical Cards," FreightWaves, accessed April 28, 2020, https://www.freightwaves.com/news/fmcsa-issues-waiver-for-expiring-licensesand-medical-cards.

65 "FMCSA CDL Waiver-3.24.20.Pdf," accessed April 28, 2020, https://www.fmcsa.dot.gov/sites/fmcsa.dot.gov/files/2020-03/FMCSA CDL Waiver3.24.20.pdf.

66 "FMCSA Provides Relief for Driver Training Hit by COVID-19," FreightWaves, accessed April 28, 2020, https://www.freightwaves.com/news/fmcsa-provides-relief-for-driver-traininghit-by-covid-19.

67 "FMCSA CLP Waiver_03 28 20.Pdf," accessed April 28, 2020, https://www.fmcsa.dot.gov/sites/fmcsa.dot.gov/files/2020-03/FMCSA CLP Waiver_03 28 20.pdf.

68 "FMCSA Third Party Tester Waiver Final 4.9.20.Pdf," accessed April 28, 2020, https://www.fmcsa.dot.gov/sites/fmcsa.dot.gov/files/2020-04/FMCSA Third Party Tester Waiver final 4.9.20.pdf.

69 "FMCSA Waives Procedures for CDL Testing Officials," FreightWaves, accessed April 28, 2020, https://www.freightwaves.com/news/fmcsa-waives-procedures-for-cdl-testing-officials.

70 "FMCSA's New Requirements for Entry-Level Driver Training," FleetOwner, accessed May 14, 2020, https://www.fleetowner.com/resource-center/regulations/article/21703732/fmcsasnew-requirements-for-entrylevel-driver-training. 


\section{Bibliography}

"A Covid-19 Supply Chain Shock Born in China Is Going Global." Bloomberg.com. March 20, 2020. https:/www.bloomberg.com/news/articles/2020-03-20/a-covid-19-supply-chainshock-born-in-china-is-going-global.

"A New Digital Network for Freight Forwarders Booms during COVID-19." FreightWaves. May 1, 2020. https://www.freightwaves.com/news/a-new-digital-network-for-freight-forwardersbooms-during-covid-19.

American Transportation Research Institute (ATRI). "New Data Show COVID-19 Impacts on the Trucking Industry." Accessed April 30, 2020. https://truckingresearch.org/2020/04/22/new-data-show-covid-19-impacts-on-the-trucking-industry/.

"Artificial Intelligence: A Roadmap for California." Little Hoover Commission. Accessed July 26, 2020. https://hc.ca.gov/report/artificial-intelligence-roadmap-california.

“As New Coronavirus Cases Slow In China, Factories Start Reopening.” Accessed April 1, 2020. https://www.npr.org/2020/02/29/810334985/as-new-coronavirus-cases-slow-in-china-factories-start-reopening.

Bonvillian, William B, Sanjay Sarma, Meghan Perdue, and Jenna Myers. n.d. "Preliminary Report- The Workforce Education Project," 94.

Brohan, Mark. “Coronavirus Effect: B2B Sellers Scramble for Inventory." Digital Commerce 360, March 16, 2020. https://www.digitalcommerce360.com/2020/03/16/coronavirus-effect-b2bsellers-scramble-for-inventory/

Rein, Volker, and Robert Lerman. 2015. "Building a Robust U.S. Work-Based Education and Apprenticeship System at Scale:Can Lessons from Europe Help?” AICGS, May. https://www.aicgs.org/publication/building-a-robust-u-s-work-based-education-and-apprenticeship-system-at-scale/

“CDC Issues Long-Haul Trucker COVID-19 Guidelines." FreightWaves. Accessed May 12, 2020. https://freightwaves.com/news/cdc-issues-long-haul-trucker-covid-19-guidelines.

"Charting the Path to the next Normal." McKinsey \& Company. Accessed July 1, 2020. https://www.mckinsey.com/featured-insights/coronavirus-leading-through-the-crisis/charting-the-path-to-the-next-normal.

"Container Lines Scramble to Avert 'Life-Threatening' COVID-19 Losses." FreightWaves. April 6, 2020. https://www.freightwaves.com/news/container-lines-scramble-to-avert-life-threatening-covid-19-losses. 
Cooper, Christine, Shannon Sedgwick, and Somjita Mitra. 2017. "Goods on the Move!" Los Angeles County Economic Corporation. https://laedc.org/wp-content/uploads/2017/06/TL 20170515 Final.pdf.

"Coronavirus: A Lesson in Supply Chain Risk Management." Supply Chain Dive. Accessed April 17, 2020. https://www.supplychaindive.com/news/coronavirus-supply-chain-risk-manage$\underline{\text { ment } / 572670 /}$

“COVID-19 Global Response Overview.” n.d. Logistics Cluster. Accessed September 10, 2020. https://logcluster.org/COVID-19.

“COVID-19 Action Guide Industry Dive.” Accessed May 18, 2020. https://lp.descartes.com/eblast-tm-covid19-actionguide/

“COVID-19 Impacts on the Trucking-Impacts-05-2020.Pdf." 2020. April 2020. https://truckingresearch.org/wp-content/uploads/2020/05/ATRI-OOIDA-COVID-19-Impacts-on-theTrucking-Impacts-05-2020.pdf.

Craig, Ryan, and Tom Bewick. 2018. "Making Apprenticeships Work/Five Policy Recommendations." https://universityventures.com/images/Making Apprenticeships Work UV Whitepaper.pdf.

Cummings, Mike. "Managing Roiling Labor Markets amid COVID-19." YaleNews, April 2, 2020. https://news.yale.edu/2020/04/02/managing-roiling-labor-markets-amid-covid-19.

"Dock Appointment Scheduling Software Cuts Driver Wait Times, Optimizes Warehouse Workforce." FreightWaves. Accessed April 30, 2020. https://www.freightwaves.com/news/dock-appointment-scheduling-software-cuts-driver-wait-times-optimizeswarehouse-workforce.

Dollar, Adie Tomer and David Dollar. "How Will COVID-19 Reshape America's Logistics Workforce?” Brookings (blog), April 6, 2020. https://www.brookings.edu/podcast-episode/how-will-covid-19-reshape-americas-logistics-workforce/

“Empowering a Resilient Transit Workforce." Webinar. Accessed July 24, 2020. https://www.enotrans.org/event/webinar-empowering-a-resilient-transit-workforce/

“Essential Critical Infrastructure Workers.” Accessed April 8, 2020. https://covid19.ca.gov/img/EssentialCriticalInfrastructureWorkers.pdf.

"Expanded Frequently Asked Questions for State Driver Licensing Agencies and Commercial Drivers Regarding Permissible Actions During the COVID-19 Emergency - April 13, 2020.” FMCSA. Accessed April 28, 2020. https://www.fmcsa.dot.gov/emergency/expandedfrequently-asked-questions-state-driver-licensing-agencies-and-commercial. 
Federal Motor Carrier Safety Administration (FMCSA), DOT. 2020. "Notice Of Enforcement Discretion Concerning Certain Requirements for 10-Day State Notification and Other Actions on Driver License Records." April 17, 2020.

https://www.fmcsa.dot.gov/sites/fmcsa.dot.gov/files/2020-

04/FMCSA\%20Notice\%20Enf\%20Disc\%20on\%20SDLA\%20DQs-

Convictions\%20Uploads\%20-\%20Apr\%2017\%202020.pdf.

Federal Motor Carrier Safety Administration (FMCSA), DOT. 2020. "Three-Month Waiver in Response to the COVID-19 Emergency - For States and CLP Holders Operating Commercial Motor Vehicles." March 28, 2020.

https://www.fmcsa.dot.gov/sites/fmcsa.dot.gov/files/2020-

03/FMCSA\%20CLP\%20Waiver 03\%2028\%2020.pdf.

Federal Motor Carrier Safety Administration (FMCSA), DOT. 2020. "Waiver for States Concerning Third Party CDL Skills Test Examiners in Response to the COVID-19 Emergency.” April 9, 2020. https://www.fmcsa.dot.gov/sites/fmcsa.dot.gov/files/202004/FMCSA\%20Third\%20Party\%20Tester\%20Waiver\%20final\%204.9.20.pdf.

Federal Motor Carrier Safety Administration (FMCSA), DOT. 2020. "Waiver in Response to the COVID-19 Emergency - For States, CDL Holders, CLP Holders, and Interstate Drivers Operating Commercial Motor Vehicles." March 24, 2020. https://www.fmcsa.dot.gov/sites/fmcsa.dot.gov/files/202003/FMCSA\%20CDL\%20Waiver-3.24.20.pdf.

Federal Reserve Bank of Cleveland. 2020. "Opportunity Occupations: A Way Ahead for People without a College Degree.” A Look Behind The Numbers, June. https://www.clevelandfed.org/newsroom-and-events/publications/a-look-behind-the-numbers/albtn-opportunityoccupations.

"FMCSA Allowing Cameras to Replace People for CDL Road Tests." FreightWaves, April 13, 2020. https://www.freightwaves.com/news/fmcsa-allowing-cameras-to-replace-people-forcdl-road-tests.

"FMCSA Issues Waiver for Expiring Licenses and Medical Cards." FreightWaves. Accessed April 28, 2020. https://www.freightwaves.com/news/fmcsa-issues-waiver-for-expiring-licensesand-medical-cards.

"FMCSA Loosens Enforcement of Driver Violation Reporting." FreightWaves. Accessed April 28, 2020. https://freightwaves.com/news/fmcsa-loosens-enforcement-of-driver-violation-reporting.

"FMCSA Provides Relief for Driver Training Hit by COVID-19." FreightWaves. Accessed April 28, 2020. https://www.freightwaves.com/news/fmcsa-provides-relief-for-driver-training-hitby-covid-19. 
"FMCSA Waives Procedures for CDL Testing Officials." FreightWaves. Accessed April 28, 2020. https://www.freightwaves.com/news/fmcsa-waives-procedures-for-cdl-testing-officials.

“FMCSA's New Requirements for Entry-Level Driver Training." FleetOwner. Accessed May 14, 2020. https://www.fleetowner.com/resource-center/regulations/article/21703732/fmcsasnew-requirements-for-entrylevel-driver-training.

"Freight Economy Rebound May Be Underway." SONAR. April 24, 2020. http://sonar.freightwaves.com/freight-market-pulse/freight-economy-rebound-maybe-underway-carrier-bankruptcies-and-unseated-trucks-will-drive-next-spot-rate-surge.

"Guidance on the Essential Critical Infrastructure Workforce." CISA. Accessed March 30, 2020. https://www.cisa.gov/publication/guidance-essential-critical-infrastructure-workforce.

Gutelius, Beth, and Nik Theodore. 2019. "The Future of Warehouse Work: Technological Change in the U.S. Logistics Industry." Center for Labor Research and Education (blog). October 22, 2019. http://laborcenter.berkeley.edu/future-of-warehouse-work/

"How 3PLs Are Evolving to Stay Competitive." Transport Topics. March 30, 2020. https://www.ttnews.com/articles/how-3pls-are-evolving-remain-relevant.

"How Supply Chain Digitization Benefits IMCs and Trucking Drayage. Blume Global Optimizing Drayage Through Digitizing Your Logistics.” Accessed April 30, 2020. https://www.blumeglobal.com/learning/how-supply-chain-digitization-benefits-imcs-andtrucking-drayage/

"Improving Noncollege Pathways to Skills and Successful Careers." 2019. Committee for Economic Development of The Conference Board. May 23, 2019. https://www.ced.org/reports/improving-noncollege-pathways-to-skills-and-successful-careers.

“Iowa Driver Uses Technology for CDL Skills Test.” Transport Topics. Accessed May 12, 2020. https://www.ttnews.com/articles/iowa-driver-among-first-us-use-technology-cdl-skills-test.

Kewalram, Biju. n.d. "Council Post: How The Current Pandemic Is Accelerating Supply Chain Digitalization." Forbes. Accessed July 6, 2020. https://www.forbes.com/sites/forbestechcouncil/2020/06/24/how-the-current-pandemic-is-accelerating-supply-chain-digitalization/

Kilpatrick, Jim, and Lee Barter. n.d. "COVID-19 - Managing Supply Chain Risk and Disruption,” 20. https://www2.deloitte.com/global/en/pages/risk/articles/covid-19-managing-supply-chain-risk-and-disruption.html 
"Logistics Providers Weigh Workforce Reductions amid Drop in Trade." April 8, 2020. https://www.freightwaves.com/news/logistics-providers-weigh-workforce-reductions-amiddrop-in-trade.

“Managing Supply Chain Risk and Disruption: COVID-19." Deloitte Global. Accessed April 23, 2020. https://www2.deloitte.com/global/en/pages/risk/articles/covid-19-managing-supplychain-risk-and-disruption.html.

Murray, Dan, and Seth Glidewell. 2019. "An Analysis of the Operational Costs of Trucking: 2019 Update.” American Transportation Research Institute, November, 48.

National Skills Coalition. "DOL Releases Guidance on 'Industry-Recognized' Apprenticeship Programs.” Accessed July 24, 2020. https://www.nationalskillscoalition.org/news/blog/dolreleases-guidance-on-industry-recognized-apprenticeship-programs.

National Skills Coalition. 2020. "American Workers' Digital Skills: What the Data Tells Us." https://www.nationalskillscoalition.org/resources/webinars/text/Digital-literacy-data-webinar-June-3-2020-pdf-slides.pdf.

“New Era of City Workforce Development Implores Virtual Strategies.” Accessed July 4, 2020. https://www.smartcitiesdive.com/news/virtual-city-workforce-job-hiring-strategies-coronavirus $/ 577916 /$

Ogle, Mike. "Closing the Gap." Accessed May 14, 2020. https://www.mhisolutions-digital.com $/ \mathrm{mhiq} / 0220$ volume 8 issue $2 /$ MobilePagedArticle.action?articleId=1562097.

"Port of LA March Cargo Volume Drops Nearly 31\%." FreightWaves. April 8, 2020. https://www.freightwaves.com/news/port-of-la-march-cargo-volume-drops-nearly-31.

"Registered Apprenticeship Programs and the Eligible Training Provider (ETP) List." n.d., 6.

"Resetting Supply Chains for the next Normal.” McKinsey. Accessed July 27, 2020. https://www.mckinsey.com/business-functions/operations/our-insights/resetting-supplychains-for-the-next-normal.

Seleznow, Eric M. "We Must Sustain Apprenticeship in a Post-Pandemic Downturn | JFF." Accessed April 3, 2020. https://www.jff.org/points-of-view/we-must-sustain-apprenticeshippost-pandemic-downturn/

Seleznow, Eric. 2018. "What's Next for Apprenticeship?” May 17, 2018. https://www.jff.org/points-of-view/whats-next-apprenticeship/ 
"Substituting Cargo for Passengers Becomes Mainstream Business for Airlines." FreightWaves, April 9, 2020. https://www.freightwaves.com/news/substituting-cargo-for-passengers-becomes-mainstream-business-for-airlines.

“Tank Carrier Using 'Liquidity' Advantage during COVID Crisis.” Accessed April 17, 2020. https://www.ccjdigital.com/tank-carrier-liquid-freight-growth-coronavirus/.

"The Role of Apprenticeship Intermediaries." Webinar, JFF. Accessed July 24, 2020. https://www.jff.org/events/webinar-role-apprenticeship-intermediaries/

“To Prepare for the Next 'Black Swan' Event, Supply Chains Should Rethink 'Lean.” Accessed April 17, 2020. https://www.supplychaindive.com/news/coronavirus-preparing-supplychains-next-black-swan-event $/ 576004 /$

TradeGecko. “3PL, 4PL and Other Logistics Providers, Explained.” Accessed May 5, 2020. https://www.tradegecko.com/inventory-management/what-is-4pl-3pl-logistics-providers.

“Trucking's Role in Restarting Economy Requires Measured Pace." Transport Topics. Accessed May 18, 2020. https://www.ttnews.com/articles/truckings-role-restarting-economy-requiresmeasured-pace.

Unruh, Rachel. "Manufacturing a Response to COVID-19.” Medium, April 2, 2020. https://medium.com/national-skills-coalition/manufacturing-a-response-to-covid-19-66bbbdfef9ff.

"Wearables Could Be Key for Worker Safety as Warehouses, Manufacturers Eager to Reopen." Supply Chain Dive. Accessed May 12, 2020. https://www.supplychaindive.com/news/coronavirus-warehouse-manufacturer-reopen-safety-wearables-internet-of-things-iot/577401/

Weber, Lauren. 2019. "Why Companies Are Failing at Reskilling." Wall Street Journal, April 19, 2019, sec. Business. https://www.wsj.com/articles/the-answer-to-your-companys-hiringproblem-might-be-right-under-your-nose-11555689542.

"What COVID-19 Means For Logistics, Now And In The Future." April 15, 2020. https://www.pymnts.com/news/b2b-payments/2020/covid-19-logistics-supply-chain/

"Women-Owned Trucking Gets More Access to New $\$ 320$ Billion PPP." FreightWaves. Accessed April 30, 2020. https://www.freightwaves.com/news/women-owned-trucking-getsmore-access-to-new-320-billion-ppp. 


\section{About the Authors}

\section{Thomas O'Brien, $\mathrm{PhD}$}

Dr. Thomas O'Brien is the Executive Director of the Center for International Trade and Transportation (CITT) at California State University, Long Beach (CSULB) and the Deputy Director of Long Beach Programs for the METRANS Transportation Center, a partnership between CSULB and the University of Southern California. He also serves as the Director of the FHWA Southwest Transportation Workforce Center (SWTWC). He previously served as CITT's Director of Research.

Dr. O'Brien is an instructor in CSULB's Master of Science in Supply Chain Management (MSSCM). Dr. O'Brien is a member of the Executive Committee of the Council of University Transportation Centers (CUTC), where he serves as President and is a member of the CUTC Workforce Development Taskforce and Chair of the oversight committee of the National Science Foundation's National Center for Supply Chain Technology Education. He is a member of the Transportation Research Board's Intermodal Freight Transport Committee and Urban Freight and Operations Committee. He also serves on the Boards of the Southern California Roundtable of the Council of Supply Chain Management Professionals, Los Angeles Transportation Club, Foreign Trade Association, and National Transit Institute.

Dr. O'Brien has a Master's degree in Urban Planning and Development and a $\mathrm{PhD}$ in Policy, Planning, and Development from the University of Southern California. He is both an Eno and an Eisenhower Transportation Fellow.

\section{Deanna Matsumoto}

Deanna Matsumoto is the Education and Workforce Development Analyst for CITT. She supports the Center's programmatic efforts in workforce development, policy analysis, inclusive programming, project management, curricular and instructional development, and white paper development. Ms. Matsumoto is currently Project Manager of the Southern California Regional Workforce Development Needs Assessment for the Transportation and Supply Chain Industry Sectors, funded by the California State University Transportation Consortium (CSUTC), which is led by the Mineta Transportation Institute, and the California Sustainable Freight Action Plan Workforce Development Pilot Project funded by the California Energy Commission and the Governor's Office of Business and Economic Development.

Ms. Matsumoto has a Master of Arts degree in Architecture and Urban Planning from the University of California, Los Angeles with a concentration in the Built Environment, as well as a Bachelor of Arts degree from Yale University. She is a state recipient of the California Council of Adult Education Excellence in Teaching award and a national recipient of the Edward McClure Award from the Association of Collegiate Schools of Planning, also having 
received the History Research Prize from the Society for American City and Regional Planning. Ms. Matsumoto has served on the leadership teams of two K12 Western Association of Schools and Colleges (WASC) accreditation committees.

\section{Diana Sanchez}

Diana Sanchez is a Research Associate at the Center for International Trade and Transportation (CITT). She graduated from California State University, Long Beach with a Bachelor of Arts in Economics. She has contributed toward several projects including the California Sustainable Freight Action Plan: Workforce Development for California Energy Commission; she studied the skills gap among transportation incumbents and helped craft the Sustainable Freight Foundations Certificate Pilot Project to eliminate the gap. In recognition of this work, she received the Intermodal Association of North America scholarship to study chassis management. She is the lead publishing author for the article "Where do Females Rise to Leadership Positions? A Cross-Sector Analysis," a paper published in Applied Economics Letters which supports the existence of a "glass cliff." Apart from conducting research at CITT, Diana enjoys analyzing data and has observed: (1) successful nonprofit campaign characteristics achieved by utilizing data from Twitter, and (2) patent trends in relation to human migration frequency.

\section{Caitlin Mace}

Caitlin Mace is a Research Assistant at the Center for International Trade and Transportation (CITT). She has a Bachelor's in psychology and is working toward her master's in philosophy at California State University, Long Beach. She co-authored a Highway Construction Workforce Pilot Apprenticeship Development Guide as well as participated in semi-structured interviews with workforce development boards and industry associations. She has also developed a guide for conducting interviews and focus groups in accordance with best practices for CITT.

\section{Elizabeth Warren}

Elizabeth Warren is the Senior Industry Liaison for the Center of International Trade and Transportation at California State University Long Beach, where she is focused on using her $25+$ years' experience in the goods movement and logistics industry to provide outreach and facilitate partnerships between industry stakeholders and the CITT. She is the former Executive Director of FuturePorts, a nonprofit advocacy group in Southern California, and was the Public Policy Manager for transportation and environment at the Los Angeles Area Chamber of Commerce. Prior to her career in public policy, she worked in the civil engineering and construction industry for several global engineering firms, where she acquired expertise on national port, railroad, and transportation projects. Elizabeth is an instructor in the Global Logistics Professional program at CPIE and also teaches at Long Beach City College. She has served on the CITT Policy and Steering Committee for 12 years, is Chair of the Academy of Global Logistics at Cabrillo High School (Long Beach Unified School District), and was appointed to the Los Angeles County Commission on Women. Elizabeth has earned Master's 
degrees in Global Public Policy from both the University of Southern California and the University of Hong Kong, graduating with distinction, as well as a Bachelor's degree in Business Administration from Pepperdine University.

\section{Eleni Hala}

Eleni Hala is a Research Associate for the Center for International Trade and Transportation (CITT). She is completing her last semester toward a Bachelor's in Business Administration with a focus on Management at California State University, Long Beach. She assisted in developing a project database and supported in-depth interviewing with industry and education/training partners. Eleni enjoys learning about the future of transportation, including public transportation, and she is currently working on research regarding COVID-19 lockdowns and providing information for an article.

\section{Tyler Reeb, PhD}

Dr. Tyler Reeb is the Director of Research and Workforce Development for CITT and the Associate Director of the Federal Highway Administration's Southwest Transportation Workforce Center housed at CITT. He also serves as the Editor of METRANS NEWS, a tri-quarterly publication that summarizes METRANS research, education, and outreach efforts.

Dr. Reeb leads research teams who address challenges and opportunities related to the new mobility workforce, transformational technology, institutional change, organizational management, and transportation systems management operations (TSM\&O). He draws from industry benchmarking, labor market analysis, future scenario planning, systems thinking, enterprise resource planning, and GIS tools to produce research-driven reports, articles/white papers, books, and multimedia products that promote innovation and civic partnerships between leaders in business, government, and education.

Dr. Reeb was the lead author for a successful $\$ 1.5$ million FHWA grant application to fund deployment of the National Transportation Career Pathway Initiative. He is a member of two National Academies of Sciences, Engineering, and Medicine standing committees focused on Transportation Education \& Training and Native American Transportation Issues. Dr. Reeb has a Bachelor's in English Literature and Mass Media and a PhD in English with an emphasis in Transdisciplinary Research Methods. 


\section{Hon. Norman Y. Mineta}

\section{MTI BOARD OF TRUSTEES}

Founder, Honorable Norman

Mineta*

Secretary (ret.),

US Department of Transportation

Chair,

Abbas Mohaddes

President \& COO

Econolite Group Inc.

Vice Chair,

Will Kempton

Executive Director

Sacramento Transportation Authority

Executive Director,

Karen Philbrick, PhD*

Mineta Transportation Institute

San José State University

Winsome Bowen

Chief Regional Transportation

Strategy

Facebook

David Castagnetti

Co-Founder

Mehlman Castagnetti

Rosen \&Thomas

\section{Maria Cino}

Vice President

America \& U.S. Government

Relations Hewlett-Packard

Enterprise

\author{
Grace Crunican** \\ Owner \\ Crunican LLC
}

Donna DeMartino

Managing Director

Los Angeles-San Diego-San Luis

Obispo Rail Corridor Agency

Nuria Fernandez**

General Manager \& CEO

Santa Clara Valley Transportation

Authority (VTA)

\section{John Flaherty}

Senior Fellow

Silicon Valley American

Leadership Form

William Flynn *

President \& CEO

Amtrak

Rose Guilbault

Board Member

Peninsula Corridor

Joint Powers Board

Ian Jefferies*

President \& CEO

Association of American

Railroads
Diane Woodend Jones

Principal \& Chair of Board

Lea + Elliott, Inc.

David S. Kim*

Secretary

California State Transportation

Agency (CALSTA)

Therese McMillan

Executive Director

Metropolitan Transportation

Commission (MTC)

Bradley Mims

President \& CEO

Conference of Minority

Transportation Officials

(COMTO)

Jeff Morales

Managing Principal

InfraStrategies, LLC

Dan Moshavi, PhD*

Dean, Lucas College and Graduate

School of Business

San José State University

Toks Omishakin*

Director

California Department of

Transportation (Caltrans)
Takayoshi Oshima

Chairman \& CEO

Allied Telesis, Inc.

Paul Skoutelas*

President \& CEO

American Public Transportation

Association (APTA)

Beverley Swaim-Staley

President

Union Station Redevelopment

Corporation

Jim Tymon*

Executive Director

American Association of

State Highway and

Transportation Officials

(AASHTO)

Larry Willis*

President

Transportation Trades

Dept.,AFL-CIO

* = Ex-Officio

${ }^{* *}=$ Past Chair, Board of Trustees

\section{Directors}

Karen Philbrick, PhD

Executive Director

Hilary Nixon, PhD

Deputy Executive Director

Asha Weinstein Agrawal, PhD

Education Director

National Transportation Finance

Center Director

\section{Brian Michael Jenkins}

National Transportation Security

Center Director

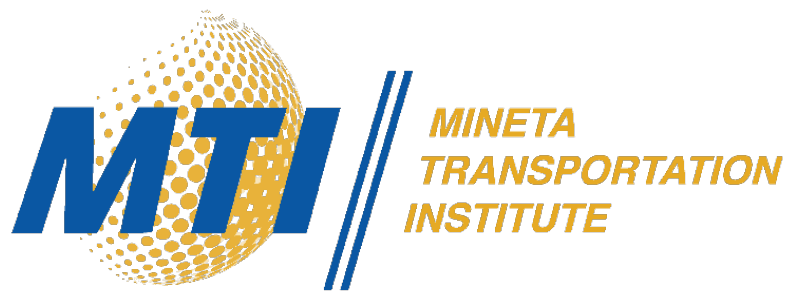

